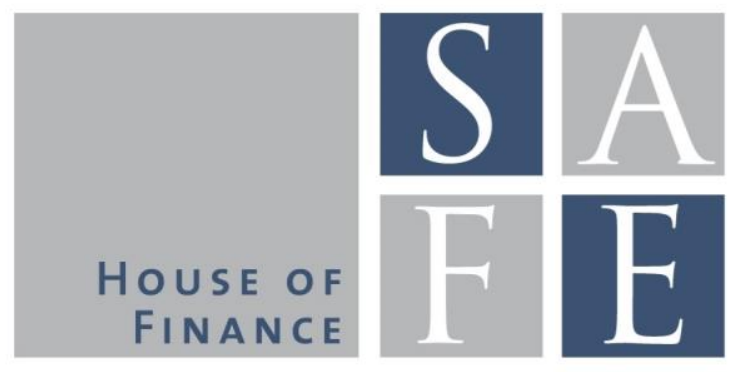

Working PAPER SERIES

Michael Donadelli - Patrick Grüning

\title{
Innovation Dynamics and Fiscal Policy: Implications for Growth, Asset Prices, and Welfare
}

SAFE Working Paper No. 171

SAFE I Sustainable Architecture for Finance in Europe A cooperation of the Center for Financial Studies and Goethe University Frankfurt 


\section{Non-Technical Summary}

It is widely accepted that any government faces a trade-off between public revenues and public expenses. The key challenge for fiscal institutions is the decision on the amount and type of taxes and public spending. Given the current macroeconomic scenario characterized by a relatively high level of economic policy uncertainty, high tax burden, and the presence of a large number of fiscally weak countries (in particular in the Euro Area) this trade-off is exacerbated. As noticed by Krugman (2013), not managing resources efficiently, in particular in times of strong fiscal consolidations, may lead to undesirable outcomes. Specifically, public disinvestment can be harmful for real economic activity. The imposition of a tight fiscal discipline like the one suggested by the European Stability and Growth pact (ESGP) have forced the majority of EU members to cut drastically public spending. However, among others, EU governments cut investments in research and development (R\&D) as reported by Veugelers (2013). It is widely accepted that innovation represents an important driver of economic growth. Therefore, as opposed to what the novel evidence on the EU suggest, investments in R\&D should be prioritized. Unquestionably, fiscal policies should be also aimed at stimulating private consumption and investment in physical capital. However, the debate on which is the most effective fiscal policy - in terms of growth and welfare - is still open. This because fiscal multipliers vary across countries and time.

The present study contributes to this debate by examining the equilibrium implications of different fiscal policies on macroeconomic quantities, asset prices, and welfare by utilizing two endogenous growth models: (i) an expanding variety model features only homogeneous innovations by entrants and (ii) a Schumpeterian growth model features heterogeneous innovations (i.e. "incremental" innovations by incumbents and "radical" innovations by entrants). It is assumed that the government can finance its public spending by imposing taxes on labor income and firms' profits. It provides subsidies to household's consumption, to final goods firm's capital investment, and to R\&D investments by entrants and, if applicable, incumbents. In other words, this study quantifies the effects of three different sector-specific policies on growth and welfare in the presence of two different innovation structures.

Regardless of the innovation structure, an increase in consumption subsidies induces lower economic growth resulting in sizable welfare costs. Higher R\&D subsidies instead induce higher economic growth alongside a welfare loss both in the homogeneous and heterogeneous innovation model. Only higher capital investment subsidies lead to jointly higher growth and welfare in both innovation models. Precisely, in the presence of homogenous (heterogeneous) innovation they produce a rise of around 30 basis points (10 basis points) in consumption growth and welfare benefits of around 3\% (1.5\%). Fiscal policies should therefore prioritize the allocation of resources to capital investment.

Via a battery of sensitivity analyses it is also shown that the inclusion or absence of wage rigidities, the utility specification, and the elasticity of $R \& D$ investments matter for growth and welfare. First, in the absence of wage rigidities the equilibrium effects of changes in the proposed sector-specific fiscal policies are slightly amplified. Second, if households display constant relative risk aversion, a rise in the $R \& D$ subsidies always leads to welfare gains. Last, a lower elasticity in R\&D investments leads to an amplification of welfare effects and higher R\&D subsidies are always welfare-enhancing. 


\title{
Innovation Dynamics and Fiscal Policy: Implications for Growth, Asset Prices, and Welfare
}

\author{
Michael Donadelli* Patrick Grüning**
}

This version: April 13, 2017

\begin{abstract}
We study the general equilibrium implications of different fiscal policies on macroeconomic quantities, asset prices, and welfare by utilizing two endogenous growth models. The expanding variety model features only homogeneous innovations by entrants. The Schumpeterian growth model features heterogeneous innovations: "incremental" innovations by incumbents and "radical" innovations by entrants. The government levies taxes on labor income and corporate profits and supplies subsidies to consumption, capital investment, and investments in research and development by entrants and, if applicable, incumbents. With these models at hand, we provide new insights on the interplay of innovation dynamics and fiscal policy.
\end{abstract}

Keywords: Endogenous growth, Asset pricing, Government, Fiscal policy, Heterogeneous innovation

JEL: E22, G12, H20, I30, O30

*Assistant Professor, Faculty of Economics and Business Administration and Research Center SAFE, Goethe University Frankfurt, House of Finance, Theodor-W.-Adorno Platz 3, 60629 Frankfurt am Main, Germany. E-mail and phone: donadelli@safe.uni-frankfurt.de, +4969798 33882.

${ }^{* *}$ Senior Economist, Center for Excellence in Finance and Economic Research (CEFER), Bank of Lithuania; Lecturer, Faculty of Economics, Vilnius University. Contact details: Totoriu g. 4, 01121 Vilnius, Lithuania. E-mail and phone: PGruening@lb.lt, +37052680069.

We would like to thank Egle Skliaustytè, Mara Solomon, and Jonas Striaukas for their excellent research assistance. Moreover, we are grateful to Aleš Maršál and Claus Munk as well as seminar participants at the Bank of Lithuania, University College of Dublin and the 20th Annual Conference of the Swiss Society for Financial Market Research (SGF) for helpful comments and constructive suggestions. We gratefully acknowledge research and financial support from the Research Center SAFE, funded by the State of Hessen initiative for research LOEWE. The views expressed herein are solely those of the authors and do not necessarily reflect the views of the Bank of Lithuania or the Eurosystem. 


\section{Introduction}

Any government faces two main challenges: (i) how to generate revenue and (ii) how to spend this revenue. In particular, the government has to choose the tax types and rates that it levies on companies and individuals to create government income. Furthermore, it decides on what to use this money for (e.g., social security, firm subsidies, public infrastructure, or the country's defense and military capabilities). Today, finding an effective mix of fiscal policy is probably more important than ever. Given the high levels of fiscal debt and the tight fiscal budgets of many major economies, optimizing public resources wisely is of utmost importance for governments around the world. The recent and ongoing European debt crisis demonstrates that high debt levels and government spending inefficiencies can lead to high unemployment and low economic growth. A recent policy treaty, namely the European Stability and Growth Pact (ESGP), requires European countries to have at least balanced budgets, but at the same time economic growth should be stimulated and unemployment lowered.

Recent empirical findings suggest that ESGP guidelines for management of public debt in the euro area may lead to undesirable outcomes (see, among others, Krugman, 2013). In this respect, Veugelers (2014) reports that, as a consequence of tightening fiscal measures, fiscally weak EU economies largely, lagging in innovation, cut their research and development (R\&D) expenditures along with all other public expenses over the last five years. The question remains whether such fiscal policy is beneficial for the respective country or the EU economy as a whole. The debate on whether fiscal consolidation is good or bad has become increasingly confusing - not only in Europe, where the matter is particularly urgent, but in the United States (U.S.) as well. The U.S. also exhibits a relatively high debt level and has experienced periods of relatively low economic growth. In particular, the dramatic consequences of reaching the debt ceiling in 2013, increasing government social benefits devoted to the Medicare program, and the relatively high level of economic policy uncertainty have shown the importance of reducing the public deficit in the U.S.

Needless to say, in these scenarios public resources should be used optimally. In particular, in a way that would improve welfare and economic growth. However, implementing effective fiscal policies can be challenging. Whether or not governments use their money efficiently is still at the 
center of the policy debate. We contribute to this debate by examining the effects of different fiscal policies on macroeconomic quantities, asset prices, and welfare. In addition, we quantify whether one policy is more effective than another in the presence of different innovation structures. To do so, we develop two modern dynamic stochastic endogenous growth general equilibrium models with government sectors generating their revenues by means of labor income and corporate taxes. These revenues are used for subsidizing consumption, capital investment, and investment in R\&D. The only difference between the two models considered in this study is that they feature different innovation structures. Specifically, the first model features homogeneous horizontal innovations by new firms ("entrants") only, whereas the second model allows for heterogeneous vertical innovations by established firms ("incumbents") and entrants. The tax and subsidy rates in each model are calibrated to match the figures in recent U.S. data. Keeping all the other parameters of the two resulting benchmark models fixed, we then investigate how changing the expenditure structure of the government, in particular, the different subsidy rates and overall amount of government expenditures, affects the equilibrium dynamics of major macroeconomic quantities, welfare, and asset prices.

In both models, households have recursive preferences, the final goods sector is perfectly competitive, and the intermediate goods sector is monopolistically competitive. The horizontal innovations developed in the first model economy foster sustainable endogenous economic growth as in Romer (1990) and Kung and Schmid (2015). Therefore, this model falls under the category of expanding variety economies. Heterogeneous innovations are introduced in the second economy to account for competition in innovation. Thus, we utilize modern Schumpeterian growth theory, developed by Grossman and Helpman (1991) and Aghion and Howitt (1992), building on ideas already proposed by Schumpeter $(1934,1942)$. More precisely, the innovation sector is modeled along the lines of Bena, Garlappi, and Grüning (2016) and Acemoglu and Cao (2015) to account for vertical innovations and creative destruction. Both incumbents and entrants invest in $R \& D$ in this setting. Regardless of the innovation structure, the government finances its expenditure stream by a combination of labor income tax and corporate tax (on the monopoly profits of intermediate goods firms). Government expenditure is partly wasteful government expenditure and partly re-distributed to the productive economy in the form of a transfer to the household for additional consumption, to the 
final goods firm for additional capital investment, and to firms in the innovation sector for additional $R \& D$ investment. Note that there are two types of innovative firms (incumbents and entrants) in the second economy and, thus, two types of R\&D investment subsidies. For the analysis to not be diluted by an additional smoothing channel available to the government, we let the government commit to a zero-deficit policy rule. To the best of our knowledge, no study has equipped the government with such a mix of policies and subsequently investigated the equilibrium effects of different sector-specific fiscal policies under both a homogeneous and a heterogeneous innovation structure. Finally, we augment our production setting by introducing two types of rigidities. First, capital investment is subject to convex adjustment costs as in Jermann (1998). Second, the labor market is subject to a Calvo-type of wage stickiness following Schmitt-Grohé and Uribe (2006).

We calibrate the model to match the government expenditure to output ratio, the corporate tax rate, the labor income tax rate, and the subsidy rates observed in recent U.S. data. In addition, we also ensure that the resulting benchmark models capture reasonably well both unconditional asset pricing and macroeconomic moments. We then consider different fiscal policy experiments. Taken together, all these ingredients allow us to study both the short- and long-run effects of different fiscal policies on economic growth and asset prices as well as to quantify welfare benefits or costs after the implementation of sector-specific policies. Specifically, our main goal is to study the tradeoff between different fiscal policies under different innovation structures. We can therefore provide a quantitative answer to the following issues: Do all sector-specific policies improve welfare? Do sector-specific policies provide similar benefits under different innovation structures?

To address these issues in practice we vary the parameters related to government expenditure and subsidy rates while keeping all other parameters fixed as in the benchmark calibrations. Specifically, for the homogeneous innovation model we look at the case where all government subsidies are reduced by one percentage point (p.p.), and at a one p.p. increase in consumption, capital investment, and $R \& D$ investment subsidy. In addition, we examine the case of a one p.p. increase in the government expenditure-to-output ratio. Similarly, for the heterogeneous innovation model, we look at the case of lower overall government subsidies, an increase in incumbent R\&D subsidies, an increase in entrant $R \& D$ subsidies, a joint increase of both incumbent and entrant R\&D subsidies, an increase in the consumption subsidy, an increase in the capital investment subsidy, and an 
increase in the government expenditure-to-output ratio.

We find that in the homogeneous innovation model higher $R \& D$ subsidies are growth-enhancing (an increase by 36 basis points (bps) relative to 1.89 p.p. average consumption growth in the benchmark model) as expected, whereas higher consumption subsidies lead to lower economic growth (a decrease of $17 \mathrm{bps}$ is observed). The latter effect is due to the substitution effect causing the household to divert resources from the productive economy to consumption and leisure since the marginal utility is lower with higher consumption subsidies. Higher capital investment subsidies also lead to higher economic growth but to a lesser extent than R\&D subsidies, i.e. an increase of only 18 bps. When all considered subsidies, as well as the amount of wasteful government expenditure, are higher (by the same amount), i.e. in the case when there is a higher government expenditureto-output ratio, the model produces a 10 bps higher average consumption growth rate than in the benchmark model. Therefore, the growth-enhancing effects of higher R\&D and capital investment subsidies dominate the adverse effects of higher consumption subsidies and a higher amount of wasteful government expenditure. The opposite is observed in the case of overall lower subsidies, i.e. a drastic 48 bps drop in economic growth.

In the heterogeneous innovation model, increasing incumbent R\&D subsidies leads to higher economic growth (of $35 \mathrm{bps),} \mathrm{and} \mathrm{increasing} \mathrm{entrant} \mathrm{R \& D} \mathrm{subsidies} \mathrm{leads} \mathrm{to} \mathrm{lower} \mathrm{economic} \mathrm{growth}$ (of $4 \mathrm{bps}$ ). R\&D investment of entrants is quite inefficient due to the displacement effect it has on incumbents. Thus, in our calibrated model, subsidizing entrants is growth-reducing . Moreover, we observe that changes in incumbents' R\&D subsidies have a much larger effect on the equilibrium dynamics of the heterogeneous innovation model than changes in the R\&D subsidies in the homogeneous innovation model since the absolute amount of government subsidy changes are assumed to be lower. However, roughly the same quantitative effect as in the homogeneous innovation model is observed. In particular, the government subsidies are increased (or decreased) by only 50 bps and not by 100 bps as in the homogeneous innovation model.

In both models, endogenous long-run risks originating from investments in $\mathrm{R} \& \mathrm{D}$ lead to a substantial equity risk premium and a relatively low risk-free rate. In particular, the aggregate risk premium is about 2.7 (2.6) p.p. in the benchmark calibration of the homogeneous (heterogeneous) innovation model. The risk-free rates are about 1.6 p.p. in both models. Thus, a reasonable fit to 
asset pricing dynamics is obtained. In both innovation models, the equity risk premium and the risk-free rate increase with economic growth.

Finally, due to the household having a preference for early resolution of uncertainty and thus an aversion against utility risk, household welfare is linked to economic growth. However, higher economic growth does not automatically imply higher welfare. Specifically, increasing R\&D subsidies in the homogeneous innovation model leads to a welfare loss of about $5 \%$ of lifetime consumption despite a substantial higher average consumption growth rate. The reason is due to the substitution effect leading to lower levels of (normalized) consumption and leisure. This, in turn, depresses welfare. For higher overall government expenditure, we also observe higher economic growth but lower welfare. For all other considered specifications of the homogeneous innovation model, welfare increases with economic growth.

In the heterogeneous innovation model, increasing incumbent $\mathrm{R} \& \mathrm{D}$ subsidies leads to a welfare loss of $0.6 \%$, whereas increasing entrant $R \& D$ subsidies implies a slightly smaller welfare loss of $0.48 \%$ of lifetime consumption despite lower economic growth than in both the benchmark and the high incumbent subsidy calibration. Hence, we observe again that welfare and economic growth are mostly inversely related when changing $R \& D$ subsidies. If the government simultaneously increases both incumbent and entrant R\&D subsidies, the welfare loss is $0.58 \%$, i.e. slightly smaller than a sole increase in the incumbent $\mathrm{R} \& \mathrm{D}$ subsidy. Therefore, subsidies can imply sizable gains in growth or welfare, but one has to take the objective of either maximizing welfare or growth and the competition structure of the innovation sector into account to make an optimal decision on whom to subsidize.

In both models, only higher subsidies to capital investment lead to joint increases in both growth and welfare. For a government trying to maximize both quantities simultaneously, subsidizing capital investment seems to be the best choice.

Sensitivity analyses show that implications for growth and welfare depend on the inclusion or absence of wage rigidities, the utility specification, and the elasticity of $R \& D$ investments. The absence of wage rigidities amplifies the equilibrium effects of changes in the fiscal policy mix. Assuming a power utility specification that results in households displaying constant relative risk aversion (CRRA) implies that increasing $R \& D$ subsidies always leads to higher welfare. Lastly, a 
lower elasticity in R\&D investments leads to amplification of welfare effects and, similarly to what has just been observed for CRRA utility, higher R\&D subsidies are welfare-enhancing in any case.

The remainder of this study is structured as follows. The next section discusses closely related empirical and theoretical contributions in the literature. Section 3 develops the homogeneous innovation model of the expanding variety type. Section 4 describes the heterogeneous innovation model featuring Schumpeterian growth. Section 5 gives the details about the benchmark calibrations of both models, and Section 6 discusses the results from our equilibrium analysis. Moreover, Section 7 looks at the sensitivity of the model with respect to key parameters. Finally, Section 8 concludes.

\section{Related Literature}

Our article belongs to the growing field of literature examining the links between heterogeneous government policies, macroeconomic quantities, welfare, and asset prices. First, our analysis is most closely related to a number of recent papers that have examined the link between innovationdriven policies and growth. Acemoglu and Cao (2015) develop a model of heterogeneous innovation and demonstrate that policies favoring the entry of new firms at the expense of existing firms' patent values can decrease economic growth under certain conditions. Most closely related to our study is the analysis by Acemoglu, Akcigit, Bloom, and Kerr (2013). The authors employ a Real Business Cycle (RBC) model with heterogeneous innovative firms, endogenous entry and exit of firms, and a heterogeneous labor market to investigate the implications for growth and welfare of three different subsidies directed to the innovation sector. First, an incumbent subsidy is shown to decrease growth and welfare due to the fact that incumbents in their model are subject to creative destruction effects as they take over products from other firms. Second, a subsidy to operating costs of incumbents also decreases growth and welfare due to a negative selection effect, i.e. a higher share of low-innovative-type firms in the economy with the subsidy. Third, a subsidy to entry leads to an improvement of growth and welfare due to a higher exit threshold and despite higher displacement effects from creative destruction. Finally, an optimal combination of those three subsidies is derived: the combination of a very large tax on operating costs of incumbents, a modest subsidy to incumbent $\mathrm{R} \& \mathrm{D}$, and a modest subsidy to entry brings the model close to the social 
planner economy, i.e. the Pareto optimum. However, the present study differs from Acemoglu, Akcigit, Bloom, and Kerr (2013) in several respects. First, they adopt standard CRRA preferences and thus abstract away from long-run valuations effects on patents, which are a main driver of results in this paper, and the resulting asset pricing implications. Second, they focus exclusively on R\&D-related subsidies. Differently, we let the government subsidize three different macroeconomic quantities (i.e. consumption, capital investment, and R\&D investments). Third, they derive the optimal fiscal policy (i.e. the optimal combination of the three R\&D-related subsidies). In this study, we abstract from deriving sector-specific optimal policies or the optimal policy mix. Instead, we rely on a battery of different fiscal policies and examine their related growth, asset pricing, and welfare implications. Fourth, they do not compare equilibrium results in the presence of different innovation structures as we do.

In a different context, Nuño (2011) studies the welfare effects of capital and R\&D subsidies relative to the decentralized equilibrium. By using a canonical Schumpeterian growth model, he derives an optimal combination of capital and $R \& D$ subsidies that restores the efficient allocation in the steady state. Moreover, in a dynamic setup countercyclical R\&D subsidies are not welfareimproving, and the optimal steady-state subsidies work well but do not fully restore the efficient allocation. An agent-based model that combines a Schumpeterian growth engine and Keynesian demand features in fiscal policy, investment decisions, and worker's consumption is developed by Dosi, Fagiolo, and Roventini (2010). The authors show that a positive shift in the opportunities of the Schumpetarian growth engine has a positive impact on growth, employment, and GDP volatility in both the short and long run. However, these effects are conditional on a Keynesian demand engine being in place. If it is shut down, long-run growth falls to about one third. Hence, the authors conclude that Schumpeterian growth and Keynesian demand act as complements.

Varga and in’t Veld (2011) provide a model-based assessment of the potential macroeconomic impact of cross-country fiscal cohesian policy transfers within the EU. They use a variant of the QUEST III NK model, developed by Röger, Varga, and in’t Veld (2008) and Ratto, Röger, and in’t Veld (2009), featuring endogenous technological change and human capital accumulation. Similarly to our model, the government provides subsidies for physical capital investment and R\&D investments. The subsidies might be augmented by cohesian policy transfers for a receiving country, 
whose effects are the central focus of the study. These transfers entail output and consumption increases in both the short and long run for the receiving countries. However, the immediate impulse to demand is partly offset by the effects of higher inflation, rising capital costs, and exchange rate appreciations in the short run. Moreover, private consumption and private investment are slightly crowded out. The output in donor countries declines, and the higher contributions to the EU budget imply a higher government indebtedness and thus lead to higher labor taxes.

Turnovsky (2000) studies optimal fiscal policy in an endogenous growth model when labor supply decisions are endogenous. He argues that it is important to look at elastic labor supply, since inelastic labor supply is an unrealistic assumption and also leads to different and possibly misleading policy implications. We are close to his study in that we also incorporate endogenous labor supply and, additionally, wage rigidities into our model.

Overall, we contribute to this literature by quantifying the effects of sector-specific policies on welfare, growth, and asset prices in the presence of either vertical or horizontal innovations. In this respect, our paper is additionally connected to the most recent endogenous growth-based asset pricing literature (Kung and Schmid, 2015) and studies examining the effects of fiscal and monetary policies on asset prices (Croce, Kung, Nguyen, and Schmid, 2012; Gomes, Michaelides, and Polkovnichenko, 2013; Horvath, Kaszab, and Maršál, 2016). Kung and Schmid (2015) point out that long-term growth prospects are endogenously determined by innovation and R\&D. Specifically, investment in R\&D endogenously drives a small and persistent component in aggregate productivity. This produces long-run uncertainty about economic growth, which in the presence of preferences for early resolution of uncertainty lower asset values and command high risk premia. Donadelli and Grüning (2016) show that the inclusion of endogenous labor dynamics and labor market frictions in the Kung and Schmid (2015) economy further increases long-run uncertainty and risk premia. Croce, Kung, Nguyen, and Schmid (2012) build a production-based economy with exogenous shocks to public expenditure. Their quantitative results suggest that both volatility and the intertemporal distribution of tax rates directly affect the cost of equity and capital accumulation. Gomes, Michaelides, and Polkovnichenko (2013) build a general equilibrium overlapping generations model with incomplete markets and heterogeneous agents to examine whether large movements in government debt and taxes affect asset prices and macroeconomic conditions. They find that a rise in 
public debt increases the riskless rate and reduces the equity premium. Differently, a higher capital income tax rate leads to a higher equity premium. Horvath, Kaszab, and Maršál (2016) study the term structure of interest rates in a New-Keynesian model with fiscal uncertainty and households displaying Epstein and Zin (1989) preferences. Fiscal uncertainty amplifies the hedging property of bonds implying a large insurance premium. The result is carefully traced back by decomposing the pricing kernel analytically. However, we differ from all these works with our novel mix of fiscal policies and our focus on two different innovation structures.

Finally, our paper also relates to the empirical literature aimed at examining the relationship between different tax instruments, government stimulating programs, and productivity (i.e. growth). In particular, it looks at the effects of fiscal policy changes on R\&D, growth, and welfare. At the micro level, early studies find that government subsidies devoted to R\&D investments tend to provide benefits for the private sectors (see, among others, Irwin and Klenow, 1996; Branstetter and Sakakibara, 1998). More recent micro empirical works corroborate this evidence by finding a positive effect on $\mathrm{R} \& \mathrm{D}$ investment, employment, and sales among firms that receive a direct government R\&D subsidy (see, among others, Foreman-Peck, 2013; Einio, 2014). At the macro

level, there are several empirical works examining whether policies in support of the R\&D sector positively affect aggregate productivity and output growth. Guellec and van Pottelsberghe (2000) using a dynamic panel of 17 OECD countries find that direct subsidies and tax incentives to business R\&D generate additional business-financed R\&D investment and stimulate productivity. Similarly, Jaumotte and Pain (2005) examine a panel of 20 OECD members over the period of 1982-2001 and find that the effect of direct public financial support for business R\&D tends to be positive. Using an updated dataset, Westmore (2013) corroborates these findings. See also Minford (2015) for an extensive theoretical and empirical literature review on the macroeconomic effects of changes in $\mathrm{R} \& \mathrm{D}$ subsidies.

\section{Homogeneous Innovation Model}

Our economy is populated by a representative household in the consumer sector, by a perfectly competitive firm in the final goods sector, and by a continuum of monopolistically competitive 
firms in the intermediate goods sector. Moreover, labor decisions are made by a central authority within the household, i.e. a union, which monopolistically supplies labor to a continuum of labor markets. Hence, in the spirit of Schmitt-Grohé and Uribe (2006), the presence of labor unions gives rise to a Calvo-type of wage stickiness in our model. Furthermore, the number of intermediate goods is growing over time due to innovation efforts by homogeneous inventors populating the innovation sector. The horizontal innovations developed in the economy foster sustainable endogenous economic growth as in Kung and Schmid (2015) and Romer (1990). Finally, a government is present in the economy. It finances its expenditure stream by a combination of labor income tax and corporate tax. The government expenditure is partly wasteful expenditure and partly re-distributed to the productive economy in the form of a transfer to the household for additional consumption, to the final goods firm for additional capital investment, and to the innovation sector for additional R\&D investment. ${ }^{1}$

\subsection{Representative household}

The representative household has Epstein and Zin (1989) preferences over the utility flow $u_{t}$ :

$$
U_{t}=\left[(1-\beta) u_{t}^{1-\frac{1}{\psi}}+\beta\left(\mathbb{E}_{t}\left[U_{t+1}^{1-\gamma}\right]\right)^{\frac{1-1 / \psi}{1-\gamma}}\right]^{\frac{1}{1-1 / \psi}}
$$

where $\gamma$ is relative risk aversion, $\psi$ determines the elasticity of intertemporal substitution, and $\beta$ is the time discount factor. The utility flow is defined over consumption including government transfers, $C_{t}^{*}=C_{t}+\tau_{c} G_{t}$, and leisure, $\bar{L}-L_{t}$, where $L_{t}=\int_{0}^{1} L_{j, t} d j$ is the total labor supply of the household and $\bar{L}$ the total time endowment of the household:

$$
u_{t}=C_{t}^{*}\left(\bar{L}-L_{t}\right)^{\varphi} .
$$

\footnotetext{
${ }^{1}$ The model presented in this section is very close to the one developed by Donadelli and Grüning (2016) who analyze the equilibrium effects of the inclusion of endogenous labor supply and wage rigidities into the Kung and Schmid (2015) economy. However, there is one main difference between their work and ours: In our economy the government plays a relevant role whereas in their work there is no government sector.
} 
Above, $\varphi$ determines the elasticity of the labor supply. The budget constraint of the household reads:

$$
C_{t}^{*}=C_{t}+\tau_{c} G_{t}=\left(1-\tau_{l, t}\right) \int_{0}^{1} W_{j, t} L_{j, t} d j+D_{a, t}+\tau_{c} G_{t}-S_{t}
$$

where $W_{j, t}$ denotes the wage rate for labor type $j \in[0,1]$ and where all labor types are supplied by the household. The supply of each type $j$ amounts to $L_{j, t}, D_{a, t}$ is aggregate dividends, $\tau_{c}$ denotes the fraction of total government expenditure $G_{t}$ transferred to the household for consumption, and $S_{t}$ is the economy's total R\&D investment. Finally, $\tau_{l, t}$ is the time-varying labor tax rate, which determines how much of the household's total labor income has to be paid to the government. The

household's stochastic discount factor (SDF) in units of the final consumption good derived using standard calculations is:

$$
\mathrm{M}_{t, t+1}=\beta\left(\frac{u_{t+1}}{u_{t}}\right)^{1-\frac{1}{\psi}}\left(\frac{C_{t+1}^{*}}{C_{t}^{*}}\right)^{-1}\left(\frac{U_{t+1}}{\mathbb{E}_{t}\left[U_{t+1}^{1-\gamma}\right]^{\frac{1}{1-\gamma}}}\right)^{\frac{1}{\psi}-\gamma}
$$

\subsection{Final goods sector}

Production of the final consumption good requires capital, a bundle of intermediate goods, and a bundle of differentiated labor services. Hence, the output of the representative final goods sector firm is given by:

$$
Y_{t}=\left(K_{t}^{\alpha}\left(A_{t} L_{t}^{d}\right)^{1-\alpha}\right)^{1-\xi} \Xi_{t}^{\xi}, \quad \Xi_{t}=\left[\int_{0}^{N_{t}} X_{i, t}^{\nu} d i\right]^{\frac{1}{\nu}}, \quad L_{t}^{d}=\left[\int_{0}^{1} L_{j, t}^{1-\frac{1}{\tilde{\eta}}} d j\right]^{\frac{1}{1-\frac{1}{\tilde{\eta}}}}
$$

The capital share, the share of intermediate goods, and the elasticity of substitution between any two intermediate goods in the intermediate goods bundle $\Xi_{t}$ are denoted by $\alpha, \xi$, and $\nu$, respectively. Furthermore, the parameter $\tilde{\eta}$ determines the intratemporal elasticity of substitution across differentiated types of labor. The total number of intermediate goods or patents in the economy is $N_{t}$. The stochastic process $A_{t}$ introduces exogenous stochastic productivity shocks to the model with dynamics:

$$
A_{t}=e^{a_{t}}, \quad a_{t}=\rho_{a} \cdot a_{t-1}+\varepsilon_{a, t},
$$


where $\rho_{a}$ determines the persistence of these shocks and $\varepsilon_{a, t} \sim \mathcal{N}\left(0, \sigma_{a}\right)$. The average wage index $W_{t}$ is given by:

$$
W_{t}=\left[\int_{0}^{1} W_{j, t}^{1-\tilde{\eta}} d j\right]^{\frac{1}{1-\tilde{\eta}}}
$$

This yields the property that the minimum wage cost is equal to $W_{t} L_{t}^{d}$. Hence, this implies:

$$
W_{t} L_{t}^{d}=\int_{0}^{1} W_{j, t} L_{j, t} d j
$$

The final goods firm maximizes its shareholder value by optimally choosing total capital investment $I_{t}^{*}$, labor demand for differentiated labor variety $j, L_{j, t}$, next period's capital $K_{t+1}$, and the demand for intermediate good $i, X_{i, t}$ :

$$
\max _{\left\{I_{t}^{*}, L_{j, t}, K_{t+1}, X_{i, t}\right\}_{t \geq 0, i \in\left[0, N_{t}\right], j \in[0,1]}} \mathbb{E}_{0}\left[\sum_{t=0}^{\infty} \mathbf{M}_{0, t} D_{t}\right],
$$

subject to the final goods firm's dividends' definition, the capital accumulation equation, and the relation between total capital investment and private capital investment (i.e. total capital investment net of subsidies):

$$
\begin{aligned}
D_{t} & =Y_{t}-I_{t}-\int_{0}^{1} W_{j, t} L_{j, t} d j-\int_{0}^{N_{t}} P_{i, t} X_{i, t} d i, \\
K_{t+1} & =(1-\delta) K_{t}+\Lambda\left(\frac{I_{t}^{*}}{K_{t}}\right) K_{t}, \\
I_{t} & =\left(1-\tau_{i n v, t}\right) I_{t}^{*}
\end{aligned}
$$

where $P_{i, t}$ is the price of intermediate good $i, \delta$ is the capital depreciation rate and $\Lambda\left(\frac{I_{t}^{*}}{K_{t}}\right)=$ $\frac{\alpha_{1}}{1-\frac{1}{\zeta}}\left(\frac{I_{t}^{*}}{K_{t}}\right)^{1-\frac{1}{\zeta}}+\alpha_{2}$ is the adjustment cost function transforming investment in new capital as in Jermann (1998), where the constants $\alpha_{1}$ and $\alpha_{2}$ are chosen so that there are no adjustment costs in the deterministic steady state. Moreover, the government subsidizes capital investment by transferring a fraction $\tau_{i}$ of its total government expenditure to the final good firm. This implies that only a fraction of effective capital investment $I_{t}^{*}$ has to be supplied by the final goods firm, i.e. $I_{t}=\left(1-\tau_{i n v, t}\right) I_{t}^{*}$. The remaining fraction $\tau_{i n v, t}$ is paid as a subsidy by the government. In 
particular, it holds that $\tau_{i} G_{t}=\tau_{i n v, t} I_{t}^{*}$. The resulting equilibrium conditions are as follows:

$$
\begin{aligned}
\frac{1-\tau_{i n v, t}}{\Lambda^{\prime}\left(\frac{I_{t}^{*}}{K_{t}}\right)} & =\mathbb{E}_{t}\left[\mathbb{M}_{t, t+1}\left\{\frac{(1-\xi) \alpha Y_{t+1}-\left(1-\tau_{i n v, t+1}\right) I_{t+1}^{*}}{K_{t+1}}+\frac{\left(1-\tau_{i n v, t+1}\right)\left(\Lambda\left(\frac{I_{t+1}^{*}}{K_{t+1}}\right)+1-\delta\right)}{\Lambda^{\prime}\left(\frac{I_{t+1}^{*}}{K_{t+1}}\right)}\right\}\right] \\
W_{j, t} & =\frac{(1-\xi)(1-\alpha) Y_{t}}{L_{t}^{d}}\left[\int_{0}^{1} L_{j, t}^{1-\frac{1}{\tilde{\eta}}} d j\right]^{\frac{1}{1-\frac{1}{\tilde{\eta}}}-1} L_{j, t}^{-\frac{1}{\tilde{\eta}}} \\
X_{i, t}\left(P_{i, t}\right) & =\left(\frac{\xi Y_{t}}{P_{i, t}}\right)^{\frac{1}{1-\nu}} \Xi_{t}^{\frac{\nu}{\nu-1}}
\end{aligned}
$$

Finally, from the average wage index definition (7) it follows from Equation (14) that:

$$
W_{t}=\frac{(1-\xi)(1-\alpha) Y_{t}}{L_{t}^{d}}
$$

and thus:

$$
L_{j, t}=\left(\frac{W_{j, t} L_{t}^{d}}{(1-\xi)(1-\alpha) Y_{t}}\right)^{-\tilde{\eta}} L_{t}^{d}=\left(\frac{W_{j, t}}{W_{t}}\right)^{-\tilde{\eta}} L_{t}^{d}
$$

\subsection{Wage rigidities and labor markets}

To account for important empirical regularities on labor markets, we include wage rigidities in the model. In particular, we follow Schmitt-Grohé and Uribe (2006) by incorporating a Calvo-type of wage stickiness. Using the demand for each labor type $j$ given in (17) in the definition of aggregate labor supply of the households gives:

$$
L_{t}=\int_{0}^{1} L_{j, t} d j=L_{t}^{d} \int_{0}^{1}\left(\frac{W_{j, t}}{W_{t}}\right)^{-\tilde{\eta}} d j
$$

The representative household maximizes the Epstein and Zin utility index $U_{t}$ given in Equation (1) subject to its budget constraint (3) and the labor supply constraint just derived in Equation (18) by choosing the optimal consumption level $C_{t}$, the optimal labor supply $L_{t}$, and the desired wage rate $W_{j, t}$. Following the approach in Schmitt-Grohé and Uribe (2006), we attach the Lagrange multiplier $\lambda_{C, t}$ to the first constraint and the Lagrange multiplier $\lambda_{C, t} W_{t}\left(1-\tau_{l, t}\right) / \lambda_{L, t}$ to the second 
constraint to obtain the Lagrangian:

$$
\begin{aligned}
\mathcal{L}= & {\left[(1-\beta)\left(\left(C_{t}+\tau_{c} G_{t}\right)\left(\bar{L}-L_{t}\right)^{\varphi}\right)^{1-\frac{1}{\psi}}+\beta\left(\mathbb{E}_{t}\left[U_{t+1}^{1-\gamma}\right]\right)^{\frac{1-1 / \psi}{1-\gamma}}\right]^{\frac{1}{1-1 / \psi}} } \\
& +\lambda_{C, t}\left(\left(1-\tau_{l, t}\right) \int_{0}^{1} W_{j, t} L_{j, t} d j+D_{a, t}-S_{t}-C_{t}\right) \\
& +\frac{\lambda_{C, t} W_{t}\left(1-\tau_{l, t}\right)}{\lambda_{L, t}}\left(L_{t}-L_{t}^{d} \int_{0}^{1}\left(\frac{W_{j, t}}{W_{t}}\right)^{-\tilde{\eta}} d j\right) .
\end{aligned}
$$

The first-order condition with respect to consumption $C_{t}$ implies:

$$
\lambda_{C, t}=(1-\beta) U_{t}^{\frac{1}{\psi}} u_{t}^{-\frac{1}{\psi}}\left(\bar{L}-L_{t}\right)^{\varphi}
$$

Next, the first-order condition with respect to the total labor supply gives:

$$
\frac{\lambda_{C, t} W_{t}\left(1-\tau_{l, t}\right)}{\lambda_{L, t}}=(1-\beta) \varphi U_{t}^{\frac{1}{\psi}} u_{t}^{-\frac{1}{\psi}} C_{t}\left(\bar{L}-L_{t}\right)^{\varphi-1}=\frac{\lambda_{C, t} \varphi C_{t}}{\bar{L}-L_{t}} \Rightarrow \frac{W_{t}\left(1-\tau_{l, t}\right)}{\lambda_{L, t}}=\frac{\varphi C_{t}}{\bar{L}-L_{t}} .
$$

Due to the Calvo-type of wage stickiness, the wage rate $W_{j, t}$ obeys the following dynamics:

$$
W_{j, t}=\left\{\begin{array}{cl}
\tilde{W}_{t} & \text { if } W_{j, t} \text { is set optimally at time } t \\
\frac{N_{t}}{N_{t-1}} W_{j, t-1} & \text { otherwise }
\end{array}\right.
$$

where $\tilde{W}_{t}$ denotes the real wage prevailing in the fraction $1-\mu$ of labor markets in which the union can set wages optimally at time $t$. We let $\tilde{L}_{t}$ denote the labor supply in those markets. If the wage is not set optimally in the period, we assume it is indexed to aggregate growth in the economy, represented by growth in the number of intermediate goods $N_{t} / N_{t-1}$. Due to the labor demand curve faced by the union being identical and the labor supply cost being the same across all labor markets, we can assume that wage rates $\tilde{W}_{t}$ and labor supply $\tilde{L}_{t}$ are identical across all labor markets updating wages optimally in a given period. Hence, Equation (17) implies that $\tilde{W}_{t}^{\tilde{\eta}} \tilde{L}_{t}=W_{j, t}^{\tilde{\eta}} L_{t}^{d}$. To derive the household's first-order condition with respect to the wage rate in those markets, in which the wage rate is set optimally in the current period, the following Lagrangian needs to be 
differentiated by $\tilde{W}_{t}$ :

$\mathcal{L}^{W}=\mathbb{E}_{t}\left[\sum_{s=0}^{\infty}(\mu \beta)^{s} \lambda_{C, t+s}\left(1-\tau_{l, t+s}\right) W_{t+s}^{\tilde{\eta}} L_{t+s}^{d} \prod_{k=1}^{s}\left(\frac{N_{t+k-1}}{N_{t+k}}\right)^{\tilde{\eta}}\left\{\tilde{W}_{t}^{1-\tilde{\eta}} \prod_{k=1}^{s}\left(\frac{N_{t+k}}{N_{t+k-1}}\right)-\frac{W_{t+s}}{\lambda_{L, t+s}} \tilde{W}_{t}^{-\tilde{\eta}}\right\}\right]$.

This first-order condition is given by:

$0=\mathbb{E}_{t}\left[\sum_{s=0}^{\infty}(\mu \beta)^{s} \lambda_{C, t+s}\left(\frac{W_{t+s}}{\tilde{W}_{t}}\right)^{\tilde{\eta}} L_{t+s}^{d} \prod_{k=1}^{s}\left(\frac{N_{t+k-1}}{N_{t+k}}\right)^{\tilde{\eta}}\left\{\frac{\tilde{\eta}-1}{\tilde{\eta}} \frac{\left(1-\tau_{l, t+s}\right) \tilde{W}_{t}}{\prod_{k=1}^{s}\left(\frac{N_{t+k-1}}{N_{t+k}}\right)}-\frac{W_{t+s}\left(1-\tau_{l, t+s}\right)}{\lambda_{L, t+s}}\right\}\right]$.

Expressing this condition in recursive form and using Equation (21) to substitute out the Lagrange multiplier $\lambda_{L, t+s}$ implies the following three equilibrium conditions:

$$
\begin{aligned}
& f_{t}^{1}=f_{t}^{2} \\
& f_{t}^{1}=\frac{\tilde{\eta}-1}{\tilde{\eta}} \lambda_{C, t}\left(1-\tau_{l, t}\right)\left(\frac{W_{t}}{\tilde{W}_{t}}\right)^{\tilde{\eta}} \tilde{W}_{t} L_{t}^{d}+\beta \mu \mathbb{E}_{t}\left[\left(\frac{N_{t}}{N_{t+1}}\right)^{\tilde{\eta}-1}\left(\frac{\tilde{W}_{t+1}}{\tilde{W}_{t}}\right)^{\tilde{\eta}-1} f_{t+1}^{1}\right] \\
& f_{t}^{2}=\frac{\varphi C_{t}}{\bar{L}-L_{t}} \lambda_{C, t}\left(\frac{W_{t}}{\tilde{W}_{t}}\right)^{\tilde{\eta}} L_{t}^{d}+\beta \mu \mathbb{E}_{t}\left[\left(\frac{N_{t}}{N_{t+1}}\right)^{\tilde{\eta}}\left(\frac{\tilde{W}_{t+1}}{\tilde{W}_{t}}\right)^{\tilde{\eta}} f_{t+1}^{2}\right]
\end{aligned}
$$

Combining the aggregate labor supply definition $L_{t}=\int_{0}^{1} L_{j, t} d j$ with the optimal labor demand condition (17), with the similar condition for labor markets, in which the wage rate is set optimally, i.e. $\tilde{L}_{t}=L_{t}^{d} \int_{0}^{1}\left(\frac{\tilde{W}_{t}}{W_{t}}\right)^{-\tilde{\eta}} d j$, and with the wage stickiness process (22), one obtains:

$$
L_{t}=(1-\mu) L_{t}^{d} \sum_{s=0}^{\infty} \mu^{s}\left(\frac{\tilde{W}_{t-s} \prod_{k=1}^{s} N_{t+k-s} / N_{t+k-s-1}}{W_{t}}\right)^{-\tilde{\eta}}
$$

Let $\tilde{s}_{t}:=(1-\mu) \sum_{s=0}^{\infty} \mu^{s}\left(\frac{\tilde{W}_{t-s} \prod_{k=1}^{s} N_{t+k-s} / N_{t+k-s-1}}{W_{t}}\right)^{-\tilde{\eta}}$. The variable $\tilde{s}_{t}$ measures the degree of wage dispersion across differentiated labor varieties. With this variable, Equation (28) can be written as:

$$
L_{t}=\tilde{s}_{t} L_{t}^{d},
$$


and $\tilde{s}_{t}$ can be recursively defined as follows:

$$
\tilde{s}_{t}=(1-\mu)\left(\frac{\tilde{W}_{t}}{W_{t}}\right)^{-\tilde{\eta}}+\mu\left(\frac{W_{t-1}}{W_{t}}\right)^{-\tilde{\eta}}\left(\frac{N_{t}}{N_{t-1}}\right)^{-\tilde{\eta}} \tilde{s}_{t-1} .
$$

Note that $\tilde{s}_{t} \geq 1$, i.e. there is always at least as much labor supply as there is labor demand. Finally, from the wage rate process (22) and the average wage index definition (7) it follows that the dynamics of the average wage rate obey:

$$
W_{t}^{1-\tilde{\eta}}=(1-\mu) \tilde{W}_{t}^{1-\tilde{\eta}}+\mu W_{t-1}^{1-\tilde{\eta}}\left(\frac{N_{t}}{N_{t-1}}\right)^{1-\tilde{\eta}}
$$

\subsection{Intermediate goods sector}

Each intermediate good $i \in\left[0, N_{t}\right]$ is produced by a monopolistically competitive firm maximizing its profits:

$$
\max _{\left\{P_{i, t}\right\}} \Pi_{i, t}=\max _{\left\{P_{i, t}\right\}}\left\{P_{i, t} X_{i, t}\left(P_{i, t}\right)-X_{i, t}\left(P_{i, t}\right)\right\}
$$

A symmetric equilibirum is obtained by solving the maximization problem (32):

$$
\begin{aligned}
P_{i, t} & \equiv P_{t}=\frac{1}{\nu} \\
\Pi_{i, t} & \equiv \Pi_{t}=\left(\frac{1}{\nu}-1\right) X_{t}, \\
X_{i, t} & \equiv X_{t}=\left(\xi \nu\left(K_{t}^{\alpha}\left(A_{t} L_{t}^{d}\right)^{1-\alpha}\right)^{1-\xi} N_{t}^{\frac{\xi}{\nu}-1}\right)^{\frac{1}{1-\xi}} .
\end{aligned}
$$

Substituting Equation (35) into the production function (5) and imposing the following restriction to ensure balanced growth, i.e. $1-\alpha=\frac{\frac{\xi}{\nu}-\xi}{1-\xi}$, implies:

$$
Y_{t}=(\xi \nu)^{\frac{\xi}{1-\xi}} K_{t}^{\alpha}\left(A_{t} N_{t} L_{t}^{d}\right)^{1-\alpha}
$$

Finally, the value $V_{i, t} \equiv V_{t}$ of owning exclusive rights to produce intermediate good $i$ using the respective patent $i$ is equal to the present value of the current and future monopoly profits:

$$
V_{i, t} \equiv V_{t}=\left(1-\tau_{\pi}\right) \Pi_{t}+(1-\phi) \mathbb{E}_{t}\left[\mathbb{M}_{t, t+1} V_{t+1}\right]
$$


where $\phi$ is the probability that a patent becomes obsolete, and $\tau_{\pi}$ is the constant tax rate levied by the government on the profits of intermediate goods firms.

\subsection{Innovation sector}

The number of intermediate goods $N_{t}$ evolves according to:

$$
N_{t+1}=\vartheta_{t} S_{t}^{*}+(1-\phi) N_{t}
$$

where $S_{t}^{*}$ denotes the economy's expenditure in $\mathrm{R} \& \mathrm{D}$. This expenditure is the sum of firm investment in $\mathrm{R} \& \mathrm{D}, S_{t}$, and government subsidies transferred to the inventors, $\tau_{s} G_{t}$. In particular:

$$
S_{t}^{*}=S_{t}+\tau_{s} G_{t}
$$

Moreover, $\vartheta_{t}$ represents the innovation sector's productivity that is taken as given by innovating firms. Its functional form is:

$$
\vartheta_{t}=\chi\left(\frac{S_{t}^{*}}{N_{t}}\right)^{\omega-1}
$$

where $\chi$ is a $R \& D$ productivity shift parameter, and $\omega$ determines the elasticity of $R \& D$ investment. The payoff to innovation is the expected value of discounted future profits on a patent, that is, $\mathbb{E}_{t}\left[\mathbb{M}_{t, t+1} V_{t+1}\right]$. An innovation happens with probability $\vartheta_{t} S_{t}^{*}$ and since the government subsidizes a part of the R\&D investment, the innovator only has to invest $\left(1-\tau_{r d, t}\right) S_{t}^{*}$ in $\mathrm{R} \& \mathrm{D}$. The remainder is financed by the government and, therefore, it holds:

$$
\tau_{s} G_{t}=\tau_{r d, t} S_{t}^{*}
$$

The optimization problem for the innovator is given by:

$$
\max _{\left\{S_{t}^{*}\right\}}\left\{\mathbb{E}_{t}\left[\mathrm{M}_{t, t+1} V_{t+1}\right] \vartheta_{t} S_{t}^{*}-\left(1-\tau_{r d, t}\right) S_{t}^{*}\right\}
$$


Thus, free entry into the innovation sector implies:

$$
\mathbb{E}_{t}\left[\mathbb{M}_{t, t+1} V_{t+1}\right]\left(N_{t+1}-(1-\phi) N_{t}\right)=\left(1-\tau_{r d, t}\right) S_{t}^{*}
$$

which states that the expected sales revenues are equal to the innovation costs. Equivalently, this can be expressed as: $\frac{1-\tau_{r d, t}}{\vartheta_{t}}=\mathbb{E}_{t}\left[\mathbb{M}_{t, t+1} V_{t+1}\right]$.

\subsection{Government and fiscal policy}

The government is responsible for a level $G_{t}$ of government expenditure, where the ratio of government expenditure to output $G_{t} / Y_{t}$ is exogenously determined by the following stochastic process, which ensures that $G_{t} / Y_{t} \in(0,1)$ :

$$
\begin{aligned}
\frac{G_{t}}{Y_{t}} & =\frac{e^{g_{t}}}{1+e^{g_{t}}}, \\
g_{t} & =\left(1-\rho_{g}\right) \bar{g}+\rho_{g} g_{t-1}+\epsilon_{g, t},
\end{aligned}
$$

where $\epsilon_{g, t} \sim \mathcal{N}\left(0, \sigma_{g}\right)$, the persistence of shocks to the government expenditure ratio is determined by $\rho_{g}$, and $\bar{g}$ determines the stationary long-run mean of the government expenditure ratio $G_{t} / Y_{t}$.

We assume that the government has to finance its expenditure level each period by taxes. Hence, the government has to comply with a zero-deficit condition and is not allowed to run any fiscal deficits. This is assumed in order to concentrate fully on the re-distributional effects of government taxation via subsidies to different agents and firms in the economy. However, we expect that results do not qualitatively change if the government would be allowed to run a temporary deficit. If the government were able to run a deficit, this would introduce a smoothing channel and would dilute the analysis of the redistribution system in our economy. The government levies taxes on labor income, $\tau_{l, t} W_{t} L_{t}^{d}$, and on the profits of intermediate goods firms, $\tau_{\pi} N_{t} \Pi_{t}$. To account for the zero-deficit condition to hold in every period, the labor tax-rate adjusts and thus is time-varying.

Furthermore, the government provides the household with a tax transfer adding to its consumption, $\tau_{c} G_{t}$, the final goods firm with a tax transfer to its capital investment, $\tau_{i} G_{t}$, and the innovation sector with a tax transfer to $\mathrm{R} \& \mathrm{D}$ investment, $\tau_{s} G_{t}$. The potential remaining part of 
government expenditure is considered as wasteful government expenditure and is denoted by $Z_{t}$. Hence, it is given by: $Z_{t}=\left(1-\tau_{c}-\tau_{i}-\tau_{s}\right) G_{t}$. We assume that $\tau_{c}+\tau_{i}+\tau_{s} \leq 1$, i.e. government subsidies are never larger than total government expenditure. This implies that the government budget constraint is:

$$
G_{t}=\tau_{l, t} W_{t} L_{t}^{d}+\tau_{\pi} N_{t} \Pi_{t}=\tau_{c} G_{t}+\tau_{i} G_{t}+\tau_{s} G_{t}+Z_{t}
$$

Furthermore, this implies that the labor tax rate is determined by:

$$
\tau_{l, t}=\frac{G_{t}-\tau_{\pi} N_{t} \Pi_{t}}{W_{t} L_{t}^{d}}
$$

\subsection{Aggregate resource constraint}

The production output of final goods is used for consumption (net of government transfers), purchasing intermediate goods, capital investment (net of government transfers), R\&D expenditure (net of government transfers), and government expenditure. Hence, the aggregate resource constraint takes the following form:

$$
Y_{t}=C_{t}+N_{t} X_{t}+I_{t}+S_{t}+G_{t}=C_{t}^{*}+N_{t} X_{t}+I_{t}^{*}+S_{t}^{*}+Z_{t}
$$

Aggregate dividends are given by:

$$
D_{a, t}=C_{t}+S_{t}-\left(1-\tau_{l, t}\right) W_{t} L_{t}^{d}=Y_{t}-N_{t} X_{t}-I_{t}-G_{t}-\left(1-\tau_{l, t}\right) W_{t} L_{t}^{d}=D_{t}+\left(1-\tau_{\pi}\right) N_{t} \Pi_{t}
$$

\subsection{Asset prices}

We study the dynamics of two asset prices in this economy: a risk-free bond and the aggregate market's stock price. First, the risk-free rate solves:

$$
r_{f, t}=\ln \left(R_{f, t}\right), \quad R_{f, t}=\frac{1}{\mathbb{E}_{t}\left[\mathrm{M}_{t, t+1}\right]}
$$


Second, the aggregate market's stock price, its return and risk premium are given by:

$$
\begin{aligned}
V_{a, t} & =D_{a, t}+\mathbb{E}_{t}\left[\mathbb{M}_{t, t+1} V_{a, t+1}\right], \\
R_{a, t} & =\frac{V_{a, t}}{V_{a, t-1}-D_{a, t-1}}, \\
r_{a, t}^{e x} & =(1+\varphi)\left(\ln \left(R_{a, t}\right)-r_{f, t}\right),
\end{aligned}
$$

where the equity premium is levered as in Boldrin, Christiano, and Fisher (2001) by imposing $\varphi=\frac{2}{3}$.

\section{Heterogeneous Innovation Model}

The previous section describes a model with only homogeneous innovations by entrants building on the endogenous growth theory with horizontal innovations as developed by Romer (1990) and utilized by Kung and Schmid (2015) to study the equilibrium effects of innovations on asset prices. In this section, we augment the model described in Section 3 to account for competition in innovation (i.e. heterogeneous innovations). Specifically, following a number of empirical studies suggesting that the majority of innovations does not originate from entrants but instead from large established firms, i.e. from so-called incumbents, ${ }^{2}$ we modify the previous innovation sector along the lines of Bena, Garlappi, and Grüning (2016) and Acemoglu and Cao (2015) to account for vertical innovations and creative destruction. To this extent, both incumbents and entrants invest in R\&D in this model. Thus, we utilize modern Schumpetarian growth theory developed by Grossman and Helpman (1991) and Aghion and Howitt (1992).

There is now a continuum of measure 1 of intermediate goods only and intermediate good $i$ 's highest available quality is denoted by $q(i, t)$. The aggregator $\Xi$ in the production function (5) thus has to be redefined as follows:

$$
\Xi_{t}=\left[\int_{0}^{1} q(i, t)^{1-\frac{1}{\nu}} x(i, t \mid q)^{\frac{1}{\nu}} d i\right]^{\nu} .
$$

\footnotetext{
${ }^{2}$ For example, evidence provided by Bartelsman and Doms (2000) and Foster, Haltiwanger, and Krizan (2001), among others, indicates that only about $25 \%$ of average TFP growth at the industry level is accounted for by new entrants (new plants), while the remaining productivity growth is due to innovations by incumbents (continuing plants).
} 
The other changes need to be made in the innovation sector. At each time $t$, each intermediate good $i$ is produced by a single incumbent holding a patent on the intermediate good's current quality. Therefore, incumbents are monopolists in the production of the intermediate good with current quality.

The government in this economy might give subsidies to both incumbents and entrants. Hence, its budget constraint is now given by:

$$
G_{t}=\tau_{l, t} W_{t} L_{t}^{d}+\tau_{\pi} N_{t} \Pi_{t}=\tau_{c} G_{t}+\tau_{i} G_{t}+\tau_{s, \mathrm{I}} G_{t}+\tau_{s, \mathrm{E}} G_{t}+Z_{t}
$$

The subsidies can also be written as follows again:

$$
\begin{gathered}
\tau_{s, \mathrm{I}} G_{t}=\tau_{r d, \mathrm{I}, t} S_{\mathrm{I}, t}^{*}, \\
\tau_{s, \mathrm{E}} G_{t}=\tau_{r d, \mathrm{E}, t} S_{\mathrm{E}, t}^{*} .
\end{gathered}
$$

Each incumbent has access to a stochastic quality-improving incremental innovation technology for its own intermediate good. If the incumbent (including the government subsidies) spends $s_{\mathrm{I}, t}^{*}(i, t) q(i, t)$ units of the consumption good on R\&D toward its intermediate good with quality $q(i, t)$ the quality increases to $q(i, t+1)=\kappa_{\mathrm{I}} q(i, t)$ in the next period with probability $\phi_{\mathrm{I}}\left(s_{\mathrm{I}, t}^{*}(i, t)\right)=$ $\chi_{\mathrm{I}}\left(s_{\mathrm{I}, t}^{*}(i, t)\right)^{\omega_{\mathrm{I}}}$, where $\chi_{\mathrm{I}}$ is the incumbents' $\mathrm{R} \& \mathrm{D}$ productivity shift parameter and $\omega_{\mathrm{I}}$ determines the elasticity of incumbents' R\&D. Furthermore, $\kappa_{\mathrm{I}}>1$ determines the innovation size of incumbents' innovations. ${ }^{3}$

If $\mathrm{R} \& \mathrm{D}$ does not result in a new innovation, we assume that the quality "depreciates" by a factor $\kappa_{\mathrm{D}}<1$, i.e. $q(i, t+1)=\kappa_{\mathrm{D}} q(i, t)$. Patent expiration and general obsolescence of intermediate goods over time are thus captured by the parameter $\kappa_{\mathrm{D}}$.

Patent protection of the intermediate goods, however, does not prevent potential entrants to invest in $\mathrm{R} \& \mathrm{D}$ trying to come up with a better intermediate good. Upon the success of such an atomistic entrant, the intermediate good of the incumbent with quality $q(i, t)$ becomes obsolete, the entrant takes over its monopoly and thus "displaces" the incumbent in the production of in-

\footnotetext{
${ }^{3}$ This implies that the private R\&D investment of incumbent $i$ amounts to $\left(1-\tau_{r d, \mathrm{I}, t}\right) s_{\mathrm{I}, t}^{*}(i, t) q(i, t)$ units of the final good.
} 
termediate good $i$. Therefore, if all entrants directing R\&D efforts to improve intermediate good $i$ (including the government subsidies) spend $s_{\mathrm{E}}^{*}(i, t) q(i, t)$ units of the consumption good on R\&D the quality increases to $q(i, t+1)=\kappa_{\mathrm{E}} q(i, t)$ next period with probability $s_{\mathrm{E}}^{*}(i, t) \phi_{\mathrm{E}}\left(s_{\mathrm{E}}^{*}(i, t)\right) .{ }^{4}$ The assumption that entrants' innovation technology is more "radical" than that of incumbents is captured by $\kappa_{\mathrm{E}}>\kappa_{\mathrm{I}}$ in the model. Since each entrant is atomistic, all entrants take $s_{\mathrm{E}}^{*}(i, t)$ as given. The functional form of the innovation technology is $\phi_{\mathrm{E}}\left(s_{\mathrm{E}}^{*}(i, t)\right)=\chi_{\mathrm{E}}\left(s_{\mathrm{E}}^{*}(i, t)\right)^{\omega_{\mathrm{E}}-1}$, where $\chi_{\mathrm{E}}$ is the entrants' productivity shift parameter and $\omega_{\mathrm{E}}$ the elasticity of entrants' R\&D. Hence, the total radical innovation probability $\hat{\phi}_{\mathrm{E}}\left(s_{\mathrm{E}, t}^{*}(i, t)\right):=s_{\mathrm{E}, t}^{*}(i, t) \phi_{\mathrm{E}}\left(s_{\mathrm{E}}^{*}(i, t)\right)$ has the same functional form as the incumbents' incremental innovation probability but with potentially different elasticity and productivity shift parameters.

Given this competitive structure in the intermediate goods and innovation sector, the value of the incumbent producing intermediate good $i$ is determined by the following Bellman equation:

$$
\begin{gathered}
V(i, t \mid q)=\max _{\left\{s_{\mathrm{I}}^{*}(i, t)\right\}}\left\{\left(1-\tau_{\pi}\right) \pi(i, t \mid q)-\left(1-\tau_{r d, \mathrm{I}, t}\right) s_{\mathrm{I}}^{*}(i, t) q(i, t)+\mathbb{E}_{t}\left[\mathbb { M } _ { t , t + 1 } \left\{\phi_{\mathrm{I}}\left(s_{\mathrm{I}}^{*}(i, t)\right) \cdot V\left(i, t+1 \mid \kappa_{\mathrm{I}} q\right)\right.\right.\right. \\
\left.\left.\left.+\left(1-\phi_{\mathrm{I}}\left(s_{\mathrm{I}, t}^{*}(i, t)\right)-\hat{\phi}_{\mathrm{E}}\left(s_{\mathrm{E}}^{*}(i, t)\right)\right) \cdot V\left(i, t+1 \mid \kappa_{\mathrm{D}} q\right)\right\}\right]\right\}
\end{gathered}
$$

Since also here each incumbent charges the same monopoly profit, and both the profit and the R\&D investment are linear in the respective quality, we focus on the linear balanced growth equilibrium additionally implying linearity of the value function:

$v_{t}=\max _{\left\{s_{\mathrm{I}, t}^{*}\right\}}\left\{\left(1-\tau_{\pi}\right) \pi_{t}-\left(1-\tau_{r d, \mathrm{I}, t}\right) s_{\mathrm{I}, t}^{*}+\mathbb{E}_{t}\left[\mathrm{M}_{t, t+1} v_{t+1}\left(\phi_{\mathrm{I}}\left(s_{\mathrm{I}, t}^{*}\right) \kappa_{\mathrm{I}}+\left(1-\phi_{\mathrm{I}}\left(s_{\mathrm{I}, t}^{*}\right)-\hat{\phi}_{\mathrm{E}}\left(s_{\mathrm{E}, t}^{*}\right)\right) \kappa_{\mathrm{D}}\right)\right]\right\}$.

The first-order condition determining the optimal investment in R\&D for incumbents is given by:

$$
1-\tau_{r d, \mathrm{I}, t}=\phi_{\mathrm{I}}^{\prime}\left(s_{\mathrm{I}, t}^{*}\right)\left(\kappa_{\mathrm{I}}-\kappa_{\mathrm{D}}\right) \mathbb{E}_{t}\left[\mathrm{M}_{t, t+1} v_{t+1}\right]
$$

\footnotetext{
${ }^{4}$ This implies that the private R\&D investment by all entrants directing R\&D efforts to good $i$ amounts to $\left(1-\tau_{r d, \mathrm{E}, t}\right) s_{\mathrm{E}, t}^{*}(i, t) q(i, t)$ units of the final good.
} 
Entrants maximize the present value of future net profits achieved if they become incumbents:

$$
\max _{\left\{s_{\mathrm{E}, t}^{*}\right\}}\left\{s_{\mathrm{E}, t}^{*} \phi_{\mathrm{E}}\left(s_{\mathrm{E}, t}^{*}\right) \kappa_{\mathrm{E}} \mathbb{E}_{t}\left[\mathbb{M}_{t, t+1} v_{t+1}\right]-\left(1-\tau_{r d, \mathrm{E}, t}\right) s_{\mathrm{E}, t}^{*}\right\}
$$

As stated earlier, since entrants are atomistic each entrant takes $\phi_{\mathrm{E}}\left(s_{\mathrm{E}, t}^{*}\right)$ as given. This assumption implies that entrants do not internalize the fact that more R\&D reduces the other entrants' probability of success. Solving Equation (61) under this assumption leads to the following free-entry condition determining the optimal level of entrants' R\&D expenditure:

$$
1-\tau_{r d, \mathrm{E}, t}=\phi_{\mathrm{E}}\left(s_{\mathrm{E}, t}^{*}\right) \kappa_{\mathrm{E}} \mathbb{E}_{t}\left[\mathbb{M}_{t, t+1} v_{t+1}\right]
$$

The key state variable in this model is not the growth of the number of intermediate goods anymore as this number is now fixed at 1 but the growth of the aggregate quality available in the economy, i.e. $Q_{t}=\int_{0}^{1} q(i, t) d i$ with dynamics:

$$
\frac{Q_{t+1}}{Q_{t}}=\phi_{\mathrm{I}}\left(s_{\mathrm{I}, t}^{*}\right) \kappa_{\mathrm{I}}+\hat{\phi}_{\mathrm{E}}\left(s_{\mathrm{E}, t}^{*}\right) \kappa_{\mathrm{E}}+\left(1-\phi_{\mathrm{I}}\left(s_{\mathrm{I}, t}^{*}\right)-\hat{\phi}_{\mathrm{E}}\left(s_{\mathrm{E}, t}^{*}\right)\right) \kappa_{\mathrm{D}} .
$$

The growth rate of aggregate quality or technology capital is due to a combination of heterogeneous innovations by incumbents and entrants and depends on the level of their R\&D expenditures. The next-period technology capital $Q_{t+1}$ is known after total $\mathrm{R} \& \mathrm{D}$ expenditures $s_{\mathrm{I}, t}^{*}$ and $s_{\mathrm{E}, t}^{*}$ are determined at time $t$. Over the next period in time, a fraction $\phi_{\mathrm{I}}\left(s_{\mathrm{I}, t}^{*}\right)$ of intermediate goods experience innovation by incumbents who increase quality by the factor $\kappa_{\mathrm{I}}$, a fraction $\hat{\phi}_{\mathrm{E}}\left(s_{\mathrm{E}, t}^{*}\right)$ of intermediate goods experience displacement by entrants who increase quality by the factor $\kappa_{\mathrm{E}}$, and the remaining intermediate goods see their quality depreciate by the factor $\kappa_{\mathrm{D}}$.

The aggregate quality index $Q_{t}$ replaces $N_{t}$ as the measure of size in the economy. Hence, in this model, $Q_{t}$ replaces $N_{t}$ in Equation (22) as the quantity with which wages change, if they are not set optimally. Moreover, the total demand for intermediate goods $X_{t}$ is now determined by the following equation which therefore replaces Equation (35):

$$
X_{i, t} \equiv X_{t}=\left(\xi \nu\left(K_{t}^{\alpha}\left(A_{t} L_{t}^{d}\right)^{1-\alpha}\right)^{1-\xi} Q_{t}^{\frac{\xi}{\nu}-\xi}\right)^{\frac{1}{1-\xi}}
$$


Furthermore, the aggregate resource constraint is slightly modified as well to take into account the $\mathrm{R} \& \mathrm{D}$ expenditure by both incumbents and entrants:

$$
Y_{t}=C_{t}+X_{t}+I_{t}+S_{\mathrm{I}, t}+S_{\mathrm{E}, t}+G_{t}=C_{t}^{*}+X_{t}+I_{t}^{*}+S_{\mathrm{I}, t}^{*}+S_{\mathrm{E}, t}^{*}+Z_{t}
$$

where $S_{\mathrm{I}, t}=\int_{0}^{1} s_{\mathrm{I}}(i, t) q(i, t) d i$ and $S_{\mathrm{E}, t}=\int_{0}^{1} s_{\mathrm{E}}(i, t) q(i, t) d i$ denote the aggregate R\&D expenditure of incumbents and entrants, respectively. These aggregate quantities have the property $S_{\mathrm{I}, t} / Q_{t}=s_{\mathrm{I}, t}$ and $S_{\mathrm{E}, t} / Q_{t}=s_{\mathrm{E}, t}$ due to focusing on the linear balanced growth equilibrium. Total R\&D investment in the economy is thus given by $S_{t}=S_{\mathrm{I}, t}+S_{\mathrm{E}, t}$. Note that aggregate monopoly profits of intermediate goods firms are given by $\Pi_{t}=\pi_{t} Q_{t}$ (in contrast to the homogeneous innovation model where these aggregate profits are given by $N_{t} \Pi_{t}$ ). Finally, the definition of aggregate dividends is now also slightly different and given by:

$$
D_{a, t}=C_{t}+S_{\mathrm{E}, t}-\left(1-\tau_{l, t}\right) W_{t} L_{t}^{d}=D_{t}+\left(1-\tau_{\pi}\right) \Pi_{t}-S_{\mathrm{I}, t} .
$$

\section{Calibration}

This section describes the calibration of our two models. First, the calibration of the homogeneous innovation model of Section 3 is detailed. The structure of the government sector in our model requires less standard parameters. To get reasonable values for the fraction of government spending transferred to households, final goods firms, and the R\&D sector, we use data from NIPA tables of the Bureau of Economic Analysis (BEA) and the OECD Main Science and Technology Indicators database. We measure the fraction of $G_{t}$ transferred to household, $\tau_{c}$, as the ratio between government expenditure in income security and total government consumption expenditure and investment. Using BEA data (NIPA Table 3.15.6) for the period 1999-2015, we find $\tau_{c}=0.033$. Similarly, $\tau_{i}$ is the government gross investment in structures divided by total government consumption expenditure and investment. BEA data (NIPA Table 3.9.6) for the period 1999-2015 suggest $\tau_{i}=0.107 .{ }^{5}$ The fraction of government spending transferred to the R\&D sector, $\tau_{s}$, is then de-

\footnotetext{
${ }^{5}$ Note that here we assume that all government social benefits, in this case income security, are used by the household exclusively for consumption purposes and government investment in structures goes directly to the private sector. We stress that the use of slightly different parameter values does not alter the direction
} 
fined as the ratio between gross domestic expenditure in R\&D (GERD) financed by the government and the final consumption expenditure of general government. Both government-financed GERD and government final consumption expenditure are from the OECD. For the period 1981-2013 we find $\tau_{s}=0.05 .^{6}$ Therefore, in our benchmark calibration we impose: $\tau_{c}=0.033, \tau_{i}=0.107$, and $\tau_{s}=0.05$. This implies that $81 \%$ of government expenditure is wasteful in our benchmark calibration. This seems to be a relatively high fraction of wasteful expenditure. However, we stress that this is more realistic than a rather typical assumption in the macro-finance literature that $100 \%$ of government expenditure is wasteful (see, for example, Croce, Nguyen, and Schmid, 2013, 2015).

Moreover, we find $E[G / Y]=15.55 \%$ and $\sigma(G / Y)=0.85 \%$ in the U.S. data between 1975 and 2015. In order to replicate these moments in the model, we set $\bar{g}=-1.6883, \rho_{g}=0.98^{1 / 4}$, and $\sigma_{g}=0.0065$. Average corporate income tax using KPMG data is $40 \%$ in the U.S. between 2006 and 2015 which we use to set $\tau_{\pi}=0.40$. The labor income tax in our model is endogenous but we can compare its level to the level of the average U.S. personal income tax rate of $37 \%$ using the same KPMG data between 2006 and 2015.

Now, turning to more standard parameters, we mostly follow Kung and Schmid (2015) for the homogeneous innovation model of Section 3. Specifically, the following parameters are taken from Kung and Schmid (2015): $\beta=0.984^{1 / 4}, \psi=1.85, \gamma=10, \alpha=0.35, \delta=0.02$, and $\omega=0.83$. The capital investment adjustment cost elasticity is set to $\zeta=0.7$. Hence, the preference parameters are in line with the literature on long-run risks (see Bansal and Yaron (2004) and subsequent studies) and the listed parameters related to final goods production are relatively standard in the macroeconomics literature. The $\mathrm{R} \& \mathrm{D}$ productivity parameter is set to $\chi=0.7374$, which implies a steady state consumption growth rate of 1.89 p.p. and thus corresponds to the long-run sample average of the U.S. economy. We set the inverse monopoly markup parameter to $\nu=1 / 1.35$, which is lower than the value used in Kung and Schmid (2015) and slightly higher than the one used by Bena, Garlappi, and Grüning (2016) in order to match well the average U.S. personal income tax rate of $37 \%$. The reason is that due to the presence of the corporate tax rate the monopoly markup of our main results.

${ }^{6}$ We measure $\tau_{s}$ also as the ratio between government investment in R\&D (NIPA Table 3.9.6, line 8) and total government consumption expenditure and gross investment (NIPA Table 3.9.6, line 1). Using data for the period 1999-2015, we find a very similar value, i.e. $\tau_{s}=0.046$. 
parameter controls the revenue generated by this tax. This, in turn, determines the size of the labor tax rate needed to balance the government's budget given the parameters for the government expenditure process. Consequently, we have to set the monopoly markup to $35 \%$ in order to match the average labor tax rate in the data.

The parameters related to sticky wages are motivated by two sources. On the one hand, the labor service substitution elasticity is set to $\tilde{\eta}=21$ as in Schmitt-Grohé and Uribe (2006). The sticky wage parameter, on the other hand, is set as in Uhlig (2007) to feature relatively mild wage rigidities.

For the heterogeneous innovation model of Section 4, we try to make it as comparable as possible to the homogeneous innovation model and calibrate the remaining parameters as in Acemoglu and Cao (2015). Hence, the R\&D technology elasticities for both incumbents and entrants are the same as the elasticity of the innovators in the homogeneous innovation model, i.e. $\omega_{\mathrm{I}}=\omega_{\mathrm{E}}=0.83$. The patent obsolescence rate is also the same and thus we set $\kappa_{\mathrm{D}}=0.9625$ giving rise to a quarterly depreciation of quality of $3.75 \%$. As in Acemoglu and Cao (2015), we set $\kappa_{\mathrm{E}}=3,{ }^{7} \kappa_{\mathrm{I}}=1.2$, and choose the parameters $\chi_{\mathrm{E}}$ and $\chi_{\mathrm{I}}$ so that two thirds of productivity growth is due to incremental innovations by incumbents, one third is due to radical innovations by entrants, and the growth rate is the same as in the homogeneous innovation model. This implies $\chi_{\mathrm{I}}=3.4542$ and $\chi_{\mathrm{E}}=0.2301$. Due to lack of guidance from the data regarding the breakdown of $R \& D$ investment subsidies into the parts accruing to incumbents and entrants, respectively, we allocate two thirds of the subsidy to incumbents and one third to entrants. This implies $\tau_{s, \mathrm{I}}=0.0333$ and $\tau_{s, \mathrm{E}}=0.0167$ and, therefore, subsidies are split according to the respective contribution of incumbents and entrants to economic growth.

Moreover, we set $\sigma_{a}=0.0115$ in both innovation models to obtain a moderate consumption growth volatility of about 0.0165 . The correlation between the two exogenous shocks in the model, productivity and government expenditure shock, is set to zero in both models for parsimony. Finally, labor supply elasticities in the models are set so that the household works one third of its time endowment in the deterministic steady state, given all other parameters. This implies $\varphi=1.6806$ in the homogeneous innovation model and $\varphi=1.6857$ in the heterogeneous innovation model.

${ }^{7}$ This choice satisfies the limit-pricing condition $\kappa_{\mathrm{E}} \geq(1 / \nu)^{\frac{1}{1 / \nu-1}}$. 
All parameter values for the benchmark calibrations of both models are summarized in Table 1. The model is solved using a third-order perturbation around the stochastic steady state implemented in Dynare ++4.4 .3 .

\section{Results}

In what follows, Section 6.1 analyzes the results obtained from the homogeneous innovation model of Section 3 and Section 6.2 analyzes the results from the heterogeneous innovation model of Section 4 .

\subsection{Analysis of homogeneous innovation model}

The results from our simulation of the model are reported in Table 2. Model (1.1) corresponds to the benchmark calibration discussed in the previous section. For Models (1.2)-(1.6) the parameters related to the subsidies or the government process are varied and all the other parameters are kept fixed as in the benchmark calibration. The comparison of the models allows us to investigate how changes in fiscal policy affect the equilibrium dynamics of the model. Specifically, Model (1.2) features one p.p. lower subsidies across all three types of subsidies. Thus, the fraction of government expenditure that is wasteful is three p.p. higher than in the benchmark model. Models (1.3), (1.4), and (1.5) look at a one p.p. increase in the subsidy for $R \& D$ investment, capital investment, and consumption, respectively. Hence, in these models the fraction of wasteful government expenditure

is one p.p. lower than in the benchmark model. Finally, Model (1.6) features a one p.p. increase in the average government expenditure-to-output ratio.

Macroeconomic quantities. First, we discuss the macro moments of the benchmark calibration. The consumption growth rate is 1.89 p.p. due to calibration choices and thus matches the sample moment for the period 1929-2008 as reported by Benzoni, Collin-Dufresne, and Goldstein (2011). In our recent data sample, the average consumption growth rate is exceptionally high and, therefore, we have chosen to calibrate that moment to this slightly more classical number. The consumption growth volatility is also very low in the recent data sample. Hence, we also have not 
aimed to match this moment but to obtain a value that is in between the post-war sample and the sample including the Great Depression. In this respect, the model produces a consumption growth volatility of 0.0165 .

The household works about one third of its time endowment due to our choice of parameters. The volatility of labor supply is not as high as in the data, but it is also far from zero. The government expenditure-to-output ratio data moments are reasonably matched, and the labor income tax rate with a value of $39 \%$ in the model is consistent with the value of $37 \%$ observed in the data. Due to the zero-deficit condition, a substantial volatility in the labor tax rate of around four p.p. is observed. Albeit not being reported in the table, it is nevertheless important to mention that the government finances about $3 \%$ of household's consumption, $13 \%$ of final goods firm's capital investment, and $7 \%$ of R\&D expenditures with its fiscal instruments.

The volatility ratios of consumption to output growth and $R \& D$ investment to output growth are reasonable, given the empirical moments. Due to the presence of relatively strong capital adjustment costs and due to the fact that there are no investment-specific shocks in the model, investment growth is not volatile enough to be compatible with the empirical evidence. The volatility ratios of labor and wage growth to output growth in our recent data sample also seem a bit exceptional, i.e. they are both above 1. However, the empirical moments reported in Papanikolaou (2011) and Favilukis and Lin (2016) for longer samples than we use are below 1 and thus much more consistent with our model-implied moments.

Correlations between various macroeconomic growth rates are higher in the model than in the data, especially for the correlation between output and wage growth. There are only two exceptions: the correlation between consumption and investment growth and between consumption and labor growth match well the empirical evidence. The reason for high correlations is that all variables grow at the same rate due to balanced growth and, consequently, the productivity shock affects the macroeconomic growth rates similarly. The government expenditure shock due to the presence of subsidies affects the growth rates differently and hence reduces correlations. However, the quantitative impact of government expenditure shocks relative to productivity shocks is relatively small.

By looking at the impulse response functions with respect to a productivity shock and a govern- 
ment expenditure shock depicted in Figures 1 and 2, respectively, one validate these claims about the correlations. A positive productivity shock induces an increase in all macroeconomic quantities of a similar shape. On impact, the risk-free rate decreases but becomes higher than the steady state from around the third quarter onwards. The aggregate market return displays an initial rise of around 0.015. Afterward, it decreases and quickly reverts back to its steady state level (Figure 1, Panel H). The price-dividend ratio persistently increases in response to a productivity shock and the size of the reaction depends on the magnitude of the subsidies.

A positive government expenditure shock mostly has adverse consequences for macroeconomic quantities except for increasing wages (Figure 2, Panel F). The magnitude of the effects depends to a large extent on how the government dynamics are specified. Both the risk-free rate and the aggregate return decrease on impact but with low persistence. Also, the price-dividend ratio decreases in response to a higher government expenditure ratio but with high persistence. In the calibration with higher $\mathrm{R} \& \mathrm{D}$ subsidies, investment reacts marginally positively to a positive government expenditure shock (Figure 2, Panel D).

Second, we now analyze the dynamics when changing the government-related parameters. Not surprisingly, the average consumption growth rate is considerably higher at 2.25 p.p. with a higher R\&D investment subsidy in Model (1.3) due to total R\&D expenditures being $2.58 \%$ higher than in the benchmark model. This goes along with a lower amount of consumption $(-1.87 \%$ relative to the benchmark calibration) and a higher amount of capital investment $(+1.26 \%)$. Hence, a higher subsidy induces the household to divert further resources away from consumption to investments. Moreover, the household works slightly more than in the benchmark calibration, i.e. the share of time the household is working becomes about $33.6 \%$ on average. All the other moments do not change much for Model (1.3) relative to the benchmark calibration.

The average consumption growth rate is also higher for higher capital investment subsidies in Model (1.4). However, it is not increasing as much as when R\&D investment subsidies are increased, i.e. it only increases to 0.0207. This does not come as a surprise in an endogenous growth model. However, the difference in the change in growth rates is relatively minor. In a semiendogenous growth model, one could expect that both subsidy changes have similar quantitative effects. Higher investment subsidies make the investment opportunity set look more favorable 
and households forgo consumption now to invest in order to stimulate consumption later. Hence, similarly to higher R\&D investment subsidies, higher capital investment subsidies also lead to lower consumption (-0.24\%), higher capital investment $(+2.60 \%)$, and higher R\&D investment $(+1.26 \%)$ relative to the benchmark model. Higher consumption subsidies in Model (1.5) reduce economic growth significantly to 1.72 p.p., whereas higher total government expenditures in Model (1.6) lead to slightly higher economic growth (1.99 p.p.). A higher consumption subsidy reduces incentive for households to work and invest via the discount rate effect through the pricing kernel. Thus, the relative amount of labor to leisure is reduced to $32.78 \%$ and investments fall by $1.32 \%$ and $1.22 \%$, respectively. This lies behind the observed lower economic growth.

The mechanism behind higher investment subsidies drive the moments of Model (1.6) where government expenditures are higher across the board. Even though the majority of government expenses is wasteful, the positive effect from higher spending by the government on investment subsidies leads to slightly higher economic growth of 0.0199. Consumption does drop significantly in this model (-6.94\% relative to the benchmark). Most of it is due to higher wasteful government expenditure. However, capital investment and R\&D investment increase by $1.15 \%$ and $0.77 \%$, explaining the positive effect on growth. Similarly, the effects of lower investment subsidies dominate the effect of lower consumption subsidies, when all subsidies are lowered by the same amount as analyzed in Model (1.2). Hence, the average consumption growth rate is the lowest among the models analyzed and equals 0.015. As investments are less favorable the amounts decrease by $2.95 \%$ for capital investment and $2.78 \%$ for R\&D investment relative to the benchmark model. On the contrary, consumption is slightly increased by $0.99 \%$.

Asset prices. Due to the presence of Epstein and Zin preferences and endogenous growth, our results are in line with those of the literature on long-run risks (see Kung and Schmid, 2015). Hence, the risk-free rate is relatively low and in line with the data but not volatile enough, and equity risk premia are substantial.

In particular, the average risk-free rate for the period 1975-2015 is almost exactly matched by the benchmark calibration (1.61 p.p. in the model vs. 1.56 in the data). However, the volatility of the risk-free rate is far too low at only 0.0035 . The aggregate risk premium is 2.73 p.p. in the 
model and 4.02 p.p. in the data. Therefore, around $70 \%$ of the equity premium is explained by the model. As usual in this type of production economies, the magnitude of the excess return volatility in the data is not reproduced, and the benchmark calibration reaches only about one third of the empirical counterpart.

Next, we analyze the asset pricing implications when one changes the government and subsidy parameters. In Model (1.3), the equity premium is significantly higher and slightly higher in Models (1.4) and (1.6) relative to the benchmark model. In other cases, it is slightly lower. The reason can be found in the dynamics of aggregate $R \& D$ expenditures. When the average level of $R \& D$ expenditures is higher, as it is the case for Models (1.3), (1.4), and (1.6), there is a higher amount of endogenous long-run risks. Thus, one obtains a higher equity premium. As the other models feature a lower amount of $\mathrm{R} \& \mathrm{D}$ expenditures (and economic growth) the equity premium declines in these cases. For the excess return volatility, the effects are similar. However, when R\&D subsidies are higher the excess return volatility does not increase alongside the equity premium due to the reduction in the volatility of output, $\mathrm{R} \& \mathrm{D}$ expenditure, and labor apparent in the reported volatility ratios. These reductions are fueled by higher R\&D expenditures making innovations less risky. Finally, the risk-free rate increases with economic growth in line with standard theory, and its volatility is essentially constant across models.

Welfare analysis. Since the model is simulated for a number of calibrations reflecting different policies, we are able to study whether all sector-specific government aids provide welfare benefits. Quantitatively, we compute the welfare costs of Models (1.2)-(1.6) relative to the benchmark calibration to provide an ordering of the models along the welfare dimension. Following Croce, Nguyen, and Schmid (2013), the welfare cost is defined as the percentage increase of time-zero utility bundle units $\Lambda$ that one must give to the household in order to make it indifferent between the utility bundle process of the benchmark calibration $\left\{u_{\text {bench }}\right\}$ and the utility bundle process $\left\{u_{i}\right\}$ of each other model $i=2, \ldots, 6$ :

$$
e^{\hat{U}_{\text {bench }}}(1+\Lambda)=e^{\hat{U}_{i}}
$$

where $\hat{U}$ denotes the natural logarithm of the ratio of the utility $U$ to the initial number of intermediate goods $N$. Since consumption is endogenous, we cannot choose its initial level. But we can 
choose the initial level of intermediate goods in different economies and assume above that it is identical. Solving for $\Lambda$, we find:

$$
\Lambda=e^{\hat{U}_{i}-\hat{U}_{\text {bench }}}-1
$$

Hence, a positive value of $\Lambda$ for a model means that the household's welfare is lower than in the benchmark calibration, whereas a negative value means that welfare increases relative to the benchmark calibration. Additionally, the increase or decrease in time-zero utility bundle units that $\Lambda$ measures as welfare gain or cost can be equivalently expressed in increases or decreases of time-zero consumption units. This property originates from the fact that the utility bundle $u_{t}=C_{t}^{*}\left(\bar{L}-L_{t}\right)^{\nu}$ is linear in total consumption $C_{t}^{*}$. Hence, when talking below about percentage increases (decreases) in welfare, it can be understood as percentage increases (decreases) in consumption only. However, part of the consumption increase or decrease can be substituted by increasing or decreasing leisure as well. ${ }^{8}$

As one can see from Table 2, welfare is lower in Models (1.2), (1.3), (1.5), and (1.6), i.e. when there are lower overall subsidies, higher R\&D investment subsidies, higher consumption subsidies, and higher overall government expenditure. Hence, even with much higher economic growth in the case of larger $R \& D$ investment subsidies, the lower amount of (normalized) consumption reduces welfare in this case. Furthermore, the effect is quantitatively important: About $5 \%$ of lifetime consumption or utility bundle units has to be given up in this case. Interestingly, Model (1.4) features both higher economic growth and higher welfare. Hence, from a welfare point of view subsidies to capital investment look more favorable due to relatively low reduction of consumption relative to the benchmark model and a nevertheless considerable increase in economic growth.

However, as discussed above, higher consumption subsidies lead to a considerable decrease in welfare (of the order of slightly more than $2.4 \%$ of lifetime utility bundle units) despite being a direct transfer to the source of utility for the household. Thus, there is a important role of economic

\footnotetext{
${ }^{8}$ Note that here we compute unconditional welfare losses and gains. Schmitt-Grohé and Uribe (2007) suggest studying conditional welfare losses and gains as well by computing perturbations around the deterministic steady state. For completeness, we have also computed welfare losses as indicated by Schmitt-Grohé and Uribe (2007). However, we have decided not to show them in the paper. The reason is that stochastic endogenous growth models lead to stochastic steady states significantly different from deterministic steady states. Hence, we mainly trust the perturbations around the stochastic steady states used for computing unconditional welfare and suspect that the perturbations around the deterministic steady states are far less accurate implying also that the welfare calculations based on these are much less accurate.
} 
growth for welfare considerations. It is not only important how much is consumed but also at which rate consumption grows. Significantly, our results show that the relationship between economic growth and welfare is non-monotonic, and it depends on the type of subsidy change considered if both welfare and growth increases or decreases or if one moment behaves oppositely to the other. In Models (1.3) and (1.6), growth and welfare behave oppositely relative to the benchmark economy, whereas Models (1.2), (1.4), and (1.5) imply simultaneous increases or decreases in welfare and economic growth.

\subsection{Analysis of heterogeneous innovation model}

The results from our simulation of the heterogeneous innovation model are reported in Table 3. As in Table 2, Model (2.1) corresponds to the benchmark calibration. The other models correspond to changes in the fiscal policy mix of the government. Specifically, Model (2.2) features 0.5 p.p. lower subsidies across all four subsidies in the heterogeneous innovation model. Models (2.3) and (2.4) look at an increase of 0.5 p.p. in the subsidy for incumbent $R \& D$ investment, and entrant R\&D investment, respectively. Model (2.5) studies the case of an increase of $0.5 \mathrm{pp}$ in both the incumbent and the entrant R\&D investment subsidy. Next, Models (2.6) and (2.7) feature a 0.5 p.p. increase in the consumption and the capital investment subsidy, respectively. Finally, Model (2.8) features a 0.5 p.p. increase in the average government expenditure-to-output ratio. The reason why we do not study one p.p. increases as in the last section is due to the fact that a one p.p. increase in the incumbent R\&D subsidy in Model (2.3) would lead to such a high growth rate that it would violate the transversality condition of the model. Hence, this model is not solvable for a one p.p. increase. Thus, we choose to study increases of only 0.5 p.p. in all models. The reason for the rather strong effect on growth of changing incumbent $R \& D$ subsidies is due to the fact that incumbents are responsible for about two thirds of aggregate economic growth, but the amount of incumbents' R\&D expenditures is roughly of the same size as entrants' R\&D expenditures. Hence, total R\&D expenditures are of roughly the same size as in the homogeneous innovation model, but this total R\&D expenditure is split into two types of innovative firms. This leads to changes in one of the subsidies having a larger effect than changing the subsidies for total R\&D investment in the homogeneous innovation model. Moreover, incumbents have access to a very efficient R\&D 
technology since it is not subject to any frictions. ${ }^{9}$ However, in the homogeneous innovation model all inventors face a congestion externality. This externality only affects entrants in the heterogeneous innovation model. Moreover, due to the negative effect of entrant R\&D investments on the value of a patent, entrants' $R \& D$ investments are even less efficient than the $R \& D$ investments of innovators in the homogeneous innovation model. Hence, the same amount of goods additionally transferred to incumbents in the heterogeneous innovation model has a much larger effect on growth than the amount transferred to inventors in the homogeneous innovation model.

Macroeconomic quantities. Similarly to the benchmark homogeneous innovation calibration (Model (1.1)), the benchmark heterogeneous innovation calibration (Model (2.1)) implies that the government finances about $3 \%$ of consumption, about $14 \%$ of capital investment, and about $7 \%$ of aggregate $R \& D$ expenditures. The last number can be further decomposed: about $9 \%$ of total incumbent R\&D investment and about $5 \%$ of total entrant $R \& D$ investment is due to government subsidies. The unconditional moments of Model (2.1) are very similar to the ones of Model (1.1) as well. Due to calibration choices, about one third of economic growth, i.e. $33.43 \%$, is induced by radical innovations of entrants, as reported in the table.

Similarly to the homogeneous innovation model, overall lower government subsidies in the heterogeneous innovation model (2.2) implies a significantly lower consumption growth rate relative to the benchmark calibration. Thus, Model (2.2) exhibits a consumption growth rate of 0.0156 . The increase in incumbent $R \& D$ subsidies, however, implies a jump in the growth rate from 1.89 to 2.24 p.p. in Model (2.3). As already discussed above, changes to R\&D subsidies have larger effects in the heterogeneous innovation model than in the homogeneous innovation model. Hence, a subsidy increase equal to one half of the one considered in the homogeneous innovation model has about the same effect on economic growth.

The higher incumbent subsidy in Model (2.3) implies an increase of $1.88 \%$ in aggregate R\&D expenditures, which is explained by the increase of $4.45 \%$ in incumbents' R\&D expenditure as entrants' R\&D expenditure drop by $1.13 \%$ due to tougher entry conditions as incumbents become

\footnotetext{
${ }^{9}$ The importance of incumbents' high innovation efficiency relative to entrants' efficiency has also been emphasized by Bena, Garlappi, and Grüning (2016) for asset pricing dynamics in models with different levels of incumbents' contribution to aggregate economic growth.
} 
more efficient in their innovation efforts while they enjoy larger government transfers. This is accompanied by an expected decrease in consumption $(-1.79 \%)$ due to the substitution effect and an increase in capital investment (1.40\%) which further stimulates economic growth.

As already noted by Acemoglu and Cao (2015), who study the non-stochastic version of a model with the same innovation structure as our heterogeneous innovation model, the effect of subsidies to entrants can have ambiguous effects on growth due to the dissipative nature of entrants' R\&D investments. Entrants destroy (patent) value due to displacing the incumbent and at the same time create value by providing the economy with a (radically) better product to utilize. This nature of entrants' innovation is behind the term "Creative Destruction" of Schumpeter (1934, 1942). Hence, there exists a non-monotonic relationship between entrants' innovation efforts and economic growth. In one range of parameters, more entrant innovation is beneficial in terms of economic growth. In another range of parameters, a larger amount of innovations by entrants harms economic growth. In particular, this results mainly depends on the fraction of growth induced by entrants' innovations, the radical innovation size of entrants, on the monopoly markup, and also on the incremental innovation size of incumbents. Here, the effect of an increase in entrant subsidies on growth is slightly negative: Model (2.4) exhibits a growth rate of only 0.0185. The higher entrant subsidy discourages incumbents' $R \& D$ investment, i.e. a reduction of $2.45 \%$ relative to the benchmark calibration is observed. On the contrary, $R \& D$ expenditures by entrants increase by more than $4 \%$, and the effects on consumption and capital investment are very small $(+0.17 \%$ and $-0.08 \%$, respectively). Aggregate $R \& D$ expenditures increase by $0.62 \%$. However, due to the displacement effect entrants' innovations have on incumbents, it does not translate to higher economic growth but instead to slightly lower economic growth. ${ }^{10}$

When both incumbent and entrant subsidies are increased, the positive effect on growth by the increase in incumbent subsidies dominates, and an increase of the consumption growth rate to 2.21

\footnotetext{
${ }^{10}$ In unreported results, which are available from the authors upon request, we checked that one needs to increase the entrant $R \& D$ subsidy rate by 7.7 p.p., i.e. one has to set $\tau_{s, \mathrm{E}}=0.0937$, in order to obtain the same growth rate as in the benchmark calibration. This result implies that if $\tau_{s, \mathrm{E}} \in(0.0167,0.0937)$ and all other parameters are kept fixed, one has lower economic growth than in the benchmark model. If $\tau_{s, \mathrm{E}}>0.0937$ one obtains higher economic growth than in the benchmark calibration. Hence, we find that the range of values where increases to entrant subsidies are growth-reducing is fairly large. The other moments of this additional calibration with $\tau_{s, \mathrm{E}}=0.0937$ are very similar to the benchmark calibration except for the entrants' growth share, which increases to about $48 \%$.
} 
p.p. is observed. Except for consumption which is about 1.6\% lower than in Model (2.1), all types of investment (incumbents' and entrants' R\&D and capital) see an increase between 1.3\% and 3.1\%, relative to the benchmark model.

To sum up, the effects of changing $\mathrm{R} \& \mathrm{D}$ subsidies depend on the type of firm that receives the subsidy. The effects are qualitatively similar for the cases of higher incumbent subsidies in the heterogeneous innovation model and higher R\&D subsidies in the homogeneous innovation model. However, the quantitative effects are larger in the heterogeneous innovation model (keeping in mind that the changes in subsidies considered in this model are lower).

Next, Models (2.6) with higher capital investment subsidy and (2.7) with higher consumption subsidy feature higher and lower economic growth, respectively. Therefore, the results are qualitatively in line with the results for the homogeneous innovation model. Quantitatively, the effects are smaller due to the less pronounced change in the subsidies (0.5 vs. 1 p.p. increases). Finally, Model (2.8), which features an increase in the government expenditure to output ratio and, sequentially, an increase in all subsidies, sees a small increase in the growth rate. This is again very similar to what has been observed for the homogeneous innovation model.

Consistent with the analysis of the model's moments, the impulse response functions for a positive productivity shock depicted in Figure 3 are similar in shape as for the homogeneous innovation model. Consequently, positive government expenditure shocks also again have a negative effect on all macroeconomic quantities except wages, as can be seen in the impulse response functions depicted in Figure 4.

It is worth mentioning that the moments related to the labor tax rate, the volatility ratios of various macroeconomic growth rates relative to output growth volatility, and to the correlations of macroeconomic growth rates are not significantly different compared to the moments of the homogeneous innovation model. This is not surprising as both models are calibrated with respect to the same target moments and all parameters, except for the innovation-related ones, are the same as in the homogeneous innovation model.

Asset prices. The general levels of the equity premia and the risk-free rates in Models (2.1)(2.8) are comparable to the ones in Models (1.1)-(1.6). However, some non-trivial observations can 
be taken from comparing Models (2.3)-(2.5) to Model (2.1) as the R\&D subsidy changes across the columns lead to some interesting insights. Higher incumbent subsidies in Model (2.3) lead to a 14 bps increase in the risk-free rate and to an increase of 34 bps in the aggregate risk premium. This is qualitatively and quantitatively similar to increasing R\&D subsidies in the homogeneous innovation model. The government granting higher entrant subsidies in Model (2.4) leads to slightly lower equity premia and a slightly lower risk-free rate. The lower risk-free rate is explained by the lower growth rate and a higher amount of precautionary savings due to a higher fraction of entrant $R \& D$ investment in aggregate $R \& D$ investment, which is slightly riskier than incumbent $R \& D$ investment. The effect of higher incumbent subsidies is dominating the effect of higher entrant subsidies in asset pricing dynamics as the moments in Model (2.5) are comparable to the moments in Model (2.3) despite the additional inclusion of higher entrant R\&D investment subsidies.

Welfare analysis. With respect to welfare costs, results are comparable to the homogeneous innovation model for Models (2.2) and (2.6)-(2.8). Lower overall subsidies and higher consumption subsidies produce welfare losses and lower economic growth. Higher capital investment subsidies lead to a welfare gain and higher economic growth. Higher overall government expenditure implies more economic growth at the costs of a welfare loss. It is again most instructive to look at the welfare effects for changes in R\&D-related subsidies, i.e. Models (2.3)-(2.5). Welfare is decreasing slightly for higher entrant subsidies despite the fact that consumption increases relative to the benchmark calibration by $0.17 \%$ in this case. This comes alongside slightly lower economic growth (-4 bps). When both entrant and incumbent subsidies are increased, one observes (small) welfare losses but significantly higher economic growth $(+32$ bps $)$. Similar observations are made when only incumbent subsidies are increased.

\section{Sensitivity Analysis}

This section discusses the sensitivity of the model with respect to three key assumptions. First, we look at the case when wage rigidities are absent in both innovation models by assuming $\mu=0$ instead of $\mu=0.35$. Second, we study the case of households having preferences of the constant 
relative risk aversion (CRRA) type by assuming $\psi=0.5$ and $\gamma=2$ instead of $\psi=1.85$ and $\gamma=10$. Third, a lower elasticity of $\mathrm{R} \& \mathrm{D}$ investments is assumed (i.e. $\omega=0.6$ in the homogeneous innovation model and $\omega_{\mathrm{I}}=\omega_{\mathrm{E}}=0.6$ in the heterogeneous innovation model). Details on these sensitivity calibrations are provided in Table 4.

Absence of wage rigidities. We set $\mu=0$ in the calibrations of both innovation models and match again a consumption growth rate of 0.0189 . With this new calibration at hand, the same fiscal policy experiments are undertaken and the results are reported in Table 5 for the homogeneous innovation model and Table 6 for the heterogeneous innovation model.

First of all, the absence of wage rigidities implies, as expected, a lower risk premium, higher risk-free rate, lower consumption growth volatility, lower labor growth volatility, higher wage growth volatility, higher correlation between consumption and labor growth, and a higher correlation between output and wage growth across all models considered and relative to the models with wage rigidities.

Second, fiscal policy changes have a slightly more pronounced effect on the moments of the model due to the higher flexibility in labor markets which translates to larger observed adjustments in quantities as the economy can now more easily adjust to the respective change in fiscal policy.

Finally, welfare dynamics change. Unsurprisingly, the unconditional utility level is higher, as the absence of wage rigidities imply benefits for households as wages can now optimally adjust. The welfare costs or gains are more pronounced as well. Quite surprisingly, there is now a welfare gain of about $1 \%$ of lifetime consumption when $R \& D$ subsidies are higher in the homogeneous innovation model (vs. a welfare loss of more than $5 \%$ when wage rigidities are present). The reason is that the long-run benefits from higher economic growth can be fully extracted through higher wages when wages are fully flexible. This extraction channel is impaired when wages cannot adjust freely. Similarly, welfare losses are slightly lower when incumbent R\&D subsidies are higher in the heterogeneous innovation model (see Model (4.3) in Table 6). Higher entrant subsidies now entail a marginally larger welfare loss of $0.49 \%$ of lifetime consumption with flexible wages than with rigid wages (see Model (2.4) in Table 3 vs. Model (4.4) in Table 6). This again points to the fact that changes in the unconditional growth rate of the economy entail higher welfare effects with flexible 
labor markets. Hence, the normalized value of consumption becomes less important to determine overall welfare.

CRRA preferences. We set $\psi=0.5$ and $\gamma=2$ in the calibrations of both innovation models and match again a consumption growth rate of 0.0189. This implies that Epstein and Zin preferences collapse to standard CRRA preferences. The results of the fiscal experiments, taking as their basis these new calibrations, are reported in Table 7 for the homogeneous innovation model and Table 8 for the heterogeneous innovation model.

With CRRA preferences, the endogenous long-run risks are not priced. Thus, the risk-free rate jumps to over 0.05 , and the equity premium is basically zero. Moreover, there is a larger amount of short-run fluctuations in consumption, resulting in a consumption growth volatility of around 2 p.p., an increase of 40 bps relative to the case with Epstein and Zin preferences. Similarly to the absence of wage rigidities, labor growth volatility is significantly lower. The correlations between labor and consumption growth and between labor and R\&D expenditure growth are also lower, whereas the correlation between consumption and investment growth increases to almost 0.9 .

The changes in economic growth are less pronounced due to the absence of valuation effects of long-run growth prospects, which affect the patent value and, thus, the dynamics of $R \& D$ in the case of households having Epstein and Zin preferences. Qualitatively, the changes in the fiscal policy mix still have the same effect with one exception: The growth-enhancing effects of higher investment and $\mathrm{R} \& \mathrm{D}$ subsidies do not dominate the growth-reducing effects of higher consumption subsidies and a larger amount of wasteful government expenditure when the government expenditure to output ratio is higher in Models (5.6) and (6.6). Hence, one observes a small reduction in economic growth relative to the benchmark models (5.1) and (6.1), respectively.

The most interesting changes can once again be observed in welfare dynamics. The welfare loss in the case of higher overall subsidies is significantly less pronounced in Models (5.2) and (6.2) relative to Models (1.2) and (2.2). Welfare gains can now be observed for all cases with higher R\&D subsidies since not that much consumption is substituted for investments as the elasticity of intertemporal substitution is now below 1, relative to the cases with Epstein and Zin utility. Welfare basically does not change anymore when consumption subsidies are increased in contrast to a considerable 
welfare loss observed when households have Epstein and Zin preferences. A higher government expenditure-to-output ratio leads to a welfare gain as before, but it is now more pronounced in the homogeneous innovation model.

Lower elasticity of $\mathbf{R} \& \mathbf{D}$ investments. In our main analysis we have chosen the elasticity of $R \& D$ investments to be equal to the value used by Kung and Schmid (2015), i.e. $\omega=\omega_{\mathrm{I}}=\omega_{\mathrm{E}}=0.83$. That value is close to the midpoint of typical estimates found in the literature, ranging from 0.6 to 1.0 (see, for example, Griliches, 1990; Comin and Gertler, 2006; Comin, Gertler, and Santacreu, 2009). Here, we set the R\&D investment elasticity instead equal to the lower bound of estimates established in the literature, i.e. $\omega=\omega_{\mathrm{I}}=\omega_{\mathrm{E}}=0.6$. This value has also recently been used in macro-finance literature (see, for example, Gavazzoni and Santacreu, 2015).

As a smaller $\omega$ implies a higher curvature of $R \& D$ investment in the creation of new intermediate goods or the creation of goods with higher quality, respectively, changes in $R \& D$ investments imply less-strong equilibrium effects for quantities and prices. Therefore, the transformation of productivity shocks to endogenous long-run risk shocks, i.e. shocks to the expected growth rate of output or consumption, is impaired relative to our benchmark analysis. The resulting lower amount of long-run risks is visible in the simulated moments in Tables 9 and 10: One obtains a lower risk premium of only around 0.017 (vs. $0.025-0.03$ in the benchmark analysis), a higher risk-free rate of almost 0.02 (vs. 0.016 in the benchmark analysis), and a higher short-run consumption growth volatility of roughly 0.018 (vs. $0.016-0.017$ in the benchmark analysis). Similarly, the excess return volatility is also lower than in the benchmark analysis, whereas the volatility of the risk-free rate stays the same. Moreover, R\&D investment growth becomes considerably less volatile and labor (wage) growth slightly less (more) volatile. The correlation between consumption and labor growth increases relative to the benchmark case and now perfectly matches the empirical counterpart of 0.71 .

Next, we look at the equilibrium effects of changes in the fiscal policy mix by comparing the results across the columns when the elasticities of $R \& D$ investment are lower. First, the effects on economic growth are quantitatively slightly weaker, as the changes in the subsidy rates do not translate as efficiently as before to changes in economic growth due to lower efficiency of R\&D. 
However, qualitatively there are no differences. Hence, the same fiscal policy changes are growthenhancing or growth-reducing as before. The effects on consumer welfare, on the other hand, are typically stronger. Now, the welfare gain in the homogeneous innovation model is almost $11 \%$ of lifetime consumption when R\&D subsidies are increased, almost $6 \%$ when capital investment subsidies are increased, and a welfare loss of almost $5 \%$ is observed when consumption subsidies are increased. Interestingly, higher incumbent R\&D subsidies in the heterogeneous innovation model are now both significantly growth-enhancing and welfare-improving, i.e. the welfare gain is now more than $10 \%$ in contrast to a small welfare loss of $0.6 \%$ in the benchmark analysis (see Model (2.3) in Table 3 vs. Model (8.3) in Table 10). The reason is that normalized consumption is reduced less here than in the benchmark case. Hence, the household suffers less from the substitution effect and the households unambiguously benefits from higher economic growth. Therefore, the policy to subsidize incumbents seems to be the best one among the considered policy instruments if the elasticities of $\mathrm{R} \& \mathrm{D}$ investments for both incumbents and entrants are low.

\section{Conclusion}

In this study, we develop and calibrate two endogenous growth models with government sectors. The first endogenous growth model is an expanding variety economy with homogeneous innovations by new firms (entrants) only. The second model is based on Schumpeterian growth theory and features competition in innovation and, therefore, two heterogeneous types of innovations: incremental innovations by incumbents and radical innovations by entrants.

The government in both economies finances an exogenous government expenditure stream by mixing labor income and corporate taxes. The government is subject to a zero-deficit constraint. Thus, every period the total government expenditure has to be financed by taxes. Moreover, the government provides subsidies to household's consumption, to final goods firm's capital investment, and to the innovation sector. In the first model, R\&D subsidies completely accrue to the only type of innovators present in the economy. In the second model, a part of $\mathrm{R} \& \mathrm{D}$ subsidies goes to incumbents, and the other part goes to entrants.

The benchmark models are calibrated to closely match the empirical moments related to gov- 
ernment expenditure, taxes, and subsidies, alongside major standard macroeconomic moments for the period 1975-2015 of the U.S. economy. We use this novel setup to examine the economic effects of sector-specific fiscal policies in the presence of different innovation structures. To do so, we vary the amount of government expenditure or subsidies relative to the benchmark calibration to study the resulting equilibrium effects on macroeconomic quantities, asset prices, and welfare.

We find that, first, the structure of the innovation sector has first-order implications on the implications of changes in certain subsidies. An increase in R\&D subsidies in the homogeneous innovation model leads to higher average consumption growth of $37 \mathrm{bps}$. On the contrary, in the heterogeneous innovation model, increasing entrants' R\&D subsidies leads to a three basis point decrease in economic growth, whereas increasing incumbents' R\&D subsidies leads to an increase of around 35 bps. Higher capital investment subsidies lead to increases in economic growth of 18 (8) bps in the homogeneous (heterogeneous) innovation model.

Second, household welfare depends on economic growth in a non-monotonic way. Increasing $\mathrm{R} \& \mathrm{D}$ subsidies in the homogeneous innovation model leads to a welfare loss of $5.02 \%$ alongside a significant increase in economic growth, whereas increasing entrant R\&D subsidies in the heterogeneous innovation model lead to only a small welfare loss of $0.48 \%$ of lifetime consumption. However, higher incumbent R\&D subsidies lead to a small welfare decrease of $0.6 \%$ (and of $0.58 \%$, if entrant subsidies are simultaneously also increased). Hence, growth and welfare are mostly inversely related when changing R\&D subsidies. Analyzing the results obtained from increasing the subsidies to capital investment shows that this fiscal policy change has the potential to increase both economic growth and welfare as welfare increases by $2.42 \%$ (1.41\%) in the homogeneous (heterogeneous) innovation model.

Finally, the equity risk premium depends on the fiscal policy mix. Higher economic growth in both innovation models leads to a higher equity premium and a lower risk-free rate.

With these results at hand, we shed new light on how a government should allocate resources efficiently. The government needs to carefully take into account the competition structure in the innovative sectors of the economy in order to efficiently allocate subsidies to investments in R\&D across the different types of firms populating those sectors. The government might need to trade-off economic growth against welfare. However, it might also be able to increase (or decrease) both with 
changes in its fiscal policy mix. In particular, the most effective policy we have found in terms of economic growth is to increase subsidies to incumbents when the innovation sector is populated by both incumbents and entrants. In terms of both an increase in welfare and growth, higher subsidies to capital investment seem to be the government's best choice in our framework. 


\section{References}

Acemoglu, D., U. Akcigit, N. Bloom, And W. R. Kerr (2013): "Innovation, Reallocation and Growth," NBER Working Paper No. 18993.

Acemoglu, D., AND D. V. CaO (2015): "Innovation by entrants and incumbents," Journal of Economic Theory, 157, 255-294.

Aghion, P., And P. Howitt (1992): "A Model of Growth Through Creative Destruction," Econometrica, $60(2), 323-351$.

Bansal, R., And A. Yaron (2004): "Risks for the Long Run: A Potential Resolution of Asset Pricing Puzzles," Journal of Finance, 59(4), 1481-1509.

Bartelsman, E. J., And M. Doms (2000): "Understanding Productivity: Lessons from Longitudinal Microdata," Journal of Economic Literature, 38(3), 569-594.

Bena, J., L. Garlappi, And P. Grüning (2016): "Heterogeneous Innovation, Firm Creation and Destruction, and Asset Prices," Review of Asset Pricing Studies, 6(1), 46-87.

Benzoni, L., P. Collin-Dufresne, And R. S. Goldstein (2011): "Explaining asset pricing puzzles associated with the 1987 market crash," Journal of Financial Economics, 101(3), 552-573.

Boldrin, M., L. J. Christiano, And J. D. Fisher (2001): "Habit Persistence, Asset Returns and the Business Cycle," American Economic Review, 91(1), 149-166.

Branstetter, L., And M. Sakakibara (1998): "Japanese Research Consortia: A Microeconometric Analysis of Industrial Policy," Journal of Industrial Economics, 46(2), 207-233.

Comin, D., And M. Gertler (2006): "Medium-Term Business Cycles," American Economic Review, 96(3), $523-551$.

Comin, D. A., M. Gertler, And A. M. Santacreu (2009): "Technology innovation and diffusion as sources of output and asset price fluctuations," Discussion paper, National Bureau of Economic Research.

Croce, M. M., H. Kung, T. T. Nguyen, And L. Schmid (2012): "Fiscal Policies and Asset Prices," Review of Financial Studies, 25(9), 1-38.

Croce, M. M., T. T. Nguyen, And L. Schmid (2013): "Fiscal Policy and the Distribution of Consumption Risk," Working Paper. 
— (2015): "Global Entropy," Working Paper.

Donadelli, M., AND P. GRÜNING (2016): "Labor market dynamics, endogenous growth, and asset prices," Economics Letters, 143, 32-37.

Dosi, G., G. Fagiolo, And A. Roventini (2010): "Schumpeter meeting Keynes: A policy-friendly model of endogenous growth and business cycles," Journal of Economic Dynamics and Control, 34, 1748-1767.

EINIO, E. (2014): "R\&D subsidies and company performance: evidence from geographic variation in government funding based on the ERDF population-density rule," Review of Economics and Statistics, 96(4), $710-728$.

Epstein, L., AnD S. Zin (1989): "Substitution, Risk Aversion, and the Temporal Behavior of Consumption Growth and Asset Returns: A Theoretical Framework," Econometrica, 57(4), 937-969.

FAVilukis, J., AND X. Lin (2016): "Wage Rigidity: A Quantitative Solution to Several Asset Pricing Puzzles," Review of Financial Studies, 29(1), 148-192.

Foreman-Peck, J. (2013): "Effectiveness and Effciency of SME Innovation Policy," Small Business Economics, 41(1), 55-70.

Foster, L., J. C. Haltiwanger, And C. J. Krizan (2001): "Aggregate productivity growth. Lessons from microeconomic evidence," in New Developments in Productivity Analysis, pp. 303-372. University of Chicago Press.

Gavazzoni, F., And A. M. Santacreu (2015): "International R\&D Spillovers and Asset Prices," FRB St. Louis Working Paper No. 2015-41.

Gomes, F. J., A. Michaelides, And V. Polkovnichenko (2013): "Fiscal Policy and Asset Prices with Incomplete Markets," Review of Financial Studies, 26(2), 531-566.

Griliches, Z. (1990): "Patent Statistics as Economic Indicators: A Survey," Journal of Economic Literature, 28(4), 1661-1707.

Grossman, G. M., And E. Helpman (1991): "Quality Ladders in the Theory of Growth," Review of Economic Studies, 58(1), 43-61.

Guellec, D., And B. van Pottelsberghe (2000): "The Impact of Public R\&D Expenditure on Business R\&D," OECD Science, Technology and Industry Working Paper No. 2000/04. 
Horvath, R., L. Kaszab, And A. MaršÁL (2016): "Fiscal Policy and the Term Structure of Interest Rates in a DSGE Model," Working Paper.

Irwin, D., AND P. KLENOw (1996): "High-tech R\&D Subsidies - Estimating the Effects of SE-MATECH," Journal of International Economics, 40(3-4), 323-344.

Jaumotte, F., And N. Pain (2005): "From Ideas to Development: The Determinants of R\&D and Patenting," OECD Economics Department Working Paper No. $45 \%$.

Jermann, U. J. (1998): "Asset Pricing in Production Economies," Journal of Monetary Economics, 41(2), $257-275$.

Krugman, P. (2013): "How the Case for Austerity Has Crumbled," The New York Review of Books.

Kung, H., And L. Schmid (2015): "Innovation, Growth, and Asset Prices," Journal of Finance, 70(3), 1001-1037.

Minford, L. (2015): "The Macroeconomic Effects of UK Tax, Regulation and R\&D Subsidies: Testing Endogenous Growth Hypotheses in an Open Economy DSGE Model," Ph.D. thesis, Cardiff University.

Nuño, G. (2011): "Optimal Research and Development and the Cost of Business Cycles," Journal of Economic Growth, 16(3), 257-283.

Papanikolaou, D. (2011): "Investment Shocks and Asset Prices," Journal of Political Economy, 119(4), 639-685.

Ratto, M., W. Röger, And J. IN’T Veld (2009): "A model-based analysis of the impact of Cohesion Policy expenditure 2000-06: Simulations with the QUEST III endogenous R\&D model," Economic Modelling, 26(1), 222-233.

Röger, W., J. Varga, And J. in’t Veld (2008): "Structural Reforms in the EU: A Simulation-Based Analysis Using the QUEST Model with Endogenous Growth," European Economy Economic Paper No. 351.

Romer, P. M. (1990): "Endogenous Technological Change," Journal of Political Economy, 98(5), 71-102.

Schmitt-Grohé, S., And M. Uribe (2006): "Optimal Fiscal and Monetary Policy in a Medium-Scale Macroeconomic Model," in NBER Macroeconomics Annual 2005, pp. 383-425. MIT Press: Cambridge MA. 
_ (2007): "Optimal simple and implementable monetary and fiscal rules," Journal of Monetary Economics, 54, 1702-1725.

Schumpeter, J. A. (1934): The Theory of Economic Development. Harvard University Press.

_ (1942): "Creative destruction," Capitalism, socialism and democracy.

Turnovsky, S. J. (2000): "Fiscal policy, elastic labor supply, and endogenous growth," Journal of Monetary Economics, 45, 185-210.

Uhlig, H. (2007): "Explaining Asset Prices with External Habits and Wage Rigidities in a DSGE Model," American Economic Review, 97(2), 239-243.

VARGA, J., AND J. IN'T VELD (2011): “A model-based analysis of the impact of Cohesion Policy expenditure 2000-06: Simulations with the QUEST III endogenous R\&D model," Economic Modelling, 28, 647-663.

Veugelers, R. (2014): "Undercutting the Future? European Research Spending in Times of Fiscal Consolidation," Bruegel Policy Contribution 2014/06.

Westmore, B. (2013): "R\&D, Patenting and Growth: The Role of Public Policy," OECD Working Paper No. $104 \%$. 
Table 1: Model parameters

(a) Panel A: Common parameters

\begin{tabular}{ccc}
\hline \hline Parameter & Description & Value \\
\hline$\beta$ & Time discount factor & $0.984^{1 / 4}$ \\
$\psi$ & Elasticity of intertemporal substitution & 1.85 \\
$\gamma$ & Relative risk aversion & 10 \\
$\nu$ & Inverse monopoly markup & $1 / 1.35$ \\
$\alpha$ & Capital share & 0.35 \\
$\xi$ & Intermediate goods share & 0.65 \\
$\delta$ & Capital depreciation rate & 0.02 \\
$\zeta$ & Capital adjustment costs elasticity & 0.7 \\
$\mu$ & Sticky wage parameter & 0.35 \\
$\tilde{\eta}$ & Labor service substitution elasticity & 21 \\
$\tau_{\pi}$ & Corporate tax rate & 0.40 \\
$\tau_{c}$ & Government subsidy to household's consumption & 0.033 \\
$\tau_{i}$ & Government subsidy to final goods firm's capital investment & 0.107 \\
$\rho_{a}$ & Productivity shock persistence & $0.95^{1 / 4}$ \\
$\sigma_{a}$ & Productivity shock volatility & 0.0115 \\
$\bar{g}$ & Parameter governing mean level of government expenditure & -1.6883 \\
$\rho_{g}$ & Government expenditure shock persistence & $0.98^{1 / 4}$ \\
$\sigma_{g}$ & Government expenditure shock volatility & 0.0065 \\
$\operatorname{corr}\left(\varepsilon_{a}, \varepsilon_{g}\right)$ & Correlation between productivity and government expenditure shocks & 0 \\
\hline \hline
\end{tabular}

(b) Panel B: Heterogeneous parameters

\begin{tabular}{cccc}
\hline \hline Parameter & Description & Homogeneous Innovation & Heterogeneous Innovation \\
\hline$\varphi$ & Labor supply elasticity & 1.6806 & 1.6857 \\
\hline \hline
\end{tabular}

(c) Panel C: Specific parameters for homogeneous innovation model

\begin{tabular}{ccc}
\hline \hline Parameter & Description & Homogeneous Innovation \\
\hline$\chi$ & R\&D productivity parameter & 0.7374 \\
$\omega$ & R\&D technology elasticity & 0.83 \\
$\phi$ & Patent obsolescence & 0.0375 \\
$\tau_{s}$ & Government subsidy to innovators' R\&D investment & 0.05 \\
\hline \hline
\end{tabular}

(d) Panel D: Specific parameters for heterogeneous innovation model

\begin{tabular}{ccc}
\hline \hline Parameter & Description & Heterogeneous Innovation \\
\hline$\chi_{\mathrm{I}}$ & Incremental innovation productivity parameter & 3.4542 \\
$\chi_{\mathrm{E}}$ & Radical innovation productivity parameter & 0.2301 \\
$\omega_{\mathrm{I}}$ & Incremental innovation technology elasticity & 0.83 \\
$\omega_{\mathrm{E}}$ & Radical innovation technology elasticity & 0.83 \\
$\kappa_{\mathrm{I}}$ & Incremental innovation size & 1.2 \\
$\kappa_{\mathrm{E}}$ & Radical innovation size & 3 \\
$\kappa_{\mathrm{D}}$ & Patent obsolescence & 0.9625 \\
$\tau_{s, \mathrm{I}}$ & Government subsidy to incumbents' R\&D investment & 0.0333 \\
$\tau_{s, \mathrm{E}}$ & Government subsidy to entrants' R\&D investment & 0.0167 \\
\hline \hline
\end{tabular}

Notes: This table reports the quarterly benchmark calibrations for both the homogeneous innovation model of Section 3 and the heterogeneous innovation model of Section 4 considered in this study. Panel A reports common parameter values used in both models, Panel B reports the parameters common to both models but set to different values in each model, Panel $\mathrm{C}$ reports the parameters and values specific to the homogeneous innovation model, and Panel D reports the parameters and values specific to the heterogeneous innovation model. 
Table 2: Simulation results - homogeneous innovation model

\begin{tabular}{|c|c|c|c|c|c|c|c|}
\hline & Data & $(1.1)$ & $(1.2)$ & $(1.3)$ & $(1.4)$ & $(1.5)$ & $(1.6)$ \\
\hline \multicolumn{8}{|l|}{ ASSET PRICES } \\
\hline $\mathbb{E}\left[r_{a}^{e x}\right]$ & 4.02 & 2.73 & 2.46 & 3.35 & 2.88 & 2.60 & 2.80 \\
\hline$\sigma\left(r_{a}^{e x}\right)$ & 14.36 & 5.46 & 5.34 & 5.42 & 5.53 & 5.40 & 5.53 \\
\hline $\mathbb{E}\left[r_{f}\right]$ & 1.56 & 1.61 & 1.47 & 1.63 & 1.68 & 1.55 & 1.63 \\
\hline$\sigma\left(r_{f}\right)$ & 2.42 & 0.35 & 0.35 & 0.36 & 0.36 & 0.35 & 0.35 \\
\hline \multicolumn{8}{|l|}{ MACRO QUANTITIES } \\
\hline$E\left[\Delta c^{*}\right]$ & 2.61 & 1.89 & 1.50 & 2.25 & 2.07 & 1.72 & 1.99 \\
\hline$\sigma\left(\Delta c^{*}\right)$ & 1.30 & 1.65 & 1.64 & 1.67 & 1.65 & 1.64 & 1.72 \\
\hline $\mathbb{E}[L / \bar{L}]$ & - & 33.19 & 32.95 & 33.59 & 33.39 & 32.78 & 33.09 \\
\hline$\sigma(\Delta l)$ & 2.59 & 1.00 & 1.00 & 0.98 & 1.00 & 1.00 & 1.04 \\
\hline $\mathbb{E}[G / Y]$ & 15.55 & 15.62 & 15.62 & 15.62 & 15.62 & 15.62 & 16.62 \\
\hline$\sigma(G / Y)$ & 0.85 & 0.90 & 0.90 & 0.90 & 0.90 & 0.90 & 0.95 \\
\hline $\mathbb{E}\left[\tau_{l}\right]$ & 37.00 & 39.03 & 39.03 & 39.03 & 39.03 & 39.03 & 43.43 \\
\hline$\sigma\left(\tau_{l}\right)$ & - & 3.96 & 3.96 & 3.96 & 3.96 & 3.96 & 4.16 \\
\hline $\mathbb{E}[\hat{U}]$ & - & 0.2205 & 0.1972 & 0.2099 & 0.2276 & 0.2153 & 0.2153 \\
\hline$\Lambda$ & - & - & 11.78 & 5.02 & -3.12 & 2.42 & 2.42 \\
\hline$\left(C^{*}-C_{\text {bench }}^{*}\right) / C_{\text {bench }}^{*}$ & - & - & 0.99 & -1.87 & -0.24 & 1.20 & -6.94 \\
\hline$\left(I^{*}-I_{\text {bench }}^{*}\right) / I_{\text {bench }}^{*}$ & - & - & -2.95 & 1.26 & 2.60 & -1.32 & 1.15 \\
\hline$\left(S^{*}-S_{\text {bench }}^{*}\right) / S_{\text {bench }}^{*}$ & - & - & -2.78 & 2.58 & 1.26 & -1.22 & 0.77 \\
\hline$\sigma\left(\Delta c^{*}\right) / \sigma(\Delta y)$ & 0.64 & 0.77 & 0.77 & 0.79 & 0.77 & 0.77 & 0.79 \\
\hline$\sigma\left(\Delta i^{*}\right) / \sigma(\Delta y)$ & 4.62 & 1.01 & 1.00 & 1.01 & 1.01 & 1.01 & 1.01 \\
\hline$\sigma\left(\Delta s^{*}\right) / \sigma(\Delta y)$ & 2.04 & 1.66 & 1.70 & 1.63 & 1.66 & 1.67 & 1.64 \\
\hline$\sigma(\Delta l) / \sigma(\Delta y)$ & 1.29 & 0.47 & 0.47 & 0.46 & 0.47 & 0.47 & 0.48 \\
\hline$\sigma(\Delta w) / \sigma(\Delta y)$ & 1.15 & 0.67 & 0.67 & 0.68 & 0.67 & 0.68 & 0.66 \\
\hline $\operatorname{corr}\left(\Delta c^{*}, \Delta i^{*}\right)$ & 0.65 & 0.73 & 0.75 & 0.72 & 0.72 & 0.74 & 0.69 \\
\hline $\operatorname{corr}\left(\Delta y, \Delta i^{*}\right)$ & 0.88 & 1.00 & 1.00 & 1.00 & 1.00 & 1.00 & 1.00 \\
\hline $\operatorname{corr}\left(\Delta c^{*}, \Delta l\right)$ & 0.71 & 0.59 & 0.60 & 0.57 & 0.58 & 0.61 & 0.59 \\
\hline $\operatorname{corr}(\Delta y, \Delta w)$ & 0.15 & 0.92 & 0.92 & 0.92 & 0.92 & 0.92 & 0.91 \\
\hline $\operatorname{corr}\left(\Delta c^{*}, \Delta s^{*}\right)$ & 0.41 & 0.69 & 0.70 & 0.68 & 0.68 & 0.70 & 0.65 \\
\hline $\operatorname{corr}\left(\Delta y, \Delta s^{*}\right)$ & 0.37 & 0.98 & 0.98 & 0.98 & 0.98 & 0.98 & 0.98 \\
\hline $\operatorname{corr}\left(\Delta l, \Delta s^{*}\right)$ & 0.46 & 0.90 & 0.90 & 0.90 & 0.91 & 0.90 & 0.90 \\
\hline $\operatorname{corr}\left(\Delta w, \Delta s^{*}\right)$ & 0.42 & 0.83 & 0.83 & 0.84 & 0.83 & 0.83 & 0.83 \\
\hline
\end{tabular}

Notes: This table reports the moments obtained from a stochastic simulation of the homogeneous innovation model, developed in Section 3. The moments are computed using a simulation of 3,000 economies at quarterly frequency for 304 quarters, from which the first 80 quarters are not considered for the calculation of the moments ("burn in-period"). The quantity $\Lambda$ is the welfare cost relative to the benchmark calibration (1.1), rigorously defined in Equation (68). The moments in the data column are computed using data described in Appendix A for the period 1975-2015. All numbers are given in percentage points except for the average utility index $E[U / N]$, the ratios of volatilities, and the correlations which are given in decimal points. Model (1.1): Benchmark homogeneous innovation model whose parameters are reported in Table 1, Panels A, B, and C. Model (1.2): Jointly lower government subsidies, i.e. $\tau_{c}=0.023, \tau_{i}=0.097, \tau_{s}=0.04$ and all other parameters as in Model (1.1). Model (1.3): Higher R\&D investment subsidies, i.e. $\tau_{s}=0.06$ and all other parameters as in Model (1.1). Model (1.4): Higher capital investment subsidies, i.e. $\tau_{i}=0.117$ and all other parameters as in Model (1.1). Model (1.5): Higher consumption subsidies, i.e. $\tau_{c}=0.043$ and all other parameters as in Model (1.1). Model (1.6): Higher government expenditure, i.e. $\bar{g}=-1.6142$ implying $E[G / Y]=16.6 \%$, and all other parameters as in Model (1.1). 
Figure 1: Impulse response functions - homogeneous innovation model - productivity shock

Panel A: $C_{t}^{*}$

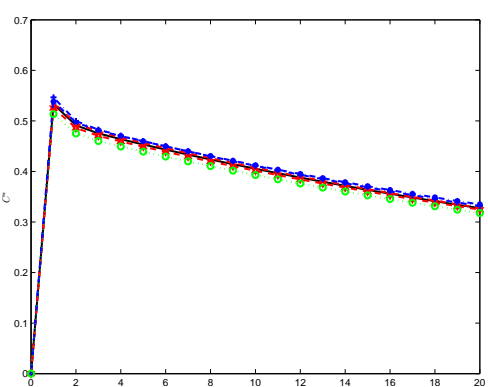

Panel D: $S_{t}^{*}$

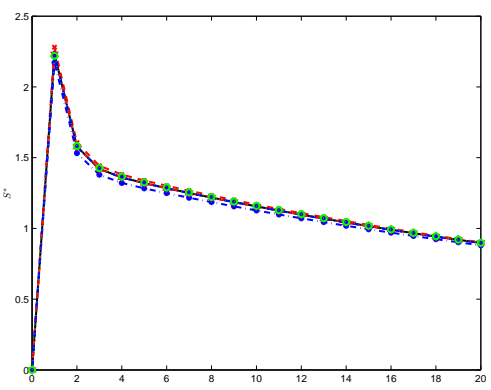

Panel G: $R_{f, t}$

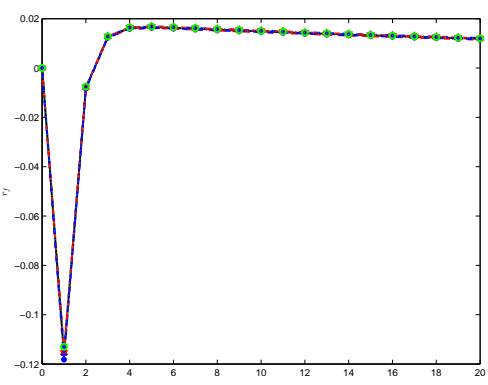

Panel B: $Y_{t}$

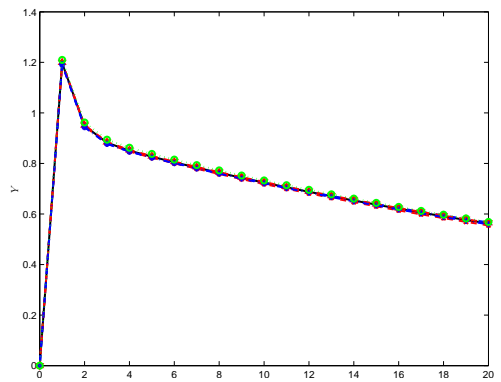

Panel E: $L_{t}$

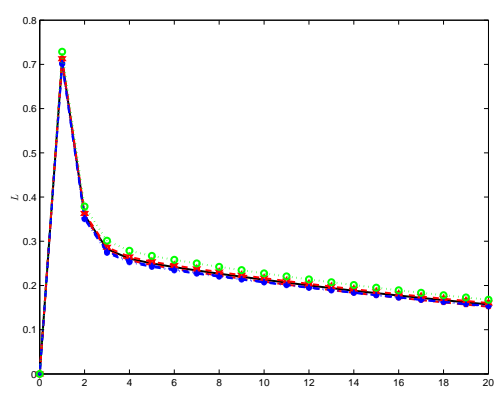

Panel H: $R_{a, t}$

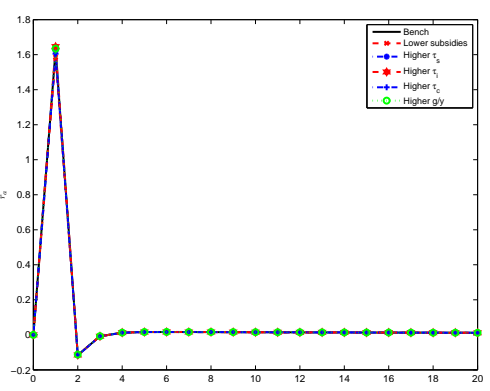

Panel C: $I_{t}^{*}$

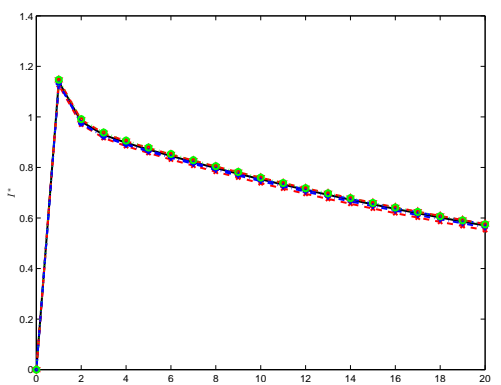

Panel F: $W_{t}$

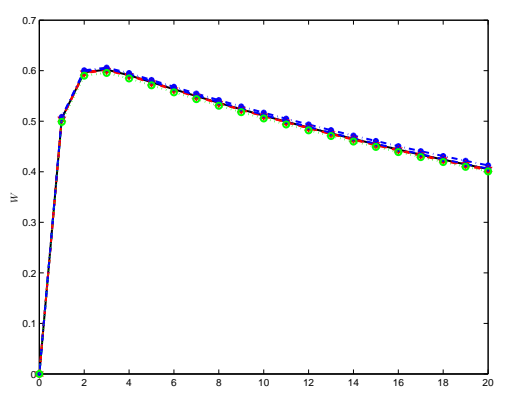

Panel I: $\left(V_{a, t}-D_{a, t}\right) / D_{a, t}$

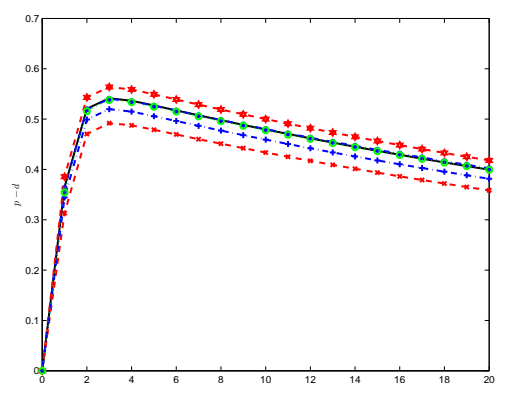

Notes: This figure depicts total consumption $C_{t}^{*}$, output $Y_{t}$, total capital investment $I_{t}^{*}$, total R\&D expenditure $S_{t}^{*}$, labor $L_{t}$, wages $W_{t}$, risk-free rate $r_{f, t}$, aggregate return $r_{a, t}$, and price-dividend ratio $\left(V_{a, t}-D_{a, t}\right) / D_{a, t}$ in response to a positive one-standard-deviation shock in the productivity process $a_{t}$. The impulse response functions are depicted for all six calibrations (Models (1.1)-(1.6)) of the homogeneous innovation model discussed in Section 6.1 and developed in Section 3. The details on the different models are given in Table 2. The values reported are log deviations from the steady state in percentage points. 
Figure 2: Impulse response functions - homogeneous innovation model - government expenditure shock

Panel A: $C_{t}^{*}$

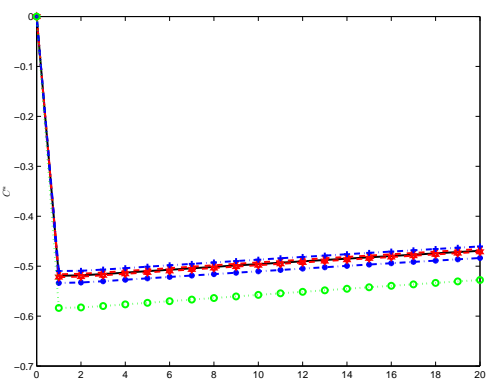

Panel D: $S_{t}^{*}$

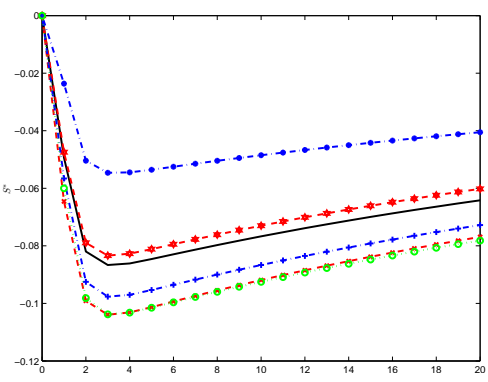

Panel G: $R_{f, t}$

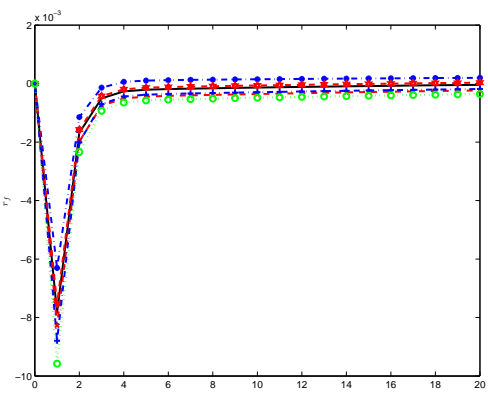

Panel B: $Y_{t}$

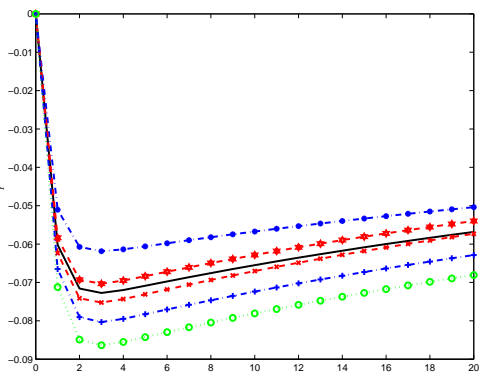

Panel E: $L_{t}$

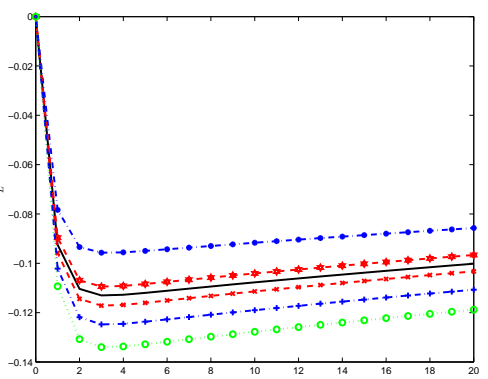

Panel H: $R_{a, t}$

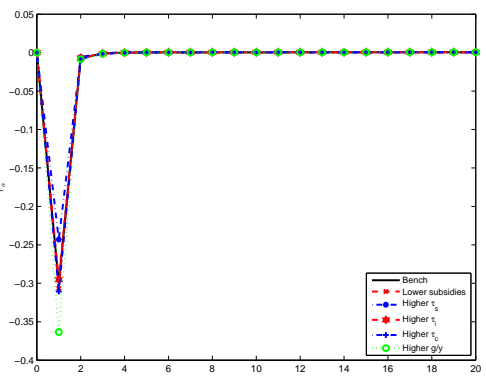

Panel C: $I_{t}^{*}$

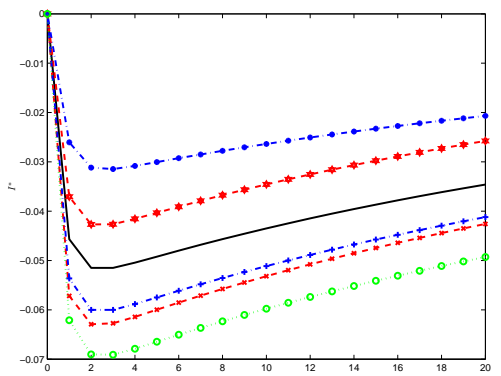

Panel F: $W_{t}$

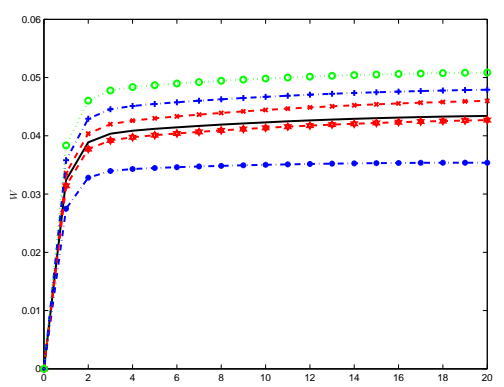

Panel I: $\left(V_{a, t}-D_{a, t}\right) / D_{a, t}$

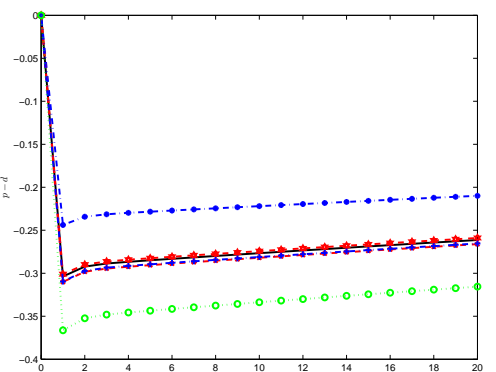

Notes: This figure depicts total consumption $C_{t}^{*}$, output $Y_{t}$, total capital investment $I_{t}^{*}$, total R\&D expenditure $S_{t}^{*}$, labor $L_{t}$, wages $W_{t}$, risk-free rate $r_{f, t}$, aggregate return $r_{a, t}$, and price-dividend ratio $\left(V_{a, t}-D_{a, t}\right) / D_{a, t}$ in response to a positive one-standard-deviation shock in the government expenditure process $g_{t}$. The impulse response functions are depicted for all six calibrations (Models (1.1)-(1.6)) of the homogeneous innovation model discussed in Section 6.1 and developed in Section 3. The details on the different models are given in Table 2. The values reported are log deviations from the steady state in percentage points. 
Table 3: Simulation results - heterogeneous innovation model

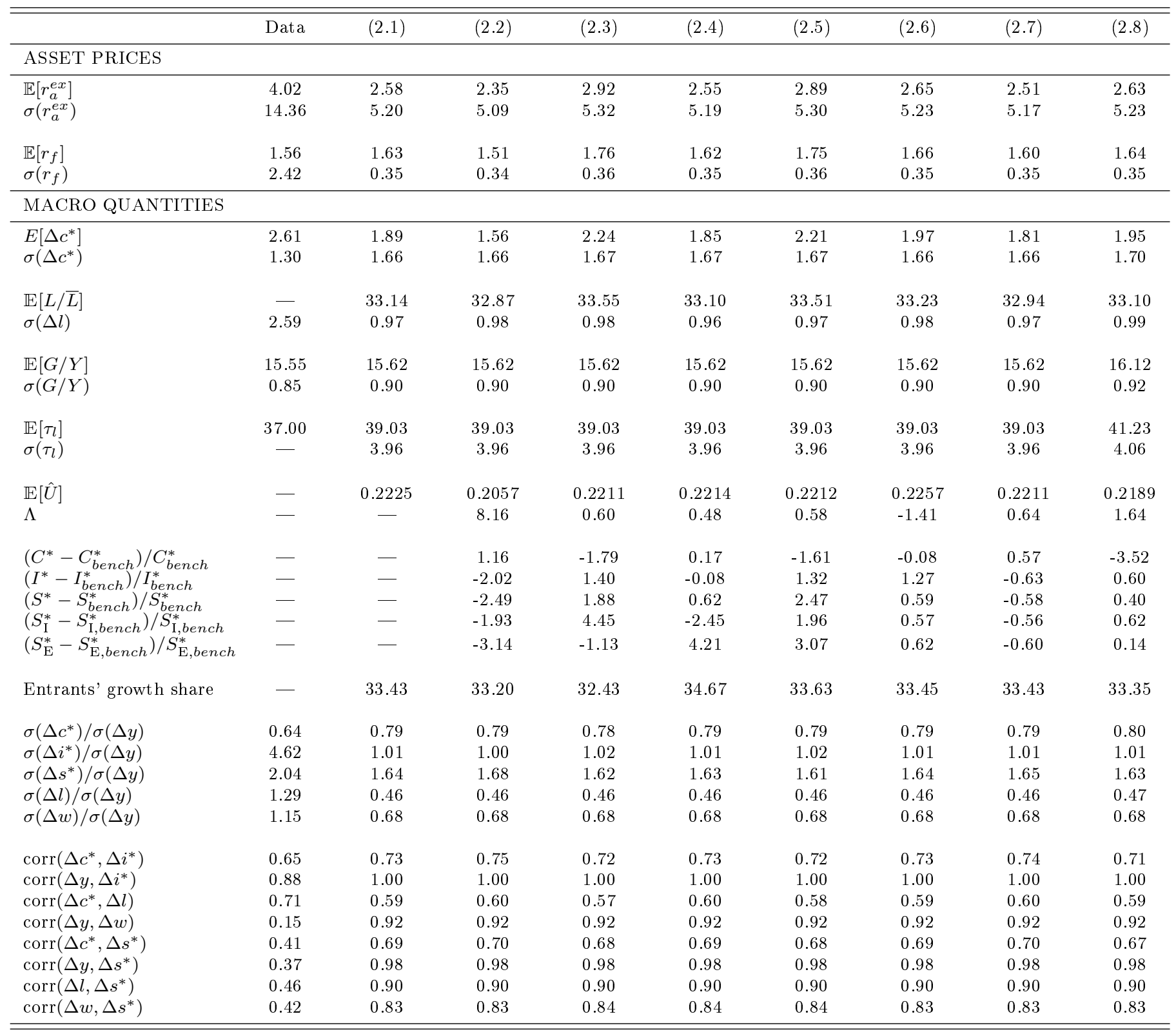

Notes: This table reports the moments obtained from a stochastic simulation of the heterogeneous innovation model, developed in Section 4. Details on the simulation, the data, and the reported numbers are the same as in Table 2. The entrants' growth share is given by the expression $\frac{\left(\kappa_{\mathrm{E}}-\kappa_{\mathrm{D}}\right) \mathbb{E}\left[\hat{\phi}_{\mathrm{E}}\left(s_{\mathrm{E}}^{*}\right)\right]}{\left(\kappa_{\mathrm{I}}-\kappa_{\mathrm{D}}\right) \mathbb{E}\left[\phi_{\mathrm{I}}\left(s_{\mathrm{I}}^{*}\right)\right]+\left(\kappa_{\mathrm{E}}-\kappa_{\mathrm{D}}\right) \mathbb{E}\left[\hat{\phi}_{\mathrm{E}}\left(s_{\mathrm{E}}^{*}\right)\right]}$. Model $(2.1)$ : Benchmark heterogeneous innovation model whose parameters are reported in Table 1, Panels A, B, and D. Model (2.2): Jointly lower government subsidies, i.e. $\tau_{c}=0.028, \tau_{i}=0.102, \tau_{s, \mathrm{I}}=0.0283, \tau_{s, \mathrm{E}}=0.0117$ and all other parameters as in Model (2.1). Model (2.3): Higher incumbent R\&D investment subsidies, i.e. $\tau_{s, \mathrm{I}}=0.0383$ and all other parameters as in Model (2.1). Model (2.4): Higher entrant R\&D investment subsidies, i.e. $\tau_{s, \mathrm{E}}=0.0217$ and all other parameters as in Model (2.1). Model (2.5): Jointly higher incumbent and entrant R\&D investment subsidies, i.e. $\tau_{s, \mathrm{I}}=0.0383$ and $\tau_{s, \mathrm{E}}=0.0217$ and all other parameters as in Model (2.1). Model (2.6): Higher capital investment subsidies, i.e. $\tau_{i}=0.112$ and all other parameters as in Model (2.1). Model (2.7): Higher consumption subsidies, i.e. $\tau_{c}=0.038$ and all other parameters as in Model (2.1). Model (2.8): Higher government expenditure, i.e. $\bar{g}=-1.6508$ implying $E[G / Y]=16.1 \%$, and all other parameters as in Model (2.1). 
Figure 3: Impulse response functions - heterogeneous innovation model - productivity shock

Panel A: $C_{t}^{*}$

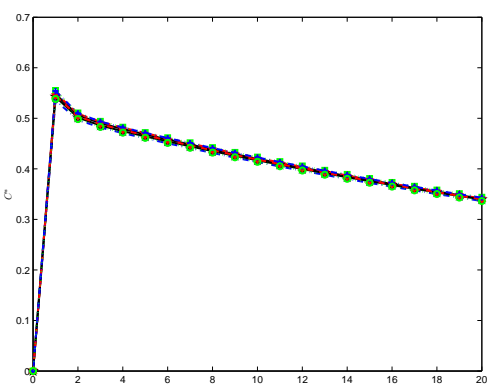

Panel D: $S_{t}^{*}$

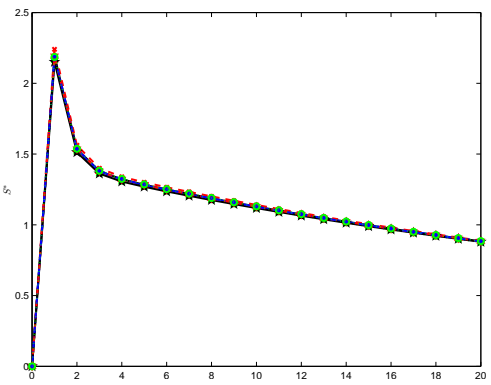

Panel G: $S_{\mathrm{I}, t}^{*}$

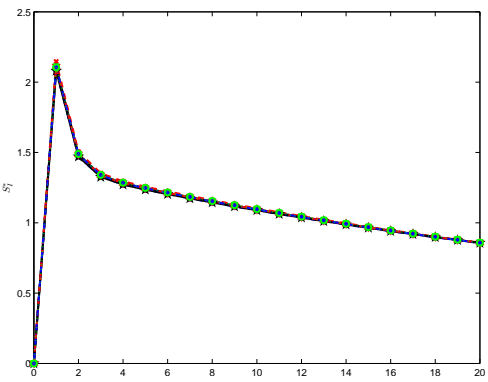

Panel J: $R_{f, t}$

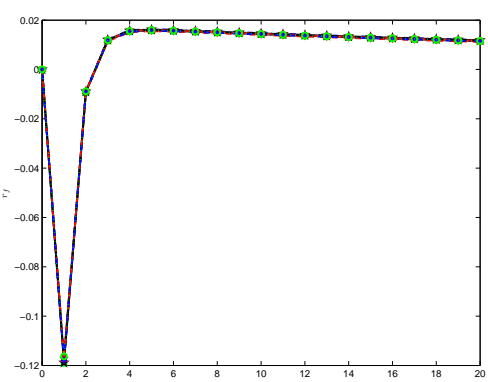

Panel B: $Y_{t}$

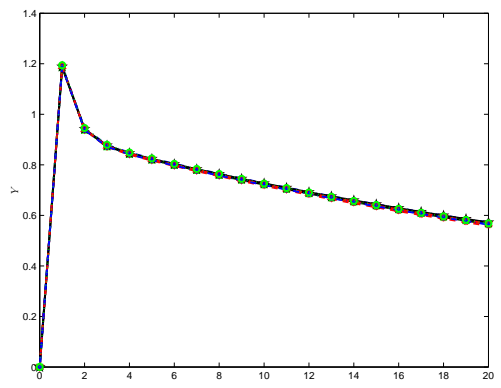

Panel E: $L_{t}$

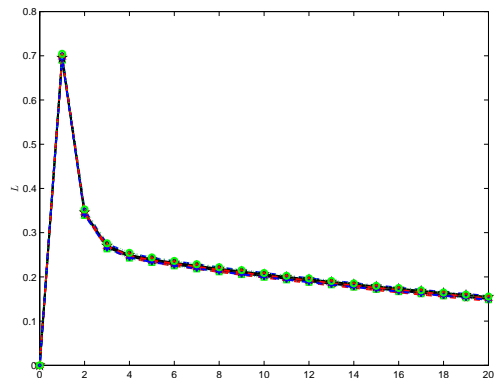

Panel H: $S_{\mathrm{E}, t}^{*}$

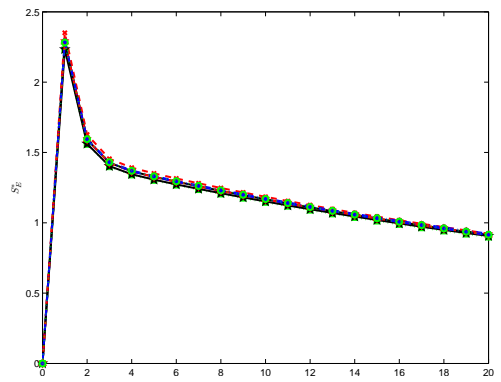

Panel K: $R_{a, t}$

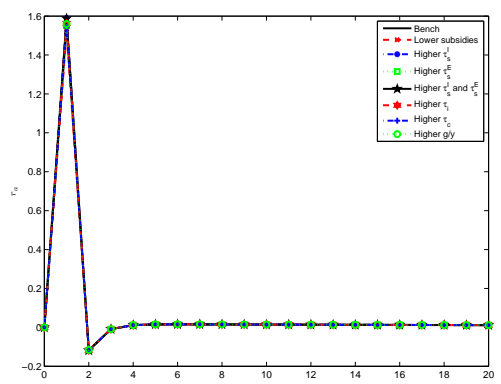

Panel C: $I_{t}^{*}$

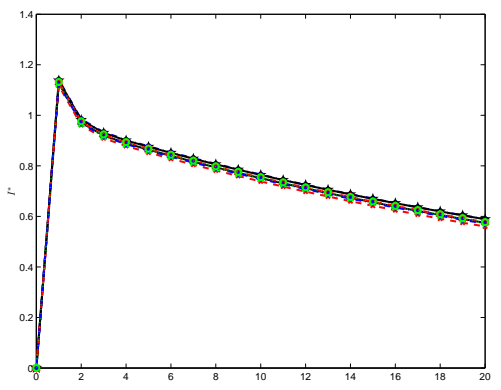

Panel F: $W_{t}$

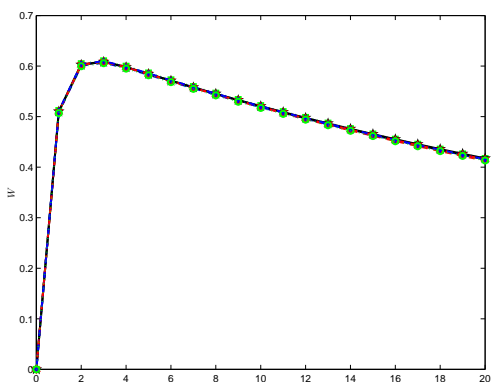

Panel I: $v_{t}$

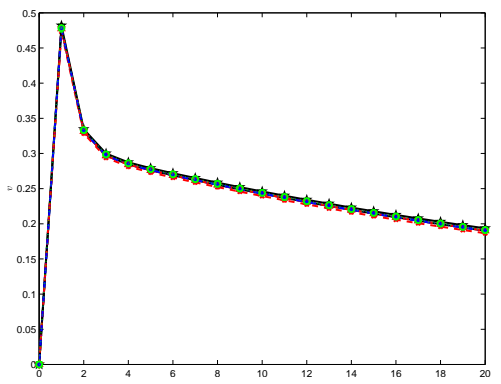

Panel L: $\left(V_{a, t}-D_{a, t}\right) / D_{a, t}$

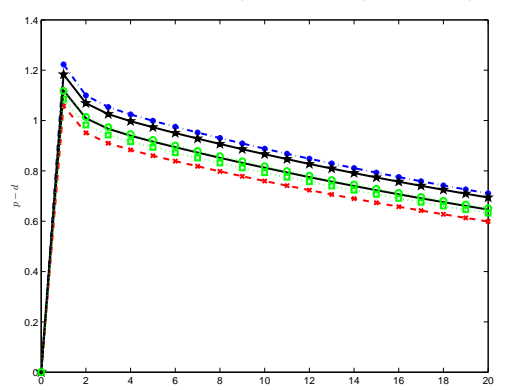

Notes: This figure depicts total consumption $C_{t}^{*}$, output $Y_{t}$, total capital investment $I_{t}^{*}$, total R\&D expenditure $S_{t}^{*}$, labor $L_{t}$, wages $W_{t}$, total incumbent R\&D expenditure $S_{\mathrm{I}, t}^{*}$, total entrant R\&D expenditure $S_{\mathrm{E}, t}^{*}$, incumbent value $v_{t}$, risk-free rate $r_{f, t}$, aggregate return $r_{a, t}$, and price-dividend ratio $\left(V_{a, t}-D_{a, t}\right) / D_{a, t}$ in response to a positive one-standard-deviation shock in the productivity process $a_{t}$. The impulse response functions are depicted for all eight calibrations (Models (2.1)-(2.8)) of the heterogeneous innovation model discussed in Section 6.2 and developed in Section 4. The details on the different models are given in Table 3 . The values reported are log deviations from the steady state in percentage points. 
Figure 4: Impulse response functions - heterogeneous innovation model - government expenditure shock

Panel A: $C_{t}^{*}$

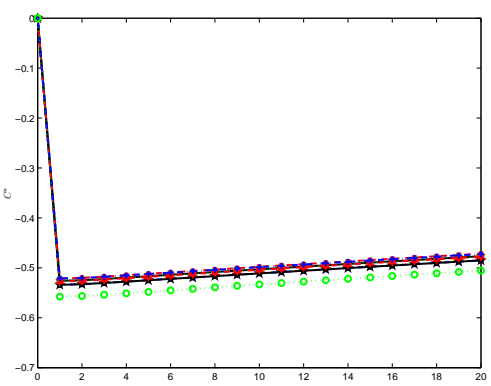

Panel D: $S_{t}^{*}$

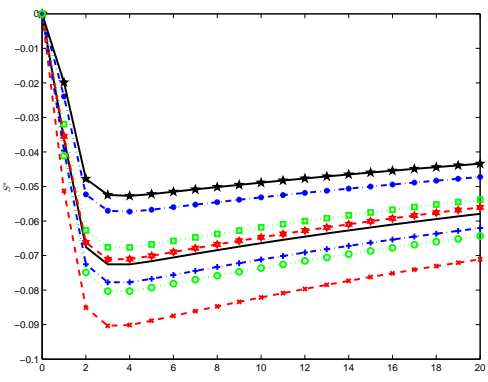

Panel G: $S_{\mathrm{I}, t}^{*}$

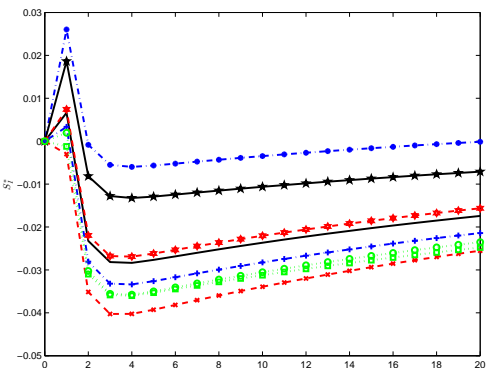

Panel J: $R_{f, t}$

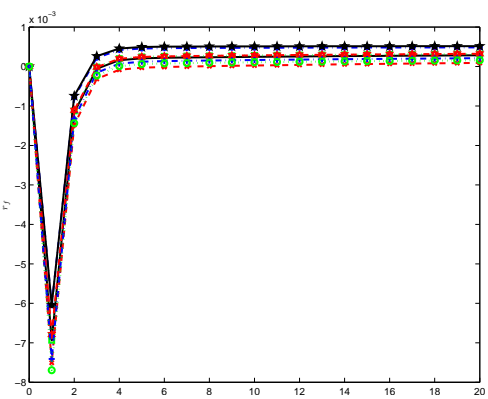

Panel B: $Y_{t}$

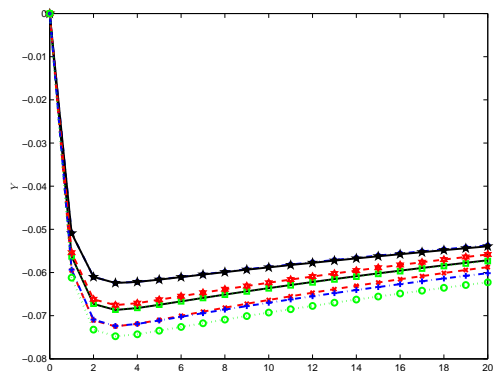

Panel E: $L_{t}$

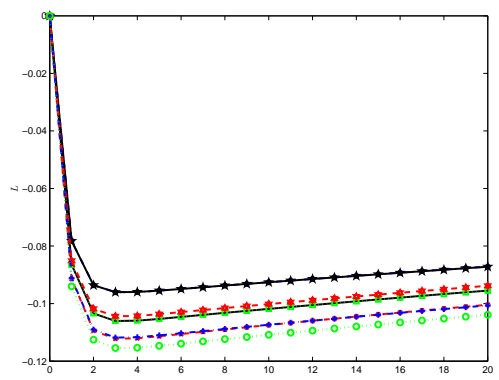

Panel H: $S_{\mathrm{E}, t}^{*}$

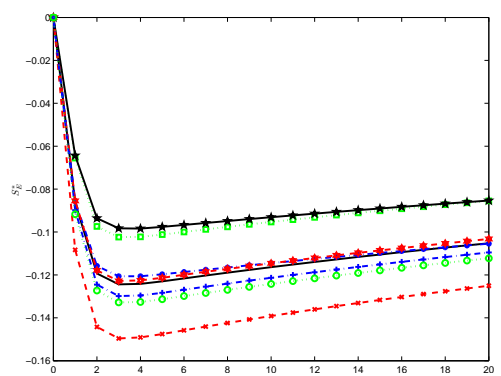

Panel K: $R_{a, t}$

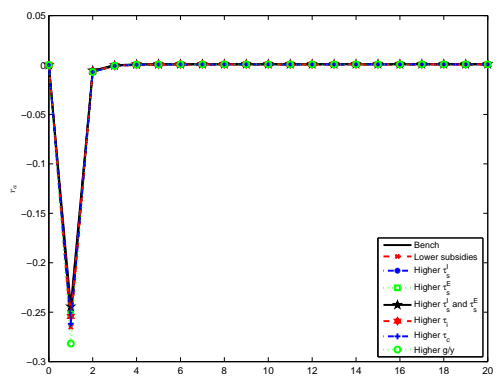

Panel C: $I_{t}^{*}$

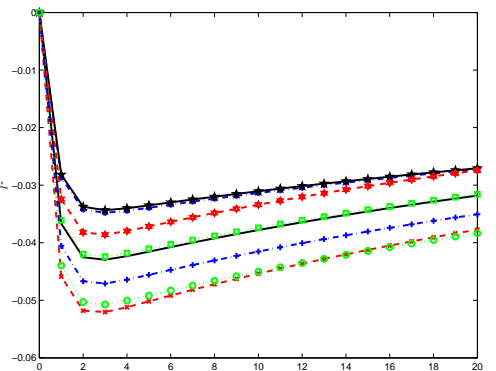

Panel F: $W_{t}$

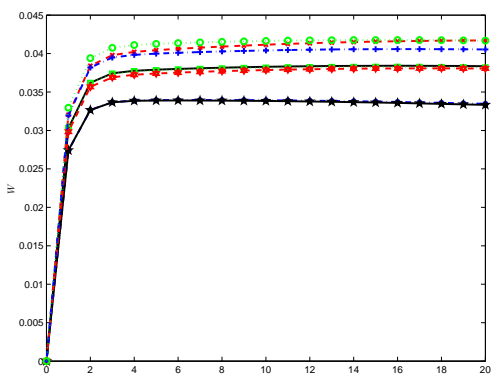

Panel I: $v_{t}$

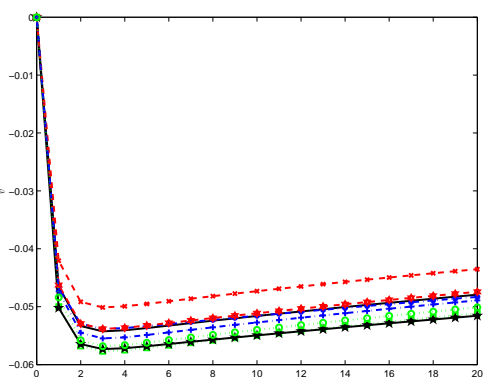

Panel L: $\left(V_{a, t}-D_{a, t}\right) / D_{a, t}$

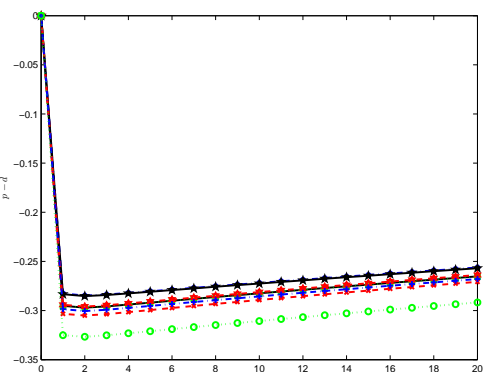

Notes: This figure depicts total consumption $C_{t}^{*}$, output $Y_{t}$, total capital investment $I_{t}^{*}$, total R\&D expenditure $S_{t}^{*}$, labor $L_{t}$, wages $W_{t}$, total incumbent $\mathrm{R} \& \mathrm{D}$ expenditure $S_{\mathrm{I}, t}^{*}$, total entrant R\&D expenditure $S_{\mathrm{E}, t}^{*}$, incumbent value $v_{t}$, risk-free rate $r_{f, t}$, aggregate return $r_{a, t}$, and price-dividend ratio $\left(V_{a, t}-D_{a, t}\right) / D_{a, t}$ in response to a positive one-standard-deviation shock in the government expenditure process $g_{t}$. The impulse response functions are depicted for all eight calibrations (Models (2.1)-(2.8)) of the heterogeneous innovation model discussed in Section 6.2 and developed in Section 4 . The details on the different models are given in Table 3 . The values reported are log deviations from the steady state in percentage points. 
Table 4: Model parameters for sensitivity analysis

\begin{tabular}{|c|c|c|c|c|c|c|}
\hline Parameter & (3.1) & $(4.1)$ & $(5.1)$ & $(6.1)$ & $(7.1)$ & $(8.1)$ \\
\hline$\beta$ & $0.984^{1 / 4}$ & $0.984^{1 / 4}$ & $0.984^{1 / 4}$ & $0.984^{1 / 4}$ & $0.984^{1 / 4}$ & $0.984^{1 / 4}$ \\
\hline$\psi$ & 1.85 & 1.85 & 0.5 & 0.5 & 1.85 & 1.85 \\
\hline$\gamma$ & 10 & 10 & 2 & 2 & 10 & 10 \\
\hline$\nu$ & $1 / 1.35$ & $1 / 1.35$ & $1 / 1.35$ & $1 / 1.35$ & $1 / 1.35$ & $1 / 1.35$ \\
\hline$\alpha$ & 0.35 & 0.35 & 0.35 & 0.35 & 0.35 & 0.35 \\
\hline$\xi$ & 0.65 & 0.65 & 0.65 & 0.65 & 0.65 & 0.65 \\
\hline$\delta$ & 0.02 & 0.02 & 0.02 & 0.02 & 0.02 & 0.02 \\
\hline$\zeta$ & 0.7 & 0.7 & 0.7 & 0.7 & 0.7 & 0.7 \\
\hline$\mu$ & 0 & 0 & 0.35 & 0.35 & 0.35 & 0.35 \\
\hline$\tilde{\eta}$ & 21 & 21 & 21 & 21 & 21 & 21 \\
\hline$\tau_{\pi}$ & 0.40 & 0.40 & 0.40 & 0.40 & 0.40 & 0.40 \\
\hline$\tau_{c}$ & 0.033 & 0.033 & 0.033 & 0.033 & 0.033 & 0.033 \\
\hline$\tau_{i}$ & 0.107 & 0.107 & 0.107 & 0.107 & 0.107 & 0.107 \\
\hline$\rho_{a}$ & $0.95^{1 / 4}$ & $0.95^{1 / 4}$ & $0.95^{1 / 4}$ & $0.95^{1 / 4}$ & $0.95^{1 / 4}$ & $0.95^{1 / 4}$ \\
\hline$\sigma_{a}$ & 0.0115 & 0.0115 & 0.0115 & 0.0115 & 0.0115 & 0.0115 \\
\hline $\bar{g}$ & -1.6883 & -1.6883 & -1.6883 & -1.6883 & -1.6883 & -1.6883 \\
\hline$\rho_{g}$ & $0.98^{1 / 4}$ & $0.98^{1 / 4}$ & $0.98^{1 / 4}$ & $0.98^{1 / 4}$ & $0.98^{1 / 4}$ & $0.98^{1 / 4}$ \\
\hline$\sigma_{g}$ & 0.0065 & 0.0065 & 0.0065 & 0.0065 & 0.0065 & 0.0065 \\
\hline $\operatorname{corr}\left(\varepsilon_{a}, \varepsilon_{g}\right)$ & 0 & 0 & 0 & 0 & 0 & 0 \\
\hline$\underline{\varphi}$ & $1.68 \overline{0} 2$ & 1.6857 & 1.3658 & 1.3702 & 1.6893 & $\overline{1} .6 \overline{8} 4 \overline{5}$ \\
\hline $\bar{\chi}$ & $0.73 \overline{7} 2$ & - & 0.9035 & - & $0.3 \overline{3} 55$ & - \\
\hline$\omega$ & 0.83 & - & 0.83 & - & 0.60 & - \\
\hline$\phi$ & 0.0375 & - & 0.0375 & - & 0.0375 & - \\
\hline$\tau_{s}$ & 0.05 & - & 0.05 & - & 0.05 & - \\
\hline $\bar{\chi}_{\mathrm{I}}^{-}$ & $\ldots$ & $\overline{3} . \overline{4} \overline{4} \overline{2}$ & 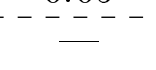 & $\overline{4} . \overline{1} \overline{6} 3^{-}$ & - & $\overline{1} . \overline{4} \overline{5} 1^{-}$ \\
\hline$\chi_{\mathrm{E}}$ & - & 0.2301 & - & 0.2808 & - & 0.0802 \\
\hline$\omega_{\text {I }}$ & - & 0.83 & - & 0.83 & - & 0.60 \\
\hline$\omega_{\mathrm{E}}$ & - & 0.83 & - & 0.83 & - & 0.60 \\
\hline$\kappa_{\mathrm{I}}$ & - & 1.2 & - & 1.2 & - & 1.2 \\
\hline$\kappa_{\mathrm{E}}$ & - & 3 & - & 3 & - & 3 \\
\hline$\kappa_{\mathrm{D}}$ & - & 0.9625 & - & 0.9625 & - & 0.9625 \\
\hline$\tau_{s, \mathrm{I}}$ & - & 0.0333 & - & 0.0333 & - & 0.0333 \\
\hline$\tau_{s, \mathrm{E}}$ & - & 0.0167 & - & 0.0167 & - & 0.0167 \\
\hline
\end{tabular}

Notes: This table reports the quarterly benchmark calibrations for both the homogeneous innovation model of Section 3 and the heterogeneous innovation model of Section 4, respectively, when wage rigidities are absent (Models (3.1) and (4.1), respectively), when preferences are of the CRRA type (Models (5.1) and (6.1), respectively), and when the elasticity of R\&D investment is lower (Models (7.1) and (8.1), respectively). 
Table 5: Simulation results - homogeneous innovation model (no wage rigidities)

\begin{tabular}{|c|c|c|c|c|c|c|c|}
\hline & Data & $(3.1)$ & $(3.2)$ & $(3.3)$ & $(3.4)$ & $(3.5)$ & $(3.6)$ \\
\hline \multicolumn{8}{|l|}{ ASSET PRICES } \\
\hline $\mathbb{E}\left[r_{a}^{e x}\right]$ & 4.02 & 2.47 & 2.21 & 2.82 & 2.61 & 2.34 & 2.56 \\
\hline$\sigma\left(r_{a}^{e x}\right)$ & 14.36 & 4.90 & 4.78 & 5.03 & 4.96 & 4.48 & 4.99 \\
\hline $\mathbb{E}\left[r_{f}\right]$ & 1.56 & 1.76 & 1.61 & 1.90 & 1.82 & 1.70 & 1.77 \\
\hline$\sigma\left(r_{f}\right)$ & 2.42 & 0.28 & 0.27 & 0.29 & 0.29 & 0.28 & 0.29 \\
\hline \multicolumn{8}{|l|}{ MACRO QUANTITIES } \\
\hline$E\left[\Delta c^{*}\right]$ & 2.61 & 1.89 & 1.50 & 2.27 & 2.07 & 1.72 & 1.99 \\
\hline$\sigma\left(\Delta c^{*}\right)$ & 1.30 & 1.61 & 1.61 & 1.62 & 1.62 & 1.61 & 1.69 \\
\hline $\mathbb{E}[L / \bar{L}]$ & - & 33.21 & 32.97 & 33.66 & 33.42 & 32.80 & 33.12 \\
\hline$\sigma(\Delta l)$ & 2.59 & 0.62 & 0.62 & 0.62 & 0.62 & 0.62 & 0.67 \\
\hline $\mathbb{E}[G / Y]$ & 15.55 & 15.62 & 15.62 & 15.62 & 15.62 & 15.62 & 16.62 \\
\hline$\sigma(G / Y)$ & 0.85 & 0.90 & 0.90 & 0.90 & 0.90 & 0.90 & 0.95 \\
\hline $\mathbb{E}\left[\tau_{l}\right]$ & 37.00 & 39.03 & 39.03 & 39.03 & 39.03 & 39.03 & 43.43 \\
\hline$\sigma\left(\tau_{l}\right)$ & - & 3.96 & 3.96 & 3.96 & 3.96 & 3.96 & 4.16 \\
\hline $\mathbb{E}[\hat{U}]$ & - & 0.2233 & 0.1990 & 0.2258 & 0.2310 & 0.2177 & 21.82 \\
\hline$\Lambda$ & - & - & 12.20 & -1.12 & -3.33 & 2.59 & 2.35 \\
\hline$\left(C^{*}-C_{b e n c h}^{*}\right) / C_{b e n c h}^{*}$ & - & - & 0.99 & -1.90 & -0.23 & 1.20 & -6.95 \\
\hline$\left(I^{*}-I_{\text {bench }}^{*}\right) / I_{\text {bench }}^{*}$ & - & - & -2.95 & 1.58 & 2.60 & -1.32 & 1.15 \\
\hline$\left(S^{*}-S_{\text {bench }}^{*}\right) / S_{\text {bench }}^{*}$ & - & - & -2.78 & 2.74 & 1.26 & -1.22 & 0.79 \\
\hline$\sigma\left(\Delta c^{*}\right) / \sigma(\Delta y)$ & 0.64 & 0.82 & 0.83 & 0.82 & 0.82 & 0.82 & 0.85 \\
\hline$\sigma\left(\Delta i^{*}\right) / \sigma(\Delta y)$ & 4.62 & 1.05 & 1.04 & 1.06 & 1.05 & 1.05 & 1.05 \\
\hline$\sigma\left(\Delta s^{*}\right) / \sigma(\Delta y)$ & 2.04 & 1.54 & 1.57 & 1.51 & 1.53 & 1.54 & 1.52 \\
\hline$\sigma(\Delta l) / \sigma(\Delta y)$ & 1.29 & 0.32 & 0.32 & 0.31 & 0.32 & 0.34 & 0.34 \\
\hline$\sigma(\Delta w) / \sigma(\Delta y)$ & 1.15 & 0.74 & 0.75 & 0.74 & 0.74 & 0.75 & 0.73 \\
\hline $\operatorname{corr}\left(\Delta c^{*}, \Delta i^{*}\right)$ & 0.65 & 0.73 & 0.75 & 0.71 & 0.72 & 0.74 & 0.69 \\
\hline $\operatorname{corr}\left(\Delta y, \Delta i^{*}\right)$ & 0.88 & 1.00 & 1.00 & 1.00 & 1.00 & 1.00 & 1.00 \\
\hline $\operatorname{corr}\left(\Delta c^{*}, \Delta l\right)$ & 0.71 & 0.78 & 0.79 & 0.75 & 0.77 & 0.80 & 0.77 \\
\hline $\operatorname{corr}(\Delta y, \Delta w)$ & 0.15 & 0.98 & 0.98 & 0.98 & 0.98 & 0.98 & 0.97 \\
\hline $\operatorname{corr}\left(\Delta c^{*}, \Delta s^{*}\right)$ & 0.41 & 0.73 & 0.74 & 0.71 & 0.72 & 0.74 & 0.69 \\
\hline $\operatorname{corr}\left(\Delta y, \Delta s^{*}\right)$ & 0.37 & 0.99 & 0.99 & 0.99 & 0.99 & 0.99 & 0.99 \\
\hline $\operatorname{corr}\left(\Delta l, \Delta s^{*}\right)$ & 0.46 & 0.91 & 0.91 & 0.91 & 0.91 & 0.90 & 0.90 \\
\hline $\operatorname{corr}\left(\Delta w, \Delta s^{*}\right)$ & 0.42 & 0.95 & 0.94 & 0.95 & 0.95 & 0.95 & 0.94 \\
\hline
\end{tabular}

Notes: This table reports the moments obtained from a stochastic simulation of the homogeneous innovation model in the absence of wage rigidities. The moments are computed using a simulation of 3,000 economies at quarterly frequency for 304 quarters, from which the first 80 quarters are not considered for the calculation of the moments ("burn in-period"). The quantity $\Lambda$ is the welfare cost relative to the calibration (3.1), rigorously defined in Equation (68). The moments in the data column are computed using data described in Appendix A for the period 1975-2015. All numbers are given in percentage points except for the average utility index $E[U / N]$, the ratios of volatilities, and the correlations which are given in decimal points. Model (3.1): Homogeneous innovation model in the absence of wage rigidities $(\mu=0)$ whose parameters are reported in Table 4. Model (3.2): Jointly lower government subsidies, i.e. $\tau_{c}=0.023, \tau_{i}=0.097, \tau_{s}=0.04$ and all other parameters as in Model (3.1). Model (3.3): Higher R\&D investment subsidies, i.e. $\tau_{s}=0.06$ and all other parameters as in Model (3.1). Model (3.4): Higher capital investment subsidies, i.e. $\tau_{i}=0.117$ and all other parameters as in Model (3.1). Model (3.5): Higher consumption subsidies, i.e. $\tau_{c}=0.043$ and all other parameters as in Model (3.1). Model (3.6): Higher government expenditure, i.e. $\bar{g}=-1.6142$ implying $E[G / Y]=16.6 \%$, and all other parameters as in Model (3.1). 
Table 6: Simulation results - heterogeneous innovation model (no wage rigidities)

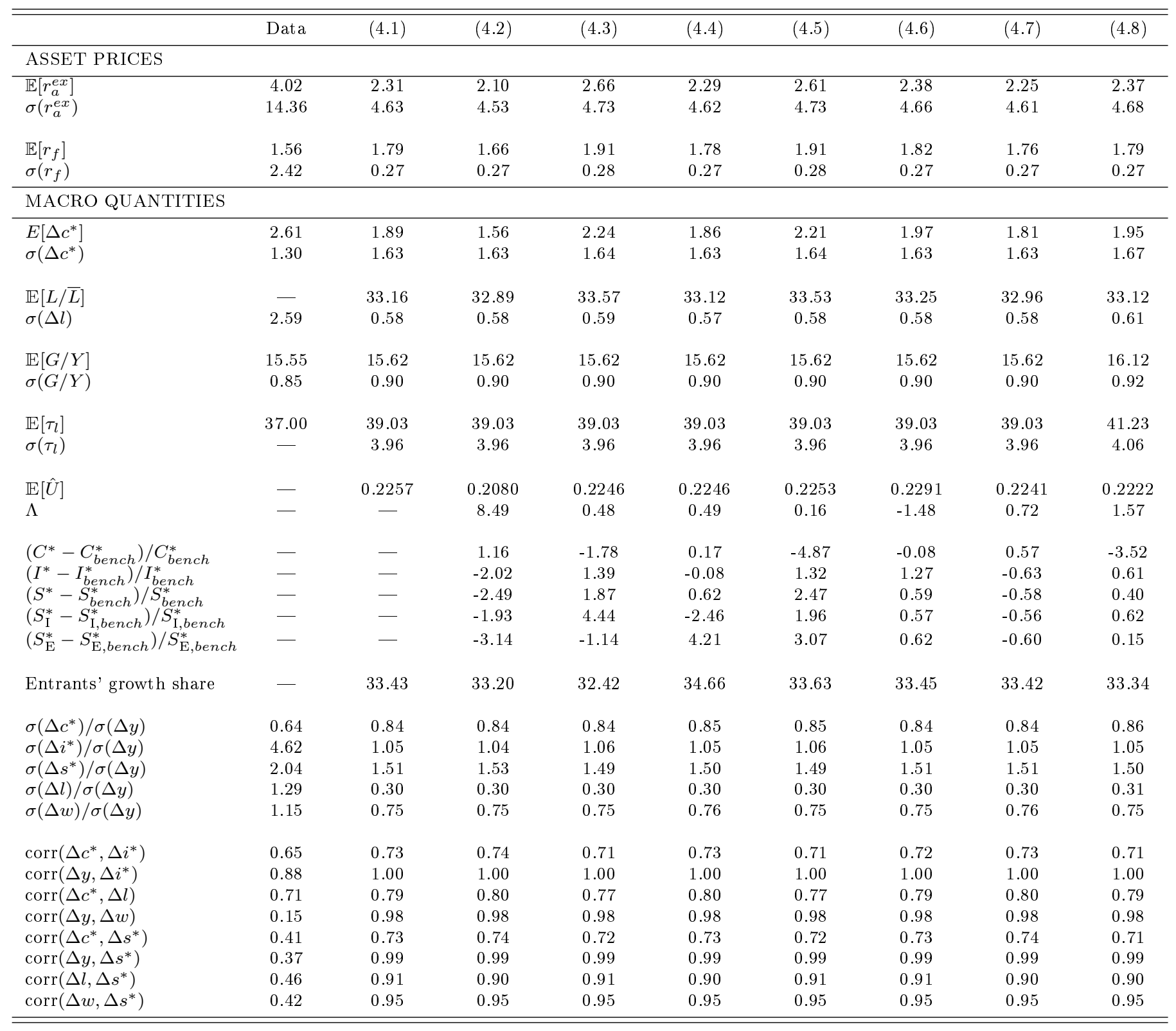

Notes: This table reports the moments obtained from a stochastic simulation of the heterogeneous innovation model in the absence of wage rigidities. Details on the simulation, the data, and the reported numbers are the same as in Table 5 . The entrants' growth share is given by the expression $\frac{\left(\kappa_{\mathrm{E}}-\kappa_{\mathrm{D}}\right) \mathbb{E}\left[\hat{\phi}_{\mathrm{E}}\left(s_{\mathrm{E}}^{*}\right)\right]}{\left(\kappa_{\mathrm{I}}-\kappa_{\mathrm{D}}\right) \mathbb{E}\left[\phi_{\mathrm{I}}\left(s_{\mathrm{I}}^{*}\right)\right]+\left(\kappa_{\mathrm{E}}-\kappa_{\mathrm{D}}\right) \mathbb{E}\left[\hat{\phi}_{\mathrm{E}}\left(s_{\mathrm{E}}^{*}\right)\right]}$. Model (4.1): Heterogeneous innovation model in the absence of wage rigidies $(\mu=0)$ whose parameters are reported in Table 4. Model (4.2): Jointly lower government subsidies, i.e. $\tau_{c}=0.028, \tau_{i}=0.102, \tau_{s, \mathrm{I}}=0.0283, \tau_{s, \mathrm{E}}=0.0117$ and all other parameters as in Model (4.1). Model (4.3): Higher incumbent R\&D investment subsidies, i.e. $\tau_{s, \mathrm{I}}=0.0383$ and all other parameters as in Model (4.1). Model (4.4): Higher entrant R\&D investment subsidies, i.e. $\tau_{s, \mathrm{E}}=0.0217$ and all other parameters as in Model (4.1). Model (4.5): Jointly higher incumbent and entrant R\&D investment subsidies, i.e. $\tau_{s, \mathrm{I}}=0.0383$ and $\tau_{s, \mathrm{E}}=0.0217$ and all other parameters as in Model (4.1). Model (4.6): Higher capital investment subsidies, i.e. $\tau_{i}=0.112$ and all other parameters as in Model (4.1). Model (4.7): Higher consumption subsidies, i.e. $\tau_{c}=0.038$ and all other parameters as in Model (4.1). Model (4.8): Higher government expenditure, i.e. $\bar{g}=-1.6508$ implying $E[G / Y]=16.1 \%$, and all other parameters as in Model (4.1). 
Table 7: Simulation results - homogeneous innovation model (CRRA preferences)

\begin{tabular}{|c|c|c|c|c|c|c|c|}
\hline & Data & $(5.1)$ & $(5.2)$ & $(5.3)$ & $(5.4)$ & $(5.5)$ & $(5.6)$ \\
\hline \multicolumn{8}{|l|}{ ASSET PRICES } \\
\hline $\mathbb{E}\left[r_{a}^{e x}\right]$ & 4.02 & 0.06 & 0.06 & 0.06 & 0.06 & 0.06 & 0.06 \\
\hline$\sigma\left(r_{a}^{e x}\right)$ & 14.36 & 1.79 & 1.78 & 1.81 & 1.79 & 1.79 & 1.83 \\
\hline $\mathbb{E}\left[r_{f}\right]$ & 1.56 & 5.33 & 5.14 & 5.49 & 5.40 & 5.27 & 5.28 \\
\hline$\sigma\left(r_{f}\right)$ & 2.42 & 0.39 & 0.39 & 0.40 & 0.40 & 0.39 & 0.39 \\
\hline \multicolumn{8}{|l|}{ MACRO QUANTITIES } \\
\hline$E\left[\Delta c^{*}\right]$ & 2.61 & 1.89 & 1.80 & 1.97 & 1.93 & 1.87 & 1.87 \\
\hline$\sigma\left(\Delta c^{*}\right)$ & 1.30 & 2.01 & 2.02 & 2.01 & 2.01 & 2.01 & 2.08 \\
\hline $\mathbb{E}[L / \bar{L}]$ & - & 33.35 & 33.61 & 33.27 & 33.31 & 33.19 & 32.85 \\
\hline$\sigma(\Delta l)$ & 2.59 & 0.56 & 0.56 & 0.56 & 0.56 & 0.57 & 0.60 \\
\hline $\mathbb{E}[G / Y]$ & 15.55 & 15.62 & 15.62 & 15.62 & 15.62 & 15.62 & 16.62 \\
\hline$\sigma(G / Y)$ & 0.85 & 0.90 & 0.90 & 0.90 & 0.90 & 0.90 & 0.95 \\
\hline $\mathbb{E}\left[\tau_{l}\right]$ & 37.00 & 39.03 & 39.03 & 39.03 & 39.03 & 39.03 & 43.43 \\
\hline$\sigma\left(\tau_{l}\right)$ & - & 3.96 & 3.96 & 3.96 & 3.96 & 3.96 & 4.16 \\
\hline $\mathbb{E}[\hat{U}]$ & - & 0.2919 & 0.2813 & 0.2975 & 0.2967 & 0.2919 & 0.2757 \\
\hline$\Lambda$ & - & - & 3.75 & -1.90 & -1.65 & -0.02 & 5.85 \\
\hline$\left(C^{*}-C_{\text {bench }}^{*}\right) / C_{\text {bench }}^{*}$ & - & - & -0.48 & -0.51 & 0.55 & 0.43 & -5.85 \\
\hline$\left(I^{*}-I_{\text {bench }}^{*}\right) / I_{\text {bench }}^{*}$ & - & - & -0.36 & -1.15 & 1.71 & -0.17 & 0.31 \\
\hline$\left(S^{*}-S_{\text {bench }}^{*}\right) / S_{\text {bench }}^{*}$ & - & - & -0.65 & 0.57 & 0.26 & -0.18 & -0.14 \\
\hline$\sigma\left(\Delta c^{*}\right) / \sigma(\Delta y)$ & 0.64 & 1.24 & 1.24 & 1.24 & 1.24 & 1.24 & 1.28 \\
\hline$\sigma\left(\Delta i^{*}\right) / \sigma(\Delta y)$ & 4.62 & 0.66 & 0.66 & 0.66 & 0.66 & 0.66 & 0.66 \\
\hline$\sigma\left(\Delta s^{*}\right) / \sigma(\Delta y)$ & 2.04 & 1.22 & 1.23 & 1.21 & 1.22 & 1.22 & 1.22 \\
\hline$\sigma(\Delta l) / \sigma(\Delta y)$ & 1.29 & 0.35 & 0.34 & 0.35 & 0.35 & 0.35 & 0.37 \\
\hline$\sigma(\Delta w) / \sigma(\Delta y)$ & 1.15 & 0.94 & 0.95 & 0.94 & 0.95 & 0.94 & 0.95 \\
\hline $\operatorname{corr}\left(\Delta c^{*}, \Delta i^{*}\right)$ & 0.65 & 0.89 & 0.89 & 0.89 & 0.89 & 0.89 & 0.88 \\
\hline $\operatorname{corr}\left(\Delta y, \Delta i^{*}\right)$ & 0.88 & 0.99 & 0.99 & 0.99 & 0.99 & 0.99 & 0.99 \\
\hline $\operatorname{corr}\left(\Delta c^{*}, \Delta l\right)$ & 0.71 & 0.47 & 0.46 & 0.47 & 0.46 & 0.47 & 0.50 \\
\hline $\operatorname{corr}(\Delta y, \Delta w)$ & 0.15 & 0.94 & 0.94 & 0.94 & 0.94 & 0.94 & 0.93 \\
\hline $\operatorname{corr}\left(\Delta c^{*}, \Delta s^{*}\right)$ & 0.41 & 0.90 & 0.90 & 0.90 & 0.90 & 0.90 & 0.89 \\
\hline $\operatorname{corr}\left(\Delta y, \Delta s^{*}\right)$ & 0.37 & 0.99 & 0.99 & 0.99 & 0.99 & 0.99 & 0.99 \\
\hline $\operatorname{corr}\left(\Delta l, \Delta s^{*}\right)$ & 0.46 & 0.43 & 0.43 & 0.42 & 0.43 & 0.43 & 0.42 \\
\hline $\operatorname{corr}\left(\Delta w, \Delta s^{*}\right)$ & 0.42 & 0.90 & 0.90 & 0.90 & 0.90 & 0.90 & 0.89 \\
\hline
\end{tabular}

Notes: This table reports the moments obtained from a stochastic simulation of the homogeneous innovation model with the household having CRRA preferences. The moments are computed using a simulation of 3,000 economies at quarterly frequency for 304 quarters, from which the first 80 quarters are not considered for the calculation of the moments ("burn in-period"). The quantity $\Lambda$ is the welfare cost relative to the calibration (5.1), rigorously defined in Equation (68). The moments in the data column are computed using data described in Appendix A for the period 1975-2015. All numbers are given in percentage points except for the average utility index $E[U / N]$, the ratios of volatilities, and the correlations which are given in decimal points. Model (5.1): Homogeneous innovation model where the household has CRRA preferences $(\psi=0.5, \gamma=2)$ whose parameters are reported in Table 4. Model (5.2): Jointly lower government subsidies, i.e. $\tau_{c}=0.023, \tau_{i}=0.097, \tau_{s}=0.04$ and all other parameters as in Model (5.1). Model (5.3): Higher R\&D investment subsidies, i.e. $\tau_{s}=0.06$ and all other parameters as in Model (5.1). Model (5.4): Higher capital investment subsidies, i.e. $\tau_{i}=0.117$ and all other parameters as in Model (5.1). Model (5.5): Higher consumption subsidies, i.e. $\tau_{c}=0.043$ and all other parameters as in Model (5.1). Model (5.6): Higher government expenditure, i.e. $\bar{g}=-1.6142$ implying $E[G / Y]=16.6 \%$, and all other parameters as in Model (5.1). 
Table 8: Simulation results - heterogeneous innovation model (CRRA preferences)

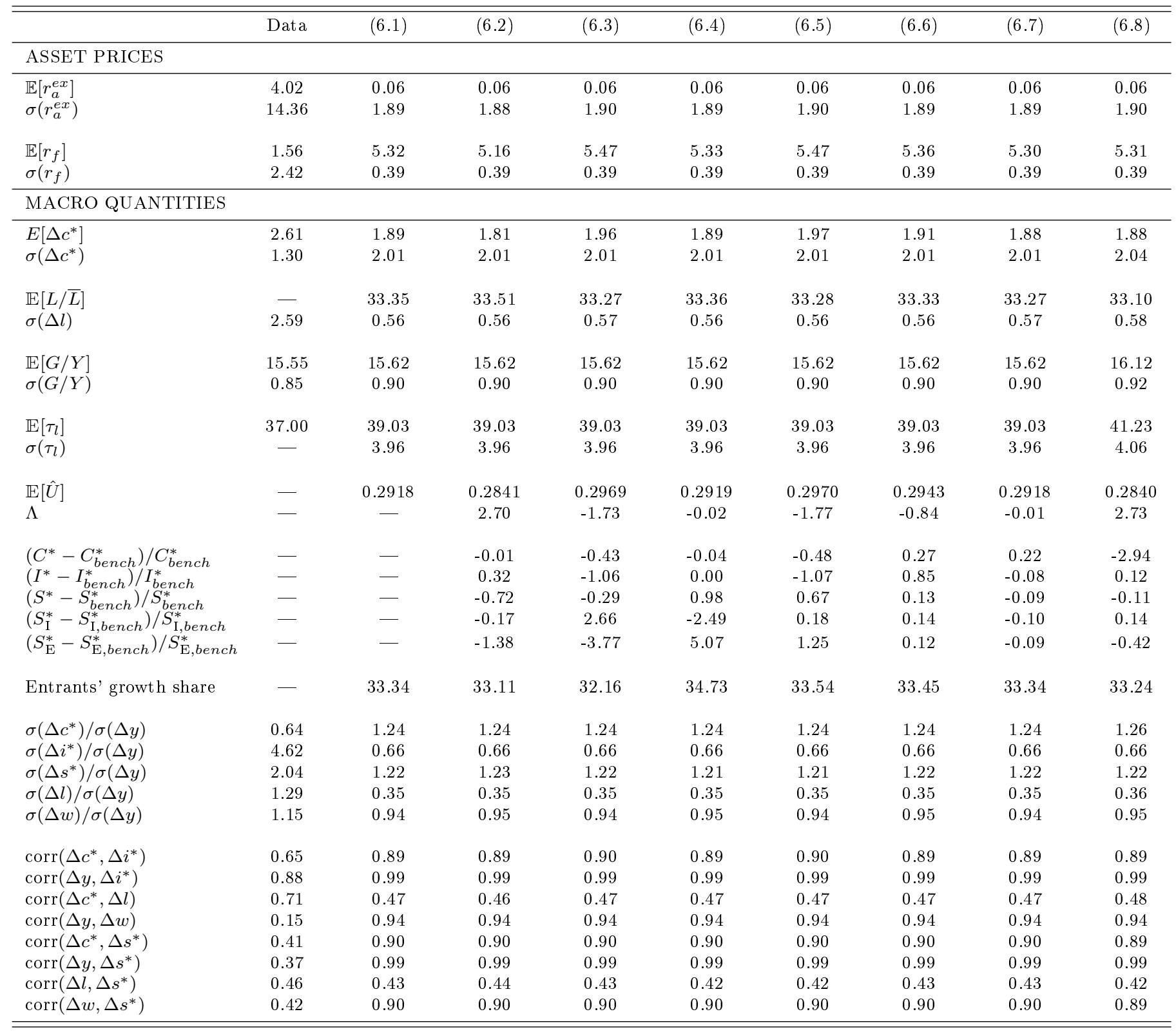

Notes: This table reports the moments obtained from a stochastic simulation of the heterogeneous innovation model with the household having CRRA preferences. Details on the simulation, the data, and the reported numbers are the same as in Table 7. The entrants' growth share is given by the expression $\frac{\left(\kappa_{\mathrm{E}}-\kappa_{\mathrm{D}}\right) \mathbb{E}\left[\hat{\phi}_{\mathrm{E}}\left(s_{\mathrm{E}}^{*}\right)\right]}{\left(\kappa_{\mathrm{I}}-\kappa_{\mathrm{D}}\right) \mathbb{E}\left[\phi_{\mathrm{I}}\left(s_{\mathrm{I}}^{*}\right)\right]+\left(\kappa_{\mathrm{E}}^{-}-\kappa_{\mathrm{D}}\right) \mathbb{E}\left[\hat{\phi}_{\mathrm{E}}\left(s_{\mathrm{E}}^{*}\right)\right]}$. Model (6.1): Heterogeneous innovation model where the household has CRRA preferences $(\psi=0.5, \gamma=2)$ whose parameters are reported in Table 4. Model (6.2): Jointly lower government subsidies, i.e. $\tau_{c}=0.028, \tau_{i}=0.102, \tau_{s, \mathrm{I}}=0.0283, \tau_{s, \mathrm{E}}=0.0117$ and all other parameters as in Model (6.1). Model (6.3): Higher incumbent R\&D investment subsidies, i.e. $\tau_{s, \mathrm{I}}=0.0383$ and all other parameters as in Model (6.1). Model (6.4): Higher entrant R\&D investment subsidies, i.e. $\tau_{s, \mathrm{E}}=0.0217$ and all other parameters as in Model (6.1). Model (6.5): Jointly higher incumbent and entrant R\&D investment subsidies, i.e. $\tau_{s, \mathrm{I}}=0.0383$ and $\tau_{s, \mathrm{E}}=0.0217$ and all other parameters as in Model (6.1). Model (6.6): Higher capital investment subsidies, i.e. $\tau_{i}=0.112$ and all other parameters as in Model (6.1). Model (6.7): Higher consumption subsidies, i.e. $\tau_{c}=0.038$ and all other parameters as in Model (6.1). Model (6.8): Higher government expenditure, i.e. $\bar{g}=-1.6508$ implying $E[G / Y]=16.1 \%$, and all other parameters as in Model (6.1). 
Table 9: Simulation results - homogeneous innovation model (lower R\&D elasticity)

\begin{tabular}{|c|c|c|c|c|c|c|c|}
\hline & Data & $(7.1)$ & $(7.2)$ & $(7.3)$ & $(7.4)$ & $(7.5)$ & $(7.6)$ \\
\hline \multicolumn{8}{|l|}{ ASSET PRICES } \\
\hline $\mathbb{E}\left[r_{a}^{e x}\right]$ & 4.02 & 1.69 & 1.61 & 1.79 & 1.73 & 1.65 & 1.74 \\
\hline$\sigma\left(r_{a}^{e x}\right)$ & 14.36 & 4.74 & 5.69 & 4.78 & 4.76 & 4.71 & 4.79 \\
\hline $\mathbb{E}\left[r_{f}\right]$ & 1.56 & 1.93 & 1.83 & 2.02 & 1.97 & 1.89 & 1.93 \\
\hline$\sigma\left(r_{f}\right)$ & 2.42 & 0.38 & 0.38 & 0.38 & 0.38 & 0.38 & 0.38 \\
\hline \multicolumn{8}{|l|}{ MACRO QUANTITIES } \\
\hline$E\left[\Delta c^{*}\right]$ & 2.61 & 1.89 & 1.68 & 2.10 & 1.98 & 1.80 & 1.94 \\
\hline$\sigma\left(\Delta c^{*}\right)$ & 1.30 & 1.78 & 1.78 & 1.79 & 1.78 & 1.78 & 1.85 \\
\hline $\mathbb{E}[L / \bar{L}]$ & - & 33.13 & 33.10 & 33.36 & 33.24 & 32.80 & 32.97 \\
\hline$\sigma(\Delta l)$ & 2.59 & 0.69 & 0.69 & 0.68 & 0.69 & 0.69 & 0.71 \\
\hline $\mathbb{E}[G / Y]$ & 15.55 & 15.62 & 15.62 & 15.62 & 15.62 & 15.62 & 16.62 \\
\hline$\sigma(G / Y)$ & 0.85 & 0.90 & 0.90 & 0.90 & 0.90 & 0.90 & 0.95 \\
\hline $\mathbb{E}\left[\tau_{l}\right]$ & 37.00 & 39.03 & 39.03 & 39.03 & 39.03 & 39.03 & 43.43 \\
\hline$\sigma\left(\tau_{l}\right)$ & - & 3.96 & 3.96 & 3.96 & 3.96 & 3.96 & 4.16 \\
\hline $\mathbb{E}[\hat{U}]$ & - & 0.3808 & 0.3297 & 0.4276 & 0.4049 & 0.3634 & 0.3682 \\
\hline$\Lambda$ & - & - & 15.49 & -10.94 & -5.95 & 4.77 & 3.43 \\
\hline$\left(C^{*}-C_{\text {bench }}^{*}\right) / C_{\text {bench }}^{*}$ & - & - & 0.08 & -1.03 & 0.18 & 0.80 & -6.70 \\
\hline$\left(I^{*}-I_{\text {bench }}^{*}\right) / I_{\text {bench }}^{*}$ & - & - & -2.16 & 0.87 & 2.27 & -1.05 & 0.95 \\
\hline$\left(S^{*}-S_{\text {bench }}^{*}\right) / S_{\text {bench }}^{*}$ & - & - & -2.12 & 2.07 & 0.94 & -0.94 & 0.56 \\
\hline$\sigma\left(\Delta c^{*}\right) / \sigma(\Delta y)$ & 0.64 & 0.96 & 0.97 & 0.97 & 0.96 & 0.96 & 1.00 \\
\hline$\sigma\left(\Delta i^{*}\right) / \sigma(\Delta y)$ & 4.62 & 0.98 & 0.97 & 0.98 & 0.98 & 0.97 & 0.98 \\
\hline$\sigma\left(\Delta s^{*}\right) / \sigma(\Delta y)$ & 2.04 & 1.37 & 1.38 & 1.36 & 1.37 & 1.37 & 1.36 \\
\hline$\sigma(\Delta l) / \sigma(\Delta y)$ & 1.29 & 0.37 & 0.37 & 0.37 & 0.37 & 0.37 & 0.38 \\
\hline$\sigma(\Delta w) / \sigma(\Delta y)$ & 1.15 & 0.77 & 0.77 & 0.77 & 0.77 & 0.77 & 0.76 \\
\hline $\operatorname{corr}\left(\Delta c^{*}, \Delta i^{*}\right)$ & 0.65 & 0.81 & 0.82 & 0.80 & 0.80 & 0.81 & 0.79 \\
\hline $\operatorname{corr}\left(\Delta y, \Delta i^{*}\right)$ & 0.88 & 1.00 & 1.00 & 1.00 & 1.00 & 1.00 & 1.00 \\
\hline $\operatorname{corr}\left(\Delta c^{*}, \Delta l\right)$ & 0.71 & 0.71 & 0.71 & 0.71 & 0.71 & 0.72 & 0.73 \\
\hline $\operatorname{corr}(\Delta y, \Delta w)$ & 0.15 & 0.95 & 0.95 & 0.95 & 0.95 & 0.95 & 0.94 \\
\hline $\operatorname{corr}\left(\Delta c^{*}, \Delta s^{*}\right)$ & 0.41 & 0.82 & 0.82 & 0.81 & 0.81 & 0.82 & 0.79 \\
\hline $\operatorname{corr}\left(\Delta y, \Delta s^{*}\right)$ & 0.37 & 0.99 & 0.99 & 0.99 & 0.99 & 0.99 & 0.99 \\
\hline $\operatorname{corr}\left(\Delta l, \Delta s^{*}\right)$ & 0.46 & 0.80 & 0.80 & 0.80 & 0.80 & 0.79 & 0.79 \\
\hline $\operatorname{corr}\left(\Delta w, \Delta s^{*}\right)$ & 0.42 & 0.91 & 0.91 & 0.92 & 0.91 & 0.91 & 0.91 \\
\hline
\end{tabular}

Notes: This table reports the moments obtained from a stochastic simulation of the homogeneous innovation model with innovators facing a lower elasticity of R\&D investment than in the benchmark calibrations. The moments are computed using a simulation of 3,000 economies at quarterly frequency for 304 quarters, from which the first 80 quarters are not considered for the calculation of the moments ("burn in-period"). The quantity $\Lambda$ is the welfare cost relative to the calibration (7.1), rigorously defined in Equation (68). The moments in the data column are computed using data described in Appendix A for the period 1975-2015. All numbers are given in percentage points except for the average utility index $E[U / N]$, the ratios of volatilities, and the correlations which are given in decimal points. Model (7.1): Homogeneous innovation model with innovators facing a lower elasticity of R\&D investment $(\omega=0.6)$ than in the benchmark calibrations whose parameters are reported in Table 4 . Model (7.2): Jointly lower government subsidies, i.e. $\tau_{c}=0.023, \tau_{i}=0.097, \tau_{s}=0.04$ and all other parameters as in Model (7.1). Model (7.3): Higher R\&D investment subsidies, i.e. $\tau_{s}=0.06$ and all other parameters as in Model (7.1). Model (7.4): Higher capital investment subsidies, i.e. $\tau_{i}=0.117$ and all other parameters as in Model (7.1). Model (7.5): Higher consumption subsidies, i.e. $\tau_{c}=0.043$ and all other parameters as in Model (7.1). Model (7.6): Higher government expenditure, i.e. $\bar{g}=-1.6142$ implying $E[G / Y]=16.6 \%$, and all other parameters as in Model (7.1). 
Table 10: Simulation results - heterogeneous innovation model (lower R\&D elasticity)

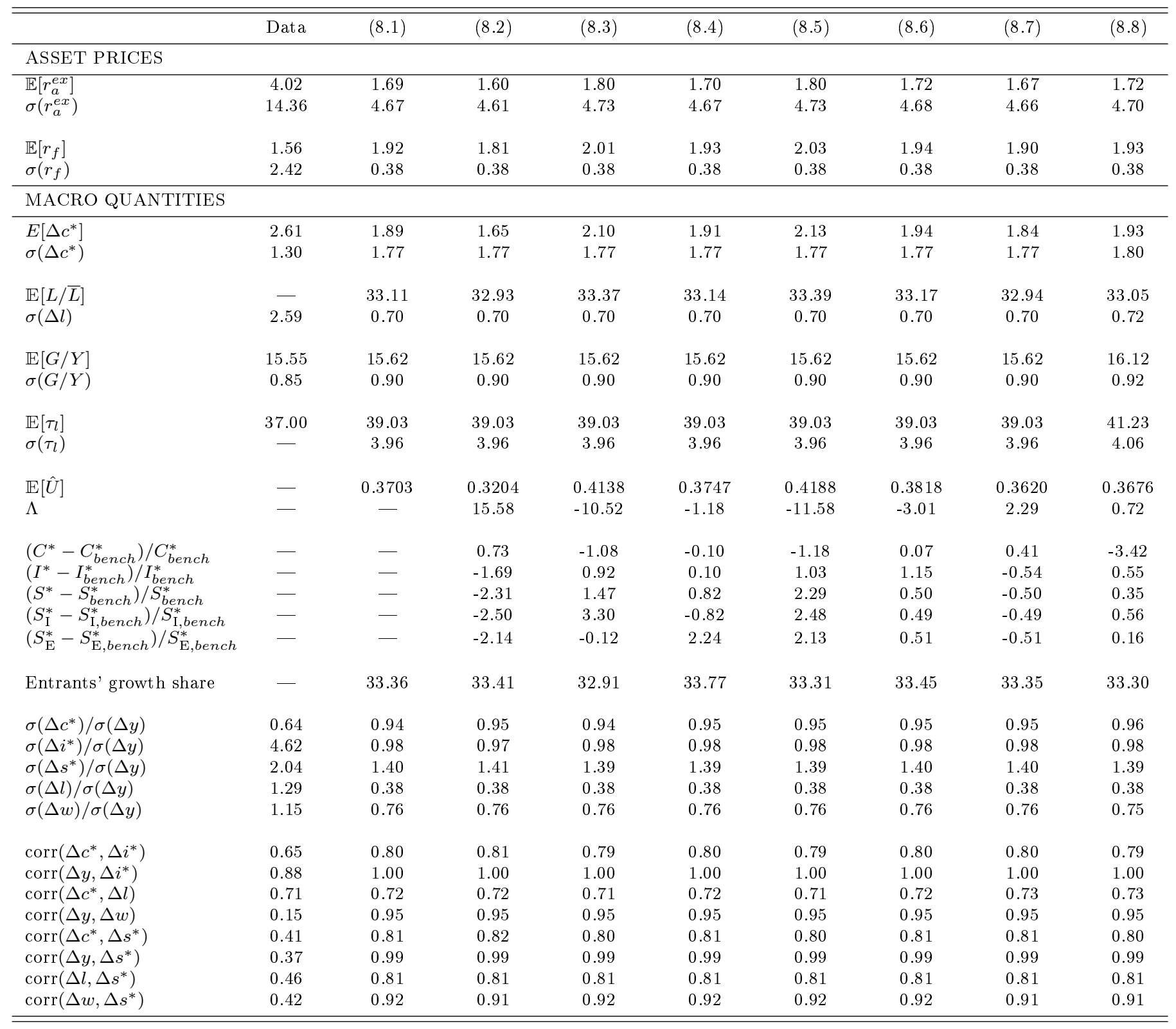

Notes: This table reports the moments obtained from a stochastic simulation of the heterogeneous innovation model with both incumbents and entrants facing a lower elasticity of R\&D investment than in the benchmark calibrations. Details on the simulation, the data, and the reported numbers are the same as in Table 9. The entrants' growth share is given by the expression

$\frac{\left(\kappa_{\mathrm{E}}-\kappa_{\mathrm{D}}\right) \mathbb{E}\left[\hat{\phi}_{\mathrm{E}}\left(s_{\mathrm{E}}^{*}\right)\right]}{\left(\kappa_{\mathrm{I}}-\kappa_{\mathrm{D}}\right) \mathbb{E}\left[\phi_{\mathrm{I}}\left(s_{\mathrm{I}}^{*}\right)\right]+\left(\kappa_{\mathrm{E}}-\kappa_{\mathrm{D}}\right) \mathbb{E}\left[\hat{\phi}_{\mathrm{E}}\left(s_{\mathrm{E}}^{*}\right)\right]}$. Model (8.1): Heterogeneous innovation model with both incumbents and entrants facing a lower elasticity of R\&D investment $\left(\omega_{\mathrm{I}}=\omega_{\mathrm{E}}=0.6\right)$ than in the benchmark calibrations whose parameters are reported in Table 4. Model (8.2): Jointly lower government subsidies, i.e. $\tau_{c}=0.028, \tau_{i}=0.102, \tau_{s, \mathrm{I}}=0.0283, \tau_{s, \mathrm{E}}=0.0117$ and all other parameters as in Model (8.1). Model (8.3): Higher incumbent R\&D investment subsidies, i.e. $\tau_{s, \mathrm{I}}=0.0383$ and all other parameters as in Model (8.1). Model (8.4): Higher entrant R\&D investment subsidies, i.e. $\tau_{s, \mathrm{E}}=0.0217$ and all other parameters as in Model (8.1). Model (8.5): Jointly higher incumbent and entrant R\&D investment subsidies, i.e. $\tau_{s, \mathrm{I}}=0.0383$ and $\tau_{s, \mathrm{E}}=0.0217$ and all other parameters as in Model (8.1). Model (8.6): Higher capital investment subsidies, i.e. $\tau_{i}=0.112$ and all other parameters as in Model (8.1). Model (8.7): Higher consumption subsidies, i.e. $\tau_{c}=0.038$ and all other parameters as in Model (8.1). Model (8.8): Higher government expenditure, i.e. $\bar{g}=-1.6508$ implying $E[G / Y]=16.1 \%$, and all other parameters as in Model (8.1). 


\section{A Data}

Data for consumption, investment, and output are from NIPA Tables, Bureau of Economic Analysis (BEA). Annual real output (GDP), consumption (nondurable consumption plus services), and investment (gross private domestic investment) growth rates are from NIPA Table 1.1.1.

Labor supply is measured as non-farm business hours. The labor supply annual growth rate is obtained from the "Nonfarm Business Sector: Hours of All Persons" index downloaded from the U.S. Bureau of Labor Statistics (BLS). Data on wages are from NIPA Tables. The total wage bill is the sum of compensation of employees in the private sector (NIPA Table 2.1, line 2) and supplements to wages (NIPA Table 2.1, line 6). The wage is then defined as the ratio between the total wage bill and the number of employees in the private sector (NIPA Table 6.4, line 3).

R\&D investments are measured as Business Enterprise Expenditure in Research and Development (BERD). Annual data on BERD are from the OECD Main Science and Technology Indicators dataset.

Nominal stock returns for the U.S. are computed from the U.S. Morgan Stanley Capital International (MSCI) Total Return Index (TRI). The U.S. MSCI TRI is downloaded from Datastream. The risk free rate is the one-month Treasury bill rate from Ken French's web page: "http://mba.tuck.dartmouth.edu/pages/faculty/ken.french/data_library.html". Nominal returns are deflated by using the GDP Implicit Price Deflator in United States from the OECD Main Economic Indicators (database).

All data are from 1975 to 2015, except for BERD data which are available for the period 19822013. 


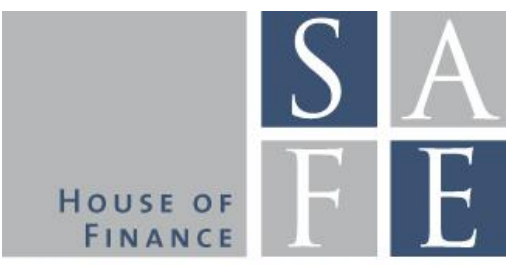

WORKING PAPER SERIES

\section{Recent Issues}

No. 170 Raimond Maurer, Olivia S. Mitchell

No. 169 Max Groneck, Alexander Ludwig, Alexander Zimper

No. 168 Guido Friebel, Marie Lalanne, Bernard Richter, Peter Schwardmann, Paul Seabright

No. 167 Felix Noth, Ulrich Schüwer

No. 166 Monica Billio, Massimiliano Caporin, Roberto Panzica, Loriana Pelizzon

No. 165 Giovani Bonaccolto, Massimiliano Caporin, Roberto Panzica

No. 164 Raimond Maurer, Olivia S. Mitchell, Ralph Rogalla, Tatjana Schimetschek

No. 163

Giuliano Curatola, Michael Donadelli, Patrick Grüning

No. 162

Gabriele Camera, Alessandro Gioffré

No. 161 Tobin Hanspal

No. 160 Domenico Rocco Cambrea, Stefano Colonnello, Giuliano Curatola, Giulia Fantini
Older People's Willingness to Delay Social Security Claiming

The Impact of Biases in Survival Beliefs on Savings Behavior

Women form social networks more selectively and less opportunistically than men

Natural disaster and bank stability: Evidence from the U.S. financial system

The impact of network connectivity on factor exposures, asset pricing and portfolio diversification

Estimation and model-based combination of causality networks

Optimal Social Security Claiming Behavior under Lump Sum Incentives: Theory and Evidence

Technology Trade with Asymmetric Tax Regimes and Heterogeneous Labor Markets: Implications for Macro Quantities and Asset Prices

Asymmetric Social Norms

The Effect of Personal Financing Disruptions on Entrepreneurship

Abandon Ship: Inside Debt and Risk-Taking Incentives in Bad Times 